Purdue University

Purdue e-Pubs

CTRC Research Publications

Cooling Technologies Research Center

2004

\title{
Microscale Pumping Technologies for Microchannel Cooling Systems
}

V. Singhal

S V. Garimella

Purdue University, sureshg@purdue.edu

A. Raman

Follow this and additional works at: http://docs.lib.purdue.edu/coolingpubs

Singhal, V.; Garimella, S V.; and Raman, A., "Microscale Pumping Technologies for Microchannel Cooling Systems" (2004). CTRC Research Publications. Paper 293.

http://dx.doi.org/10.1115/1.1695401\#

This document has been made available through Purdue e-Pubs, a service of the Purdue University Libraries. Please contact epubs@purdue.edu for additional information. 


\title{
Microscale pumping technologies for microchannel cooling systems
}

\author{
Vishal Singhal, Suresh V Garimella, ${ }^{\dagger}$ and Arvind Raman \\ NSF Cooling Technologies Research Center, School of Mechanical Engineering, Purdue \\ University, 585 Purdue Mall, West Lafayette, Indiana 47907-2088; sureshg@ecn.purdue.edu
}

\begin{abstract}
A review of the state of the art in micropumping technologies for driving fluid through microchannels is presented with a particular emphasis on small-scale cooling applications. An extensive variety of micropumping techniques developed over the past fifteen years in the literature is reviewed. The physical principles, engineering limitations, and advantages of approximately twenty different kinds of micropumps are reviewed. The available micropumping techniques are compared quantitatively, primarily in terms of the maximum achievable flow rate per unit cross-sectional area of the microchannel and the maximum achievable back pressure. A concise table is developed to facilitate the convenient comparison of the micropumps based on different criteria including their miniaturization potential, size (in-plane and out-of-plane), actuation voltage and power required per unit flow rate, ease and cost of fabrication, minimum and maximum frequency of operation, and suitability for electronics cooling. Some important performance characteristics of the micropumps, which are likely to be decisive for specific applications, are also discussed. The current state of the art in micropump design and fabrication is also comprehensively reviewed. There are 171 references cited in this review article. [DOI: 10.1115/1.1695401]
\end{abstract}

\section{INTRODUCTION}

Decreasing feature sizes and increasing current densities in microelectronic chips and circuits are causing ever greater heat fluxes at the chip and component levels. Heat generation rates in excess of $250 \mathrm{~W} / \mathrm{cm}^{2}$ have been projected for some of the next-generation intensive computing devices [1]. Traditional electronics cooling approaches such as forced convective air cooling using conventional heat sinks and heat pipes cannot handle such high heat removal rates.

Among the newer technologies, forced convective liquid cooling through microchannel heat sinks is one of the more promising methods for achieving very high heat removal rates. However, the pressure heads encountered in microchannels are very high [2]. This requires the use of an external pump to drive the flow through microchannels. Conventional rotary pumps are unsuitable for this purpose due to their large size and power consumption, especially for personal computers and mobile electronic devices. In response to this critical need, novel pumping strategies have been developed in last two decades, which have been miniaturized to submillimeter dimensions. These micropumps offer significant advantages for future electronics cooling applications, as they a) are much smaller in size than conventional pumps, and b) can be potentially integrated into the microchannels.

Micropumps are also an integral part of many MEMS- based microfluidic devices such as chemical analysis systems, micromixers, and microdosing systems, with applications in small-scale electronics, pharmaceutical and medical devices, telecommunications, and military hardware. Because of the importance of micropumps in such systems, a large body of literature has dealt with the design, fabrication, and analysis of different kinds of micropumps.

Reviews of micropumping technologies developed through the early 1990s are available in [3-5]. A discussion of the various actuation principles and pumping techniques is provided, along with a review of other microfluidic devices. However, many new micropumping technologies have been developed since these papers were published. The differences between fluid mechanics at the macro and microlength scales, arising from different scalings of forces affecting the flow, are explored in [6,7]. Models for liquid and gas flows are discussed along with various applications of MEMS in fluid mechanics, particularly in flow and turbulence control.

In the area of electronics cooling, however, micropumping needs are very diverse depending on the specific application, ranging from low-voltage, low-power pumping solutions required for handheld and other mobile electronic devices to very high flow rates required for microprocessors in larger computers. Micropumps for microchannel heat sinks typically require both high flow rates to meet the high

$\overline{T r a n s m i t t e d ~ b y ~ A s s o c i a t e ~ E d i t o r ~ M ~ G a d-e l-H a k ~}$

${ }^{\dagger}$ Author to whom correspondence should be addressed. 
heat flux needs, as well as large pressure heads to overcome the pressure drops. None of the micropump designs presented in the literature are able to simultaneously meet these demands.

Several challenges exist in designing micropumps to achieve both high flow rates and high pressure drops. Most stem from the fact that the flow and device physics are not very well understood at the small scales encountered in micropumps. This is because various forces affecting the fluid flow and the pump operation scale at different rates with the device size, and hence, their relative magnitudes at small scales can be considerably different from those at large scales.

The true promise of micropumps lies in their potential for integration into microchannel heat sinks. Because an individual micropump may not be able to generate sufficient pressure head and flow rate, a number of micropumps may need to be used through the length of the microchannels. The entire submillimeter microchannel cooling system can then be integrated directly onto the chip. Because the pressure head generated by the multiple micropumps will be distributed through the length of the channels, such a pumping system design could enable a smaller microchannel wall thickness in comparison to traditional external pumps. The further reduction in size of micropumps to tens of micrometers while maintaining a reasonably high flow rate can result in heat transfer rates of more than $1000 \mathrm{~W} / \mathrm{cm}^{2}$ [2]. Such a capability is likely to address the problem of highperformance electronics cooling for the foreseeable future.

In this article, a comprehensive review of the state of the art with respect to micropumping approaches for driving fluid through microchannels is presented with a particular emphasis on small-scale cooling applications. The physical principles, engineering limitations, and advantages of micropumps discussed in the literature are included; a quantitative comparison is provided, in terms of the maximum achievable flow rate per unit cross-sectional area of the microchannel and the maximum achievable back pressure. The micropumps are also compared based on criteria such as miniaturization potential, size, actuation voltage and power required per unit flow rate, ease and cost of fabrication, minimum and maximum frequency of operation, and suitability to electronics cooling.

The working principles of different kinds of micropumps are discussed in Section 2. This is followed by a detailed review of specific micropump designs presented in the literature in Section 3. Finally, the micropumps are compared based on several design parameters together with a discussion of their suitability to electronics cooling (Section 4).

\section{MICROPUMPING TECHNIQUES}

This section is devoted to a discussion of the working principles of different kinds of micropumps. The most basic design of each kind of pump is explained, and natural extensions of the design identified. The micropumps considered in the literature are classified broadly according to their pumping mechanisms into the following categories:

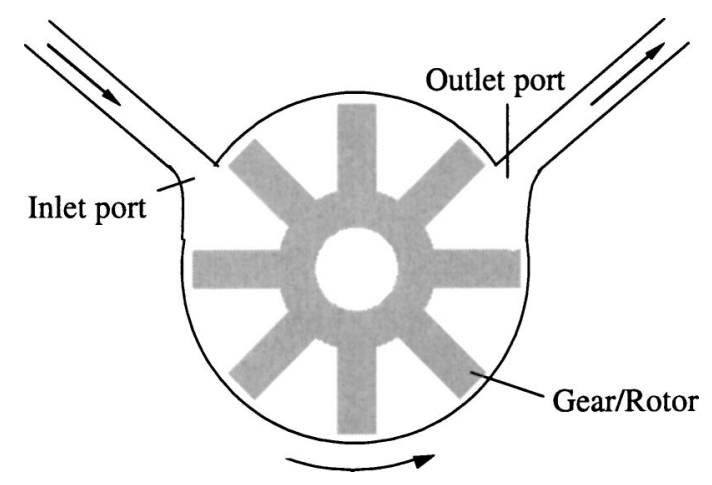

Fig. 1 Principle of operation of a rotary micropump

i) Mechanical micropumps: these include rotary pumps, vibrating diaphragms, and peristaltic micropumps

ii) Electrokinetic and magnetokinetic micropumps: electrokinetic micropumps include electrohydrodynamic (EHD) and electroosmotic micropumps, while magnetokinetic micropumps include magnetohydrodynamic (MHD) micropumps

iii) Phase change micropumps: these include bubble pumps and electrochemical pumps

iv) Other/novel micropumps such as flexural plate wave devices and electrowetting micropumps

Micropumps in any of the above categories can be further divided into subcategories, for example, the vibrating diaphragm and peristaltic micropumps can be divided based on their actuation principle, ie, piezoelectric, electrostatic, or thermopneumatic. Vibrating diaphragm micropumps can also be classified based on the type of valve mechanism used, and EHD micropumps can be classified as induction type, injection type, or polarization type.

\subsection{Mechanical micropumps}

Mechanical micropumps use the motion of an object such as a gear or a diaphragm to generate the pressure difference needed to move a fluid. Mechanical micropumps can be divided into three main categories: rotary pumps, vibrating diaphragm pumps, and peristaltic pumps.

\subsubsection{Rotary pumps}

In its most basic form, a rotary micropump consists of a long-toothed gear in a fluidic chamber with an inlet and an outlet port [8]. The gear is attached to the rotor of an electric motor and rotates with the motor. The rotating gear entraps fluid between the teeth and transports it from the inlet port to the outlet port. The geometries of the inlet and outlet ports are asymmetric ensuring that fluid is transported unidirectionally from the inlet to the outlet. The principle is schematically shown in Fig. 1.

\subsubsection{Vibrating diaphragm pumps}

As shown in Fig. $2 a$, a vibrating diaphragm pump consists of a pumping chamber connected to the inlet and outlet through valves [9]. In the suction mode, as the volume of the pumping chamber increases, the pressure in the chamber decreases. If the inlet pressure is higher than the chamber pres- 


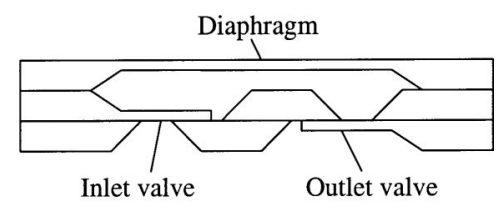

(a)

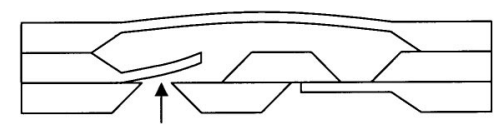

(b)

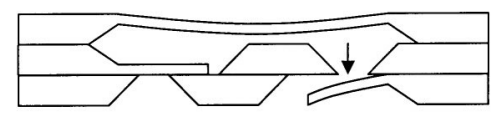

(c)

Fig. 2 a) Vibrating diaphragm micropump, $b$ ) action in the suction mode, and $c$ ) action in the pumping mode

sure, the inlet valve opens and fluid enters the chamber (Fig. $2 b)$. In the pumping mode, the volume of the pumping chamber decreases, the pressure increases, and the fluid discharges through the outlet valve (Fig. $2 c$ ). A variety of actuation mechanisms and valves have been used in vibrating diaphragm pumps. Typical actuation mechanisms include piezoelectric, electrostatic, thermopneumatic, and shape memory alloys. Vibrating diaphragm pumps have also been designed using electromagnetic, magnetostriction, and bubble actuation. Valves used in vibrating diaphragm pumps can be broadly classified as cantilever or diaphragm type, or alternatively, as active or passive. In addition, different types of fixed valves, such as nozzle-diffuser elements and valvular conduits have also been used. These will be explained in detail in Section 3.

\subsubsection{Peristaltic pumps}

As the name suggests, these pumps use peristaltic motion of a series of actuators to cause pumping action. Most peristaltic pumps described in the literature use three pumping chambers with diaphragms as actuators in series [10]. A simple operation sequence of such a pump is shown in Fig. 3. When the first diaphragm is actuated, a part of the fluid is pushed out to the second and third chambers. This also closes the inlet to the pump. While the first diaphragm remains closed, the second diaphragm is actuated and fluid is pushed out to the third pumping chamber. Finally, actuation of the third diaphragm expels the fluid out of the pump. All three diaphragms are then de-actuated. This sequence is repeated continually for pumping action from left to right.

\subsection{Electrokinetic and magnetokinetic micropumps}

These pumps convert electric or magnetic energy directly into fluid motion. Most electrokinetic pumps use an electric field to pull ions in the pumping channel, which in turn drag along the bulk fluid by momentum transfer due to viscosity. Magnetokinetic pumps use the Lorentz force on the bulk fluid to drive it through the microchannel.

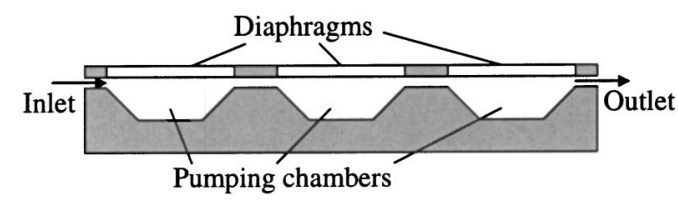

(a)

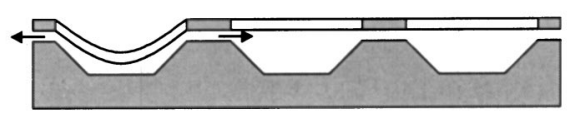

(b)

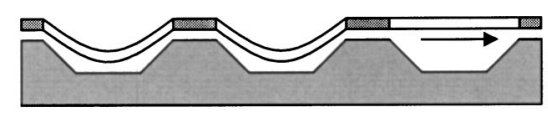

(c)

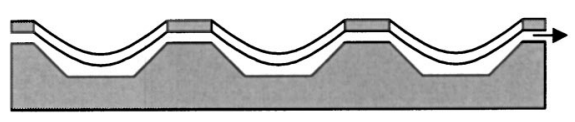

(d)

Fig. 3 Structure and operation of a peristaltic micropump. The flow direction can be reversed by changing the actuation sequence of the diaphragms.

\subsubsection{Electrohydrodynamic pumps}

Induction-type electrohydrodynamic (EHD) pumps [11] create a gradient either in the electrical conductivity or the permittivity of the working fluid. This is achieved by anisotropic heating of the fluid or through the use of layers of nonmixing fluids or suspended particles in the fluid. Application of alternating voltage to the electrodes deposited in the pumping channel creates electric waves through the working fluid traveling perpendicular to the conductivity gradient (Fig. $4 a$ ). In the presence of a conductivity or permittivity gradient, these traveling electric field waves induce charges at the fluid/fluid and fluid/solid interfaces or in the bulk of the working fluid. Due to the charge relaxation effect, these charges lag in phase with respect to the traveling wave. Coulomb forces thus generated move the charges in the same (or opposite) direction to that of the traveling wave. These moving charges carry bulk fluid with them due to viscous effects and this leads to the pumping action. The direction of fluid motion can be the same or opposite to that of the traveling waves depending on the direction of the temperature gradient.

In injection-type EHD micropumps [12], electrochemical reactions at the electrodes cause the injection of free ions into the bulk liquid. These ions experience Coulomb forces due to the presence of the electric field. This causes the movement of ions, which in turn carry the bulk fluid with them. A basic injection-type EHD pump is illustrated in Fig. $4 b$.

EHD pumps, in general, work for low-conductivity fluids such as organic fluids, and nonpolar fluids (eg, alcohols). The induction-type pumps can operate with higher conductivity 


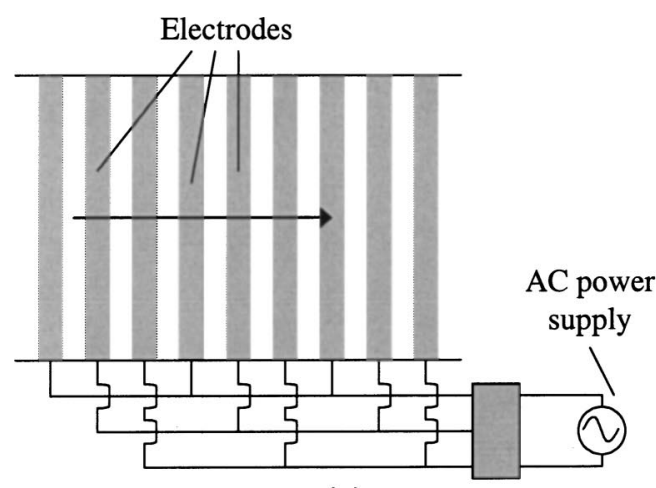

(a)

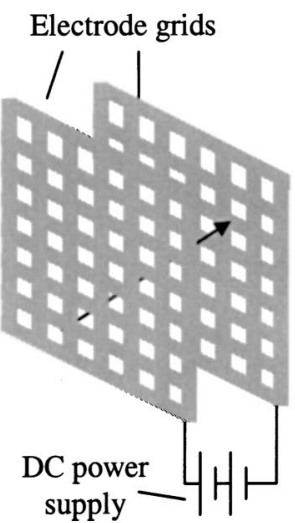

(b)

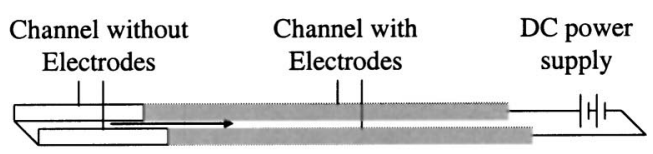

(c)

Fig. 4 Schematics of $a$ ) Induction-type, $b$ ) Injection-type, and $c$ ) Polarization-type EHD micropumps. All these pumps are bidirectional; representative flow directions are shown.

fluids. Deionized water can also be pumped by injection-type pumps, although not very efficiently because of the resulting electrolysis.

In a polarization-type EHD micropump a nonuniform electric field is applied to a dielectric fluid [13]. This creates an electric field gradient in the fluid, which in turn generates a gradient in the energy of the dipoles in the fluid. The dipoles in the regions of higher electric field have lower energy. Hence, in the structure shown in Fig. $4 c$, dipoles inside the channel created by the electrodes will have lower energy as compared to those outside. For this reason, fluid tends to move into the channel between the two electrodes and this causes the pumping action.

\subsubsection{Electroosmotic pumps}

An electroosmotic pump can be realized in a fused silica or glass capillary, fitted with electrodes on two ends as shown in Fig. 5 [14]. When an electrolyte solution is filled in such a capillary, the spontaneous deprotonation of surface silanol groups negatively charges the surface of the capillary. This

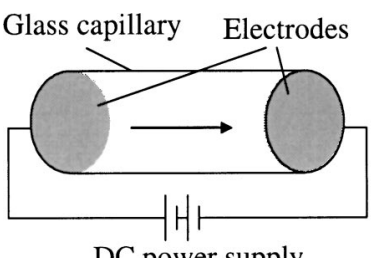

DC power supply

(a)

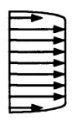

(b)
Fig. 5 a) Schematic of an electroosmotic micropump and $b$ ) Velocity profile in the channel cross-section. The flow direction can be reversed by changing the polarity of the electrodes.

charge attracts positively charged ions and repels negatively charged ions in the solution, which leads to the formation of an electric double layer along the inner surface of the capillary. Hence, the charge density along the surface of the capillary is much higher than in the interior. Consequently, when a voltage is applied between the two electrodes, the body force experienced by the bulk fluid near the surface of the capillary is much larger than that experienced by the fluid in the interior of the capillary. The resulting fluid motion near the surface is propagated to the interior of the tube due to momentum transfer by viscous forces. This generates a uniform velocity profile across the inner cross section of the capillary (Fig. $5 b$ ).

\subsubsection{Ion-drag pumps}

Most electrokinetic pumping mechanisms described above, such as injection-type and induction-type EHD pumps and electroosmotic pumps, use ion-drag as the force driving the fluid. However, most micropumps referred to as ion-drag pumps in the literature are actually injection-type EHD pumps.

\subsubsection{Magnetohydrodynamic pumps}

Magnetohydrodynamic (MHD) pumps exploit the Lorentz force generated when a current carrying conductor is placed in a magnetic field [15]. The direction of the force is mutually perpendicular to the magnetic and the electric fields. A schematic of a simple MHD pump is shown in Fig. 6. Electrodes are deposited on the microchannel walls, which create an electric field across the width of the microchannel. Permanent magnets are used to create a magnetic field across the depth of the channel in a direction perpendicular to that of

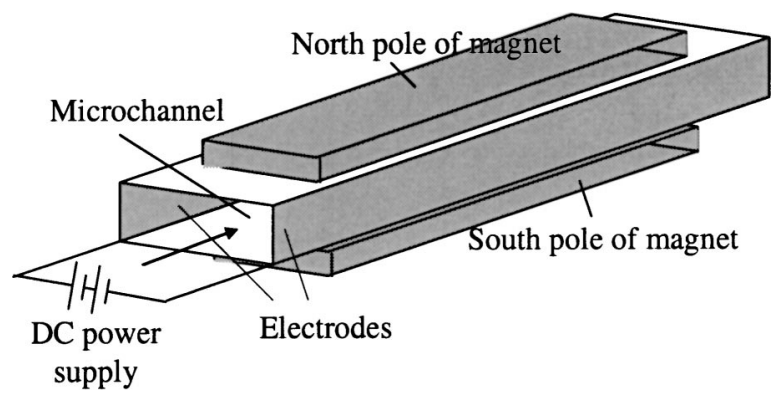

Fig. 6 Schematic and operation of an MHD micropump. The flow direction can be reversed by changing the polarity of the electrodes. 


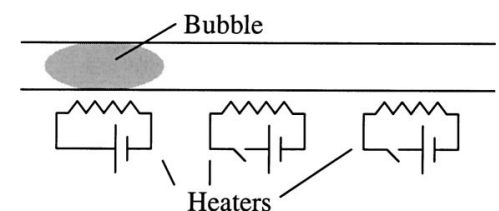

(a)

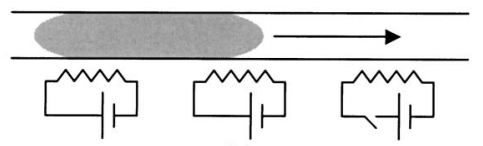

(b)

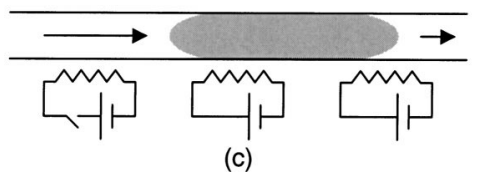

Fig. 7 Principle of operation of a bubble micropump. The flow direction can be reversed by changing the sequence of operation of the heaters.

the electric field. Therefore, a conducting fluid in the microchannel experiences a force along the length of the channel, and this leads to the pumping action. Unlike EHD pumps, MHD pumps require conductive fluids such as electrolytic solutions for normal operation.

\subsection{Phase change micropumps}

\subsubsection{Bubble pumps}

A typical bubble pump may consist of a closed microchannel with independently controlled heaters placed along its length as shown in Fig. 7 [16]. The first heater is switched on for a sufficiently long time, so that a vapor bubble grows to a steady size and fills the cross section of the channel. The next heater is switched on at this stage. The resulting asymmetric temperature gradient along the length of the bubble causes a gradient in the bubble vapor pressure. This, together with the surface tension gradient, creates a pressure gradient along the length of the channel driving the bubble from left to right in the channel. This motion of the bubble can be sustained by switching off the first heater and turning on the third, and so on sequentially. Because the bubble encompasses the entire cross section of the channel, it pumps the fluid along with it. Many other types of pumps based on the growth and collapse of vapor bubbles have been presented in the literature as will be discussed in Section 3.

\subsubsection{Electrochemical pumps}

A simple electrochemical pump might consist of a pair of closely spaced electrodes in a small reservoir filled with water connected to a liquid-filled channel [17]. As illustrated schematically in Fig. 8, a voltage applied across the electrodes electrolyses the water producing oxygen and hydrogen gas bubbles. The gas bubbles generate a pumping action by pushing the liquid in the channel.

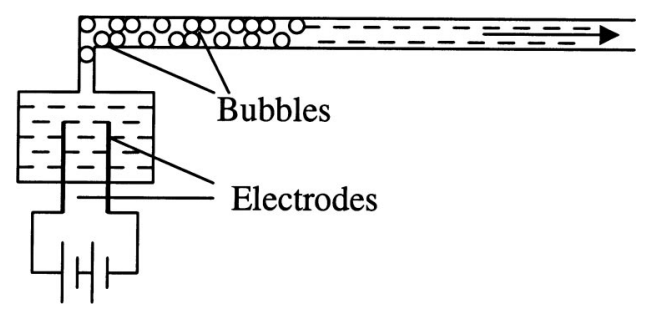

Fig. 8 Schematic and operation of an electrochemical micropump

\subsection{Other/novel micropumps}

\subsubsection{Flexural plate wave pumps}

A flexural plate wave micropump can be fabricated as shown in Fig. 9 [18]. Fingers of piezoelectric material layers with thickness of a few micrometers are deposited on a silicon substrate of comparable thickness. Alternate sets of piezoelectric fingers are connected to one of two electrodes. The two sets of piezoelectric fingers are actuated alternately at very high frequencies. This creates a flexural wave in the composite membrane, which causes the formation of a high intensity acoustic field near the surface of the membrane. This leads to the motion of the fluid present on the membrane in the direction of the waves.

\subsubsection{Electrowetting pumps}

When a liquid metal such as mercury comes in contact with an electrolyte solution, the liquid metal-electrolyte interface becomes charged due to electrochemical reactions, thus forming an electric double layer. The electric double layer behaves like a charged capacitor. An electric voltage at the interface redistributes the charge causing a variation in the electric potential along the length of the mercury-electrolyte interface. This causes a gradient in the surface tension along

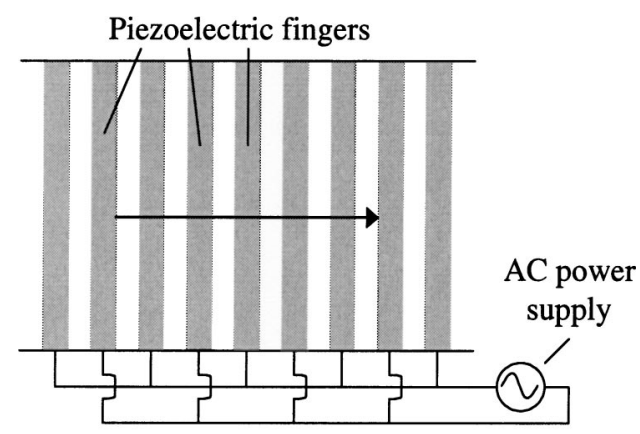

(a)

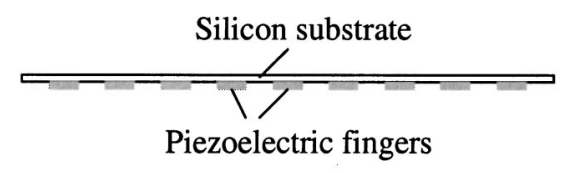

(b)

Fig. 9 Flexural plate wave micropump: $a$ ) Top view and $b$ ) Side view. The flow direction can be reversed by changing the polarity of the electrodes. 
the interface according to the Lippman's equation [19], which in turn moves the droplet towards the regions of lower surface tension. By oscillating the electric voltage, the mercury droplet can be made to oscillate periodically in opposite directions [20]. Although electrowetting can be used for direct fluid handling as in electrokinetic pumps, it is also suited for use in vibrating diaphragm micropumps. Here the oscillating droplet would push the electrolyte solution, which in turn would periodically deflect a membrane. This membrane, as a part of a vibrating diaphragm pump, can be used to pump any liquid.

\section{STATE OF THE ART}

A comprehensive literature review is now presented of the research on the micropumping techniques described in the previous section. The specifics of the design for each micropump are discussed. Quantitative data for the micropumps discussed, such as flow rate and pressure head, are presented in Tables 1-3.

\subsection{Mechanical micropumps}

\subsubsection{Rotary pumps}

A magnetically actuated rotary micropump was discussed by Ahn and Allen [8]. The pump is essentially a micromotor with built-in microchannels for inflow and outflow. As shown in Fig. 1, the pump consists of a circular pumping chamber connected to inlet and outlet chambers through microchannels. A rotor with 10 poles is free to rotate inside the pumping chamber while the stator coils lie outside the chamber. The six stator pole-pairs are in three phases, with samephase pairs located directly opposite to each other.

When a phase coil is excited, the rotor poles located nearest to the excited stator poles are attracted towards it causing the rotor to rotate. Consequently, the fluid trapped in the rotor poles moves from inlet to outlet and that trapped in the rotor poles nearest to the outlet channel moves out of the chamber. When these rotor poles are aligned with the excited stator poles, that phase is switched off and another phase is switched on (excited), thus maintaining continuous rotor rotation. The poles are located and excited such that the rotor poles at the shortest distance from the excited phase are always in the same direction, ensuring that the rotor does not swing back and forth, but rotates steadily. Because the working fluid is insulated from the current-carrying parts, the pump can also be used for pumping conductive fluids. The main advantage of the pump is that the pumped flow is continuous. Moreover, the flow direction can be easily reversed. However, the fabrication of the pump is very complex and likely to be expensive. The size of the micropump and the fluid channel are $2 \times 2 \times 0.16 \mathrm{~mm}$ and $0.2 \times 0.16 \mathrm{~mm}$, respectively. The diameter of the rotor is $100 \mu \mathrm{m}$. Information on flow rates and pressure heads for this and all other pumps to be discussed is presented in Tables 1-3.

Figure 10 shows a rotary micropump based on an internal gear system, as proposed by Weisener et al [21,22]. The internal toothing of the gears has a hypocycloid contour. The inner gear has six teeth while the outer has seven. As the two gears move with respect to each other, the chamber size (gap

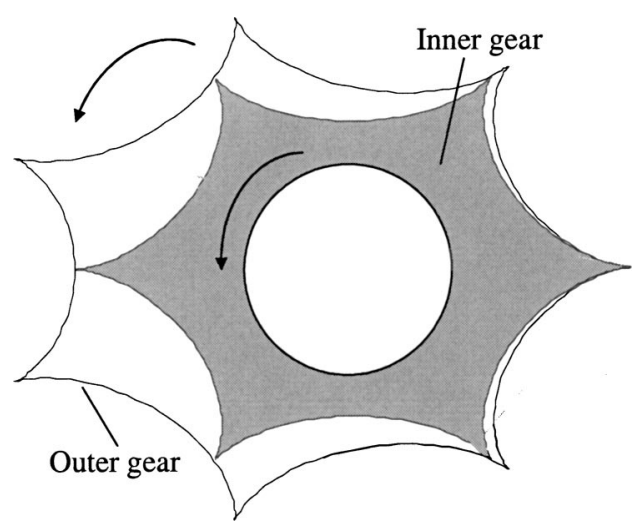

Fig. 10 Structure of the internal-gear rotary micropump [21,22]

between the two gears) varies, which drives the fluid from the inlet to the outlet port. The actuation principle of the micropump was not discussed. The different parts of the pump were fabricated using electro-discharge machining and then assembled together. Prototype pumps of two different sizes were built and tested.

Sen et al [23] demonstrated the feasibility of using viscous forces generated when a rotating cylinder is asymmetrically placed in a channel to pump fluids at low Reynolds numbers (0.01-10). A long cylinder of diameter $0.898 \mathrm{~cm}$ was rotated asymmetrically in a channel filled with glycerin, which moved the fluid throughout the depth of the channel with an almost parabolic profile. Effects of variations in eccentricity, shape and rotation speed of the cylinder, and the length of the channel were studied. The average flow velocity in the channel was approximately $10 \%$ of the surface speed of the cylinder.

A rotary micropump (Fig. 11) using two gears whose working principle is very similar to that in [8] was fabricated by Dewa et al [24]. One of the gears, the driving gear, has a $0.3 \times 1.0 \mathrm{~mm} \mathrm{NiFe}$ bar centered on it. The pump body, with

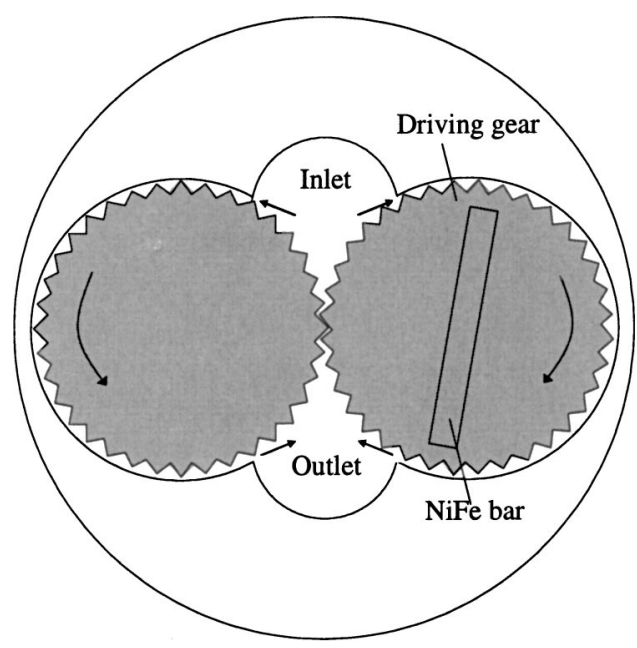

Fig. 11 Structure and operation of the two-gear rotary micropump [24]. The coupling ring and the magnets surrounding the structure are not shown in the figure. The flow direction can be reversed by changing the direction of the magnetic field. 


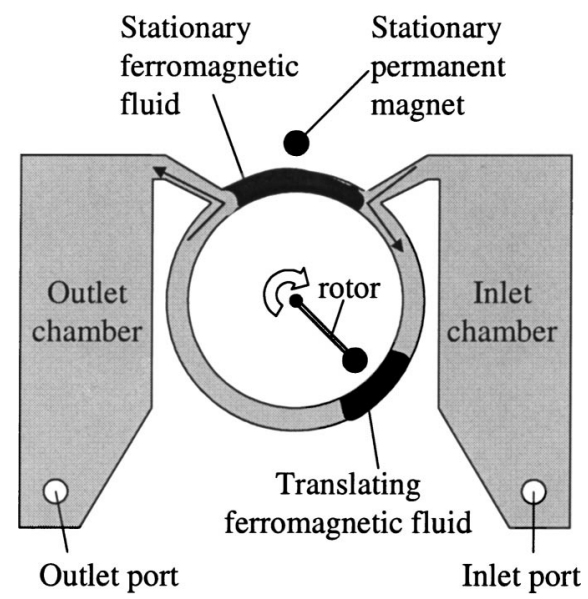

Fig. 12 Ferrofluid-actuated rotary micropump [25]. The flow direction can be reversed by changing the direction of the rotor.

the two gears and the inlet and outlet ports, is surrounded by a coupling ring which has two permanent magnets clamped on it. The magnets are placed opposite to each other. The coupling ring is driven by a conventional electric motor. As the external motor and the coupling ring attached to it rotate, the magnetic field in the pump varies. This generates torque in the $\mathrm{NiFe}$ bar which in turn drives the attached gear, thus causing a pumping action. Since the driving gear and the coupling ring are not concentric, the NiFe bar experiences a continuous change in magnetic field. LIGA is used to fabricate various components of the pump, which are assembled in a tube. LIGA is an acronym for the German Lithographie Galvanoformung Abformung. The outside diameter of the pump body (without the motor and coupling ring) is 3.175 $\mathrm{mm}$. The thickness of the micropump is $600 \mu \mathrm{m}$. The inlet and outlet ports are $0.696 \mathrm{~mm}$ in diameter. The pump is self-priming in nature and is able to pump gases. The pump was able to generate a large pressure head at the suction side (see Tables 1-3) and hence could also be used as a compressor.

The motion of a plug of ferrofluid caused due to its interaction with a translating magnetic field, brought about by a rotating permanent magnet, was exploited in a micropump design by Hatch et al [25]. The structure of the micropump is shown in Fig. 12. The inlet and the outlet chambers of the pump are connected through a circular channel of rectangular cross section. The short section of the circular channel is filled with a plug of ferrofluid, held in place by a stationary permanent magnet. A plug of the same ferrofluid rotates in the long section of the channel because of a translating magnetic field. The translating magnetic field is caused by a permanent magnet attached to the rotor of an electric motor and rotating directly above the circular channel. This rotating plug of ferrofluid pushes and pulls the working fluid from the inlet chamber to the outlet chamber. When the plug of the ferromagnetic fluid in the long section of the circular channel reaches the short section, the two plugs merge. As the translating magnet moves away, a part of the merged ferrofluid plug separates out and starts a new pumping cycle. This leads to a continuous pumping action. The pump was fabricated using silicon micromachining techniques. The circular channel is $250 \mu \mathrm{m}$ deep and $2 \mathrm{~mm}$ wide. The outer diameter of the pumping loop is $10 \mathrm{~mm}$. The ferrofluid used is a suspension of nano-size ferromagnetic particles in a hydrocarbon, which was immiscible with the working fluid, water. For motor speeds larger than $8 \mathrm{rpm}$, the pressure gradient in the channel was very large and the plug of ferromagnetic fluid in the long section was no longer coupled to the rotating permanent magnet. The pump showed an appreciable decrease (up to 34\%) in flow rate over a period of two days, mainly because of degradation of the ferromagnetic fluid.

\subsubsection{Vibrating diaphragm pumps}

The vibrating diaphragm micropumps may be further classified according to their actuation mechanism and valving scheme as in the following.

Piezoelectric actuation. van Lintel et al [26] presented the first piezoelectrically actuated vibrating diaphragm micropump. The pump uses diaphragm-type passive check valves. The diaphragm valves consist of a flexural outer ring and a rigid inner sealing ring. Pressure acting on the valve diaphragm deflects the flexible outer ring and hence the sealing ring. A small piezoelectric disc attached to the glass membrane is used for actuation. Application of an electric voltage to the piezoelectric disc causes the piezo-glass double layer to bend inwards into the pump, which pushes the fluid out of the pumping chamber through the outlet valve. When the voltage is removed, the disc bounces back, which opens the inlet valve allowing fluid to enter the pumping chamber. This reciprocating motion causes the pumping action. Two different designs of micropump are presented. The first uses a two-valve design and the second uses three valves. The extra valve in the second design is for shielding the flow rate from the effects of higher outlet pressures. Standard silicon micromachining techniques are used for fabricating the pump. The pump uses a circular diaphragm of diameter $12.5 \mathrm{~mm}$, with valving diaphragms of $7 \mathrm{~mm}$ in diameter. The depth of the pumping chamber is $0.13 \mathrm{~mm}$. The pump has been used in designing and implementing a micro Total Analysis System ( $\mu \mathrm{TAS})[27,28]$ and a flow-regulated micropump [29,30]. The flow-regulated micropump uses a flow sensor to calculate the output flow rate. A regulator then compares the outlet flow to a fixed desired output and controls the voltage applied to the piezoelectric actuator to maintain a constant flow rate.

Using a similar working principle, but with different designs for the actuation mechanism and passive check valves compared to those in [26], Esashi et al [31] proposed a piezoelectric micropump as shown in Fig. 13. The diaphragm is connected to a piezo actuator through a $2 \times 2 \mathrm{~mm}$ mesa. A stack-type piezo actuator is fixed on the other side. When a voltage is applied to the actuator, it expands and pushes the diaphragm into the pumping chamber. This increases pressure in the chamber, which opens the outlet valve. As the voltage decreases, the pressure decreases and hence the inlet valve opens. The structure of the passive check valves used in the pump is shown in Fig. 13b. It consists of circular valve lids, which cover the inlet and outlet ports and are attached to a fixed ring through arms. Standard silicon mi- 


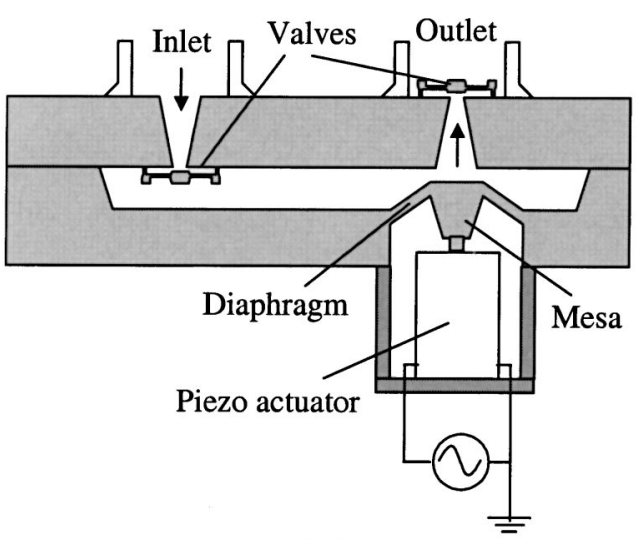

(a)

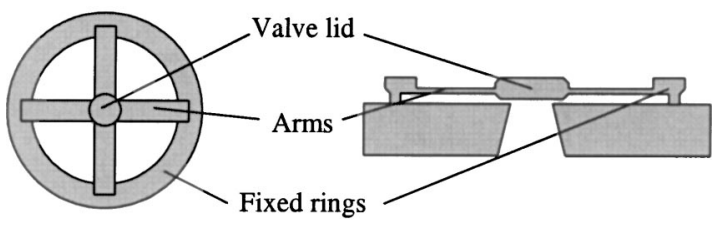

Top view

Side view

(b)

Fig. 13 a) Vibrating diaphragm micropump [31] and $b$ ) passive check valves used in the pump

cromachining techniques are used for fabricating the pump. The size of the pump is $8 \times 10 \times 10 \mathrm{~mm}$ and the diaphragm is $4 \mathrm{~mm}$ on the side. At $90 \mathrm{~V}$, the calculated pumping rate was $0.022 \mu \mathrm{l} /$ cycle with a rectangular wave.

Shoji et al [32] used the micropump design presented earlier in [31] to design two kinds of rippleless pumps-a dual pump and a buffer pump. In the dual pump, two micropumps are connected in parallel. They are actuated with complementary periodic two-phase voltages so that they pump alternately. In the buffer pump, a micropump is connected to a buffer in series. The buffer is driven in a manner that is complementary to the pump action, such that in the pumping mode it absorbs part of the outlet flow and pumps it out in the suction mode. The size of each pump is approximately $20 \times 10 \times 10 \mathrm{~mm}$.

A check valve with large forward-to-reverse flow ratio and a large reverse resistance, which can be used in a micropump to generate high pressures of more than $101 \mathrm{kPa}(1$ atm), was further developed by Shoji et al [33].

Another piezoelectrically actuated micropump is described in [34]. The pump was fabricated using stereolithography, which makes it possible to create complex 3D structures. A piezoelectric disc attached to a brass plate is used as the actuator. Ball valves are used for flow rectification. The structure of the pump is shown in Fig. 14. As the pressure in the pumping chamber increases, the outlet ball valve is lifted up and hence the outlet port opens, whereas the inlet ball valve firmly covers the inlet port. The pump is cylindrical with diameter $18 \mathrm{~mm}$ and height $5 \mathrm{~mm}$.

Stehr et al [35] presented a novel design of a piezoelectrically actuated micropump (Fig. 15). The pump does not

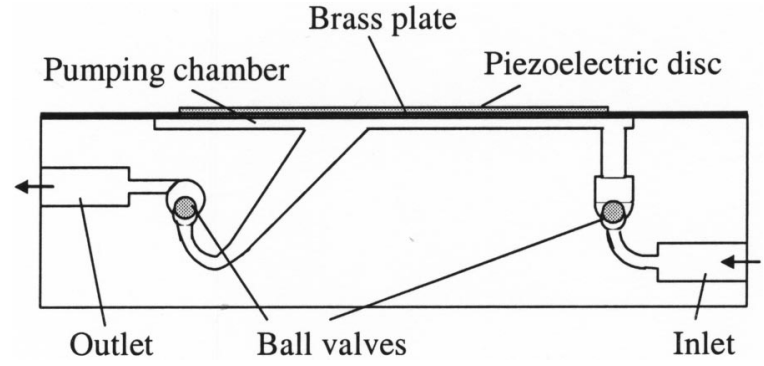

Fig. 14 Structure of the stereolithographically fabricated micropump [34]

use any check valves. Instead, the diaphragm is used to close the inlet port during the pumping mode, while both the inlet and the outlet ports remain open during the suction mode. Hence, fluid comes in both from the inlet and the outlet ports during the suction mode but goes out only through the outlet port in the pumping mode. The pump uses an elastic buffer mechanism and a variable gap mechanism to cause a pumping effect. An elastic buffer membrane is used in addition to the piezoelectrically actuated diaphragm (Fig. 15). During the suction mode, as the diaphragm is actuated, the amount of fluid inflow is very small due to the inertia of fluid during the sudden increase in volume of the pumping chamber. This is compensated by the deformation of the buffer membrane, which bends inwards and decreases the volume of the pumping chamber. Then, as the buffer membrane relaxes back, the fluid enters through both the inlet and outlet ports. During the pumping mode, as the diaphragm closes the inlet valve in a short time, the buffer membrane is pushed out. As the membrane relaxes again, fluid is pumped out through the outlet port. The resonant frequency of the pump is small $(30-150 \mathrm{~Hz})$, probably due to the large relaxation time of the elastic buffer.

The variable gap mechanism uses a variation in height of the pumping chamber with diaphragm movement and its effect on the differential pressure in the pumping chamber (and hence, on the flow rate through the inlet and outlet valves) to cause rectification. These two mechanisms working in tandem cause the pumping action. The pumps are able to work with both liquids and gases and are bi-directional in nature. The bidirectionality stems from the possibility of using the pumps at very high frequencies so that there is a phase shift between the pumping chamber pressure and the diaphragm motion. This is explained in greater detail in [36]. A pump with a $7.3 \times 7.3 \mathrm{~mm}$ square diaphragm was able to achieve a

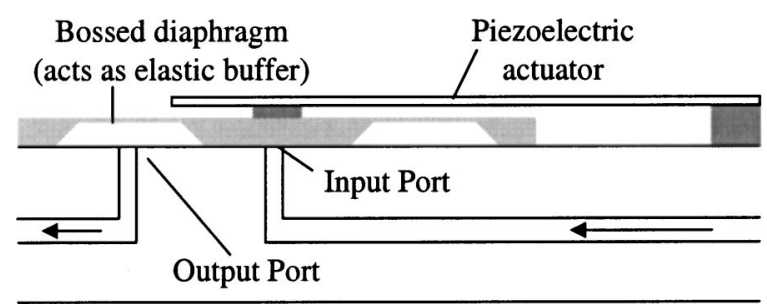

Fig. 15 Structure of the piezoelectric micropump with no valves. The pump utilizes the elastic buffer and the variable gap mechanism [35]. 
maximum flow rate of $900 \mu \mathrm{l} / \mathrm{min}$ in the forward direction and $800 \mu \mathrm{l} / \mathrm{min}$ in reverse for a supply voltage of $150 \mathrm{~V}$ and frequencies of 60 and $140 \mathrm{~Hz}$, respectively. The corresponding maximum back pressures were $6 \mathrm{kPa}$ and $3 \mathrm{kPa}$, respectively.

The principles of the elastic buffer and variable gap mechanisms from [35] were also used in the micropump described in [37]. The pump was part of a hybrid micro dosing system. A bossed diaphragm with an attached piezoelectric disk was used as the actuator. The base size of the pump was $9 \times 9 \mathrm{~mm}$. The pump was bidirectional and was able to achieve maximum flow rates of 40 and $80 \mu \mathrm{l} / \mathrm{min}$ in the two opposite directions with water.

Ederer et al [38] presented a piezoelectrically actuated micropump to inject small fluid drops in air at a controllable rate. The pump was designed for automobile applications, where it could be used to inject fuel drops into the combustion chamber. The pump consists of a piezoelectric actuator attached to a membrane, which is connected to a chamber with an inlet port for fluid entry, and micronozzles on the opposite side of the membrane. The diaphragm is actuated with a sawtooth-shaped voltage waveform. During increasing voltage, the diaphragm bends outwards which sucks fluid in from the inlet port. As the voltage starts decreasing, the diaphragm deflects back, which creates a pressure wave propagating towards the nozzles. The fluid-air interface at the nozzles first takes on a concave meniscus and then breaks away causing flying fluid droplets. The size of the pump including the chamber for storage of fluid was $19 \times 19$ $\times 10 \mathrm{~mm}$ and the nozzle had a circular cross section of diameter $50 \mu \mathrm{m}$.

In a design by Park et al [39], the vibrating diaphragm in the micropump was replaced by a metal bellows, connected to a multilayer PZT actuator. The PZT is actuated at the resonant frequency of the system. In addition, the pump uses normally-closed cantilever-type check valves. Fluid enters through the inlet port as the bellows expands and exits through the outlet port as it contracts. The bellows is cylindrical with a diameter of $8.3 \mathrm{~mm}$ and a free length of 13.3 $\mathrm{mm}$. The PZT actuator is $5 \times 5 \times 18 \mathrm{~mm}$. The overall size of the pump is $65 \times 32 \times 46 \mathrm{~mm}$. In a variation on this pump design, an additional mass was attached to the free end of the PZT actuator to achieve higher amplitudes of diaphragm displacement during resonant operation of the pump. A miniaturized version of this pump is presented in [40]. This miniaturized pump is cylindrical with a diameter of $9 \mathrm{~mm}$ and a height of $10 \mathrm{~mm}$. The resonant frequency of the loaded micropump was approximately $2200 \mathrm{~Hz}$. The effect of valve thickness on the pressure-flow characteristics was also studied experimentally.

A piezoelectrically actuated micropump using a screenprinted PZT layer on a silicon membrane was discussed in Koch et al $[41,42]$. The pump uses cantilever-type check valves. Because of the use of a screen-printed actuator instead of a glued actuator, no alignment of the actuator with the membrane is required. This makes mass production of the pump more feasible compared to other designs. The structure and the working principle of the pump are similar to other pumps described above. The size of the pump base was $8 \times 4 \mathrm{~mm}$ and the thickness of the PZT layer was 100 $\mu \mathrm{m}$. The pump achieved a maximum flow rate and a maximum back pressure of $120 \mu \mathrm{l} / \mathrm{min}$ and $2 \mathrm{kPa}$, respectively, using ethanol for a $600 \mathrm{~V}_{\mathrm{pp}}$ sine wave at $200 \mathrm{~Hz}$. A similar micropump with a surface-mounted PZT actuator layer of the same size was able to achieve $150 \mu \mathrm{l} / \mathrm{min}$ of flow with a back pressure of $4 \mathrm{kPa}$, for a $200 \mathrm{~V}_{\mathrm{pp}}$ sine wave at $200 \mathrm{~Hz}$. The improved performance of the pump with a surfacemounted PZT layer is attributed to the higher power density and displacement amplitude of these actuators.

Cunneen et al [43] described a micropump actuated using thick PZT strips with passive check valves for flow rectification. The pump is designed for microdialysis applications. Hence, the emphasis of the design is on a steady nonpulsating reproducible flow with a controllable flow rate. The design of the various pump components and operating parameters is described. The pump was fabricated using standard silicon micromachining techniques, and first tested with a pneumatic drive, using a vacuum/pressurized air supply. The pump had dimensions of $15 \times 4 \times 1 \mathrm{~mm}$ and the diaphragm was $2 \times 2 \mathrm{~mm}$ in size. With PZT actuation, the flow rate could be controlled in the range of $0.1-110 \mu \mathrm{l} / \mathrm{min}$ with drive frequencies ranging from $0.2-10 \mathrm{~Hz}$. The power input was less than $1 \mathrm{~mW}$ at a frequency of $10 \mathrm{~Hz}$. The lifetime of the pump was very small (of the order of 12 to $36 \mathrm{hrs}$ ), mainly due to degradation in the performance of the polyimide components in the pump.

A piezoelectrically actuated self-priming micropump, able to pump both liquids and gases, was described by Kaemper et al [44]. The pump design leads to a very small (essentially zero) volume for the pumping chamber with the actuator at a rest state. The volume of the pumping chamber in the deflected state is approximately 10 times that of the rest position. The large compression ratio enables an excellent pumping performance even for gases. This also leads to the selfpriming ability of the micropump, as it can build a large suction pressure and prevent agglomeration of gas bubbles in the pumping chamber. The pump was fabricated using micro-mold injection and laser-based techniques and uses a heteromorphic piezoelectric actuator consisting of a $0.25 \mathrm{~mm}$ thick piezo disc glued to a $0.10 \mathrm{~mm}$ thick brass disc and membrane check valves. The diaphragm is circular with a diameter of $10 \mathrm{~mm}$. Besides the pressure heads listed in Tables $1-3$, the pump was also able to generate a maximum suction head (vacuum) of $35 \mathrm{kPa}$. The flow rate of the pump decreased by approximately $10 \%$ after 200 hours of use.

Linnemann et al [45] also discussed a piezoelectrically actuated self-priming micropump. The approach taken towards designing a self-priming pump was similar to that in [44]. The design decreased the dead volume of the pumping chamber by decreasing the depths of etch for the valves as well as for the pumping chamber. This increased the compression ratio of the pump to $1: 9$, which enabled the pump to tolerate bubbles present in the fluid, and to self-prime. The pump used a piezoelectric disc glued to a thin silicon membrane as a diaphragm along with cantilever check valves. It was fabricated using standard silicon micromachining tech- 
niques along with mechanical grinding. The outer dimensions of the pump were $7 \times 7 \times 1.1 \mathrm{~mm}$, while the dimensions of the diaphragm were $5.7 \times 5.7 \mathrm{~mm}$.

A piezoelectrically actuated micropump for an implantable drug delivery system was reported by Maillefer et al [46]. The structure and principle of operation of the pump are based on that described in [26]. High open-loop accuracy is an important design condition for such systems and hence good control of the stroke volume of the pump is desired. For this reason, the range of deformation of the diaphragm is made small and the actuator is always over-driven to ensure that the diaphragm hits the boundaries on either side each time. This makes the pumping volume/stroke insensitive to most of the parameters. The dead volume of the pump is also minimized this way, which makes the pump self-priming. The pump has a novel output valve design, which acts as a pressure-compensating valve, by applying both inlet and outlet pressures in the same direction. This renders the pump flow rate insensitive to outlet pressure. The pump was fabricated using standard silicon bulk micromachining techniques. The size of the pump was $16 \times 12 \times 1.86 \mathrm{~mm}$. The pump was able to achieve a controllable flow rate of $0-100$ $\mu \mathrm{l} / \mathrm{hr}$ with an accuracy of $\pm 10 \%$ for a rectangular waveform of $-40 \mathrm{~V} / 100 \mathrm{~V}$ with the frequency of operation varying from $0-0.2 \mathrm{~Hz}$. The flow rate was proportional to the pump frequency. A miniaturized version of the micropump was reported in [47]. This pump uses the same actuation mechanism and principle of operation, but incorporates a new design of the inlet check valve and the pumping chamber. The size of the pump base was $6 \times 10 \mathrm{~mm}$; this pump was able to produce a controllable flow rate of $0-2 \mathrm{ml} / \mathrm{hr}$ with an improved accuracy of $\pm 5 \%$.

Li et al [48] described a piezoelectrically actuated micropump using a cylindrical piezoelectric material element. The piezoelectric material moves along its axis when actuated. The pump uses passive check valves for flow rectification. The piezoelectric element has been integrated with the microfabrication techniques and the pump uses novel bonding methods, which enable it to function at high frequencies and high power densities, thus achieving higher flow rates.

In addition to the micropumps discussed above, a number of studies have involved modeling and performance analysis of various kinds of piezoelectric actuators [49-56]. Also, considerable effort has been spent on simulating and optimizing different aspects of vibrating-diaphragm micropumps, such as the valves [57,58], diaphragms [59] and network and system models of complete pumps [60-65].

Electrostatic actuation. Zengerle et al [9] presented an electrostatically actuated micropump using cantilever-type check valves. The structure of the micropump is shown in Fig. 16. The pump uses the electrostatic forces generated by a counter electrode for actuation. As an electrical voltage is applied between the counter electrode and the silicon membrane, electrostatic forces deflect the membrane outwards towards the counter electrode. Hence the pressure in the pumping chamber decreases, the inlet valve opens, and fluid enters the chamber. When the voltage is removed, the membrane

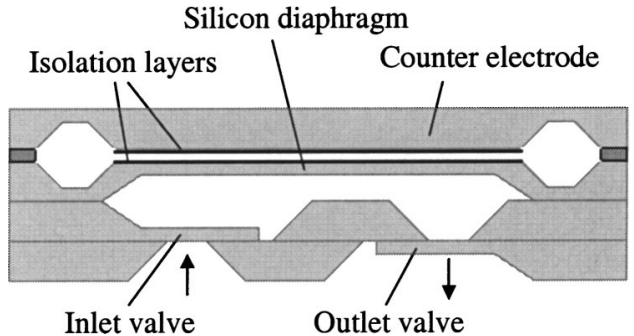

Fig. 16 Electrostatically actuated micropump [9]

bounces back, which increases the pressure in the pumping chamber. This results in the opening of the outlet valve such that fluid exits the chamber. This reciprocating motion of the membrane driven by a rectangular voltage signal causes the pumping action. The pump was fabricated using silicon micromachining techniques. The outer dimensions of the pump are $7 \times 7 \times 2 \mathrm{~mm}$. The square membrane is of side $4 \mathrm{~mm}$ and the distance between the counter electrode and the membrane is $4.4 \mu \mathrm{m}$. The volume stroke of the membrane was between 10 and $50 \mathrm{nl}$.

An electrostatically actuated bidirectional micropump similar in structure and working principle to [9] was discussed in Zengerle et al [66]. This micropump is capable of pumping fluid in both directions. When the micropump diaphragm is actuated at low frequencies (lower than the first resonant frequency of the cantilever valves), the pumping action occurs in the expected direction. However, as the frequency of the diaphragm is increased beyond the first resonant frequency of the valves, there is a phase shift in the operation of the valves and the pressure difference driving the fluid. This leads to pumping action in the reverse direction. A simple theoretical analysis was presented to verify this principle. The pump was fabricated using standard silicon micromachining techniques. The vibrating diaphragm is square of side $4 \mathrm{~mm}$ and the outer dimensions of the pump are $7 \times 7 \times 2 \mathrm{~mm}$. For a square-wave excitation voltage of $200 \mathrm{~V}$, the pump achieved maximum flow rates of $250 \mu \mathrm{l} /$ min at approximately $1000 \mathrm{~Hz}$ and $400 \mu \mathrm{l} / \mathrm{min}$ at approximately $3200 \mathrm{~Hz}$ in the forward and reverse directions, respectively, at zero back pressure. The maximum back pressure achieved was $31 \mathrm{kPa}$ and $7 \mathrm{kPa}$ in the forward and reverse directions, respectively. The resonant frequency of the flap valve in this case was $1600 \mathrm{~Hz}$. For a thicker flap valve, with a lower resonant frequency, the maximum flow rate increased in the forward and decreased in the reverse direction.

A novel electrostatically actuated dual-diaphragm pump for gases was proposed by Cabuz et al [67]. The pump uses two diaphragms, with a pumping chamber that is conformal to the maximum deflection of the two diaphragms as shown in Fig. 17. Both sides of each diaphragm and the inner walls of the pumping chamber have a very thin metal electrode covered with a dielectric. Each of the two diaphragms and the walls can be actuated separately. Both diaphragms have several through holes, which are non-coincident between the diaphragms and with the inlet and the outlet ports. Hence, when either electrode is fully deflected, it closes the corre- 


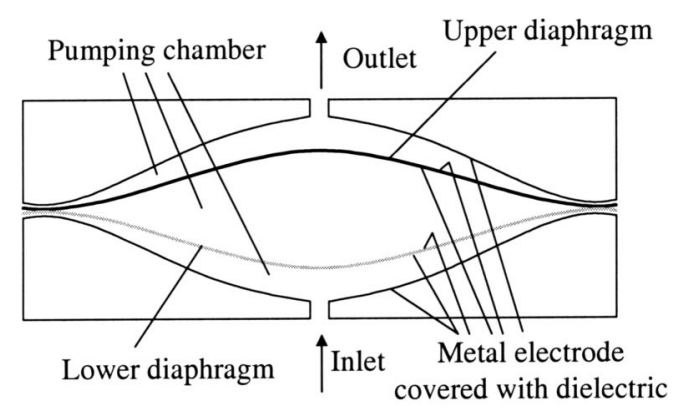

(a)

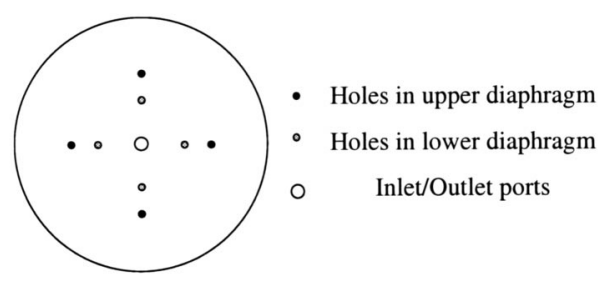

(b)

Fig. 17 Dual-diaphragm pump [66]: a) Side view and $b$ ) Top view through chamber. The flow direction can be reversed by changing the actuation sequence of the electrodes.

sponding inlet or outlet port. Also, if the two diaphragms are moving together, there is no opening through the composite diaphragm. Thus, when both diaphragms move together from the inlet toward the outlet port, air is pumped out of the chamber because the only active opening is the exit port. After both diaphragms close the outlet valve, the lower diaphragm moves back and closes the inlet valve. During this process, no air goes out of the inlet valve, even though the diaphragm is pushing it, because the resistance to flow offered by orifices in the diaphragm is much less than that offered by the inlet valve. Next, the upper diaphragm also moves back and sticks to the lower diaphragm. The two diaphragms then again move towards the outlet valve together. This process repeats at a frequency of up to $100 \mathrm{~Hz}$, which leads to the pumping action. The pump can be made to move air in the opposite direction, simply by changing the direction in which the diaphragms move together. The pump has perfect rectification and essentially zero dead volume (these terms are discussed in the section on valveless micropumps). The pump was fabricated using injection molding. The electrodes and the dielectric film were deposited using evaporation and ion beam sputtering, respectively. An array of 2 $\times 3 \times 2$ pumps of size $45 \times 35 \times 4 \mathrm{~mm}$ was able to provide a flow rate of $230 \mathrm{ml} / \mathrm{min}$ at $160 \mathrm{~V}$.

The simulation and optimization of electrostatic actuators and micropumps has been described in several studies [6770].

Electromagnetic actuation. An electromagnetically actuated vibrating diaphragm micropump using membrane-type passive check valves as shown in Fig. 18 was discussed in Böhm et al [71]. The electromagnetic actuation mechanism consists of a permanent magnet attached to the diaphragm (a

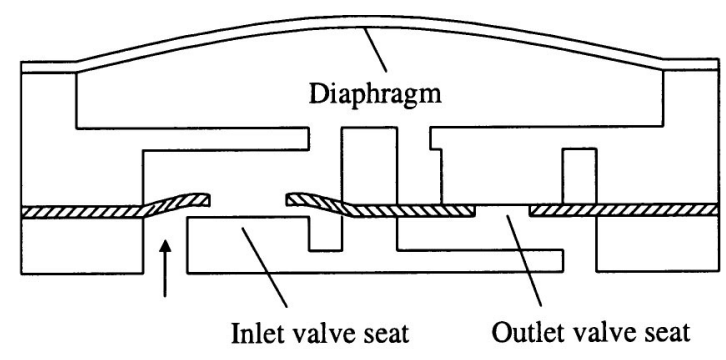

(a)

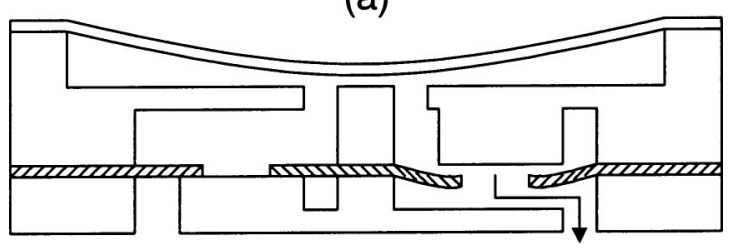

(b)

Fig. 18 Operation and structure of an electromagnetically actuated micropump [71] (actuation unit not shown): a) Suction mode and, b) Pumping mode

flexible polymer membrane) and surrounded by a coil. When an alternating current is passed through the coil, Lorentz forces move the magnet up and down, causing the diaphragm to vibrate. The membrane valves consist of two valve parts with a thin membrane in between. Each valve consists of a valve seat as shown in the figure, and was injection molded. As the diaphragm is actuated outwards, the valve membrane moves up from the inlet valve seat and fluid enters the chamber (Figure 18a). As the diaphragm moves back, the valve membrane goes back to cover the inlet valve seat and moves away from the outlet valve seat, so that the fluid goes out of the pumping chamber (Figure 18b). The pump was also tested with piezoelectric actuation. A piezoelectric disc glued to a brass membrane was used as the diaphragm. The piezoelectric actuation system is smaller (pump size $12 \times 12$ $\times 2 \mathrm{~mm}$ ), much easier to fabricate, and has lower power consumption. On the other hand, electromagnetic actuation requires a smaller voltage $(5 \mathrm{~V})$ and has a simple design of driver electronics as compared to the piezoelectric actuation. The electromagnetically actuated pump was driven with a square wave current of $100 \mathrm{~mA}$ at $50 \mathrm{~Hz}$ for water and at 400 $\mathrm{Hz}$ for air, while the piezoelectric pump was driven with a square wave voltage of $350 \mathrm{~V}_{\mathrm{pp}}$ at $50 \mathrm{~Hz}$. For the piezoelectric pump, a maximum flow rate of more than $2000 \mu \mathrm{l} / \mathrm{min}$ and a maximum back pressure of $12.5 \mathrm{kPa}$ were observed for water. Tables 1-3 show the capabilities of the electromagnetic pump. Both kinds of pumps are self-priming.

A design for a vibrating diaphragm micropump based on electromagnetics was analyzed analytically and optimized by Gong et al [72]. The deflection of the diaphragms due to a variable magnetic force (due to varying the gap between the Fe-Ni membrane and the magnetic core) on the diaphragm was analyzed using the finite element method (FEM). In addition, a system model for the micropump was used to optimize the driving frequency of the pump. A novel design of a 


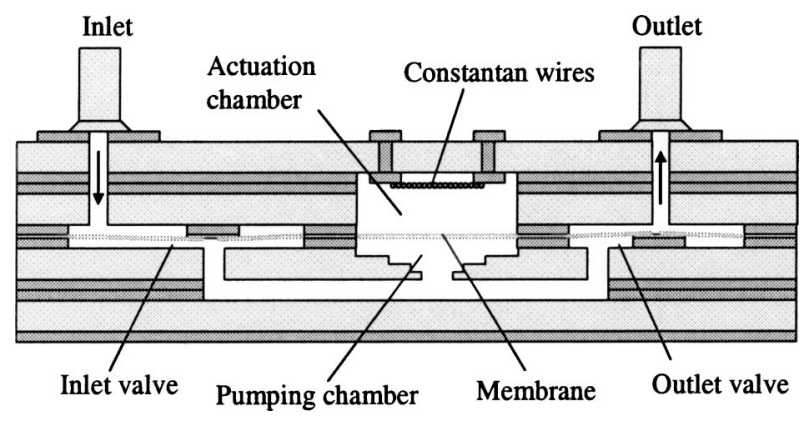

Fig. 19 Vibrating diaphragm micropump using thermopneumatic actuation [76]

membrane-type magnetic actuator, in which small magnetic pieces were embedded in a silicon elastomer membrane, was proposed by Khoo and Liu [73]. An external varying magnetic field was used for actuating the membrane. The performance of the actuator was optimized using FEM simulations. The actuator was fabricated using silicon micromachining techniques and tested. Another electromagnetic actuator design was also presented in [74].

Thermopneumatic actuation. Thermopnuematic actuation was explored by van de Pol et al [75] for driving a vibrating diaphragm micropump. The pump uses diaphragm-type circular passive check valves similar to those described in [26]. The actuation mechanism consists of a cavity filled with air, which is connected to an air chamber through small air channels. One face of the cavity is the silicon membrane. Meander-shaped (几几) aluminum heaters are fabricated on the opposite face within the cavity. On the application of voltage to the heaters, the temperature and pressure of the air in the cavity rise. This deflects the pump membrane downwards and the resultant pressure buildup in the pumping chamber causes the outlet valve to open. During this time, since the air pressure in the cavity is higher than that in the air chamber, air flows out of the cavity. The pressure in the cavity returns to the original level, the diaphragm moves back, and the outlet valve closes. As the heaters are switched off, the air in the cavity cools down, decreasing the pressure and causing the membrane to deflect inwards into the cavity. The inlet valve opens as a result and fluid enters the chamber. During this time, air enters the cavity through the channels, the pressure goes back to the original level, and the diaphragm moves back. This repeated process causes the pumping action. The pump was fabricated using silicon micromachining techniques. A square silicon membrane of size $7.2 \times 7.2 \mathrm{~mm}$ was used. The pressure and temperature rise in the cavity were estimated to be $30^{\circ} \mathrm{C}$ and $6 \mathrm{kPa}(0.06 \mathrm{~atm})$, respectively. The pump is not self-priming and requires a few $\mathrm{J} / \mu \mathrm{l}$ of pumped volume for operation. The main advantage of thermopneumatic actuation over piezoelectric counterparts is the much smaller excitation voltage required $(5-6 \mathrm{~V}$ as compared to $100 \mathrm{~V}$ ). Moreover, in piezoelectric micropumps, the need for aligning the piezo film with the membrane makes the fabrication process slower and more expensive.

The thermopneumatically actuated micropump shown in Fig. 19 was proposed by Wego and Pagel [76]. The pump uses membrane-type passive check valves for rectification. The structure and working principle of the valves is similar to the ones described in [71]. As shown in the figure, both the valves and the actuator use the same membrane. The actuator unit consists of thin constantan wires as heating elements in a cavity filled with air. As the heaters are turned on, the pressure in the cavity rises, pushing the diaphragm downwards. When the heaters are turned off, the air in the cavity cools off naturally, causing the pressure to drop and the diaphragm to move back. The pumping chamber was designed so that the gap between the chamber walls and the diaphragm in the fully deformed state is a minimum. This decreases the dead volume in the pumping chamber and makes the pump self-priming. The pump was fabricated using printed circuit board (PCB) technology as it was simpler and cheaper than using silicon micromachining techniques. The circular actuation chamber was $10 \mathrm{~mm}$ in diameter. Different kinds of heating elements for the micropump design in [76] were compared in [77]. Among the four types of heaters considered and tested, a copper membrane and constantan cantilever heaters were found to have the highest efficiency and a copper heater patterned on the PCB had the lowest. However, the copper heater on PCB was the easiest and cheapest to fabricate. Constantan wire heaters were most reliable, although it was not easy to fabricate or mount them.

Shape memory alloy actuation. The actuation mechanism in this kind of micropump uses the shape memory effect of TiNi, which involves a phase transformation between two solid phases - the high-temperature austenite phase and the low-temperature martensite phase. The martensite is much more ductile than austenite and while in this phase, TiNi can undergo large deformations. When it is heated to the phasetransformation temperature, TiNi starts to transform to the austenite phase. During this transformation, TiNi assumes its initial shape if it is not constrained. However, when constrained, it exerts a large force in trying to assume its initial shape. This effect of shape memory alloys (SMA) is used for pump actuation. Two different types of actuators based on the shape memory effect have been described by Benard et al [78]. In the complementary actuator pump, two TiNi actuators are bonded through intermediate spacers as shown in Fig. 20. Both actuators are flat when deposited, but both are deflected due to the spacer placed between them during fabrication. When one of the actuators is heated, the shape memory effect causes it to become flatter, which moves the composite actuator and further deflects the other actuator. The heated actuator is then allowed to cool down and the other actuator is heated, so that the composite actuator moves in the other direction. This process is repeated, causing the pumping action. In the alternative polyimide-springbiased micropump design, one of the TiNi actuators is replaced by a polyimide layer. Therefore, as the actuator cools, the only restoring forces arise from the elasticity of the polyimide layer. This causes the pumping stroke to be smaller but achieves chemical and thermal isolation of the fluid from TiNi. The passive check valves used in the pump for flow 


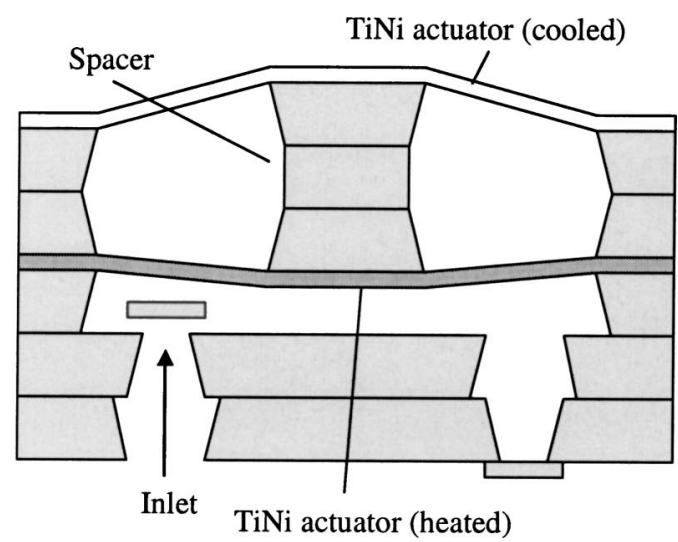

(a)

TiNi actuator (heated)

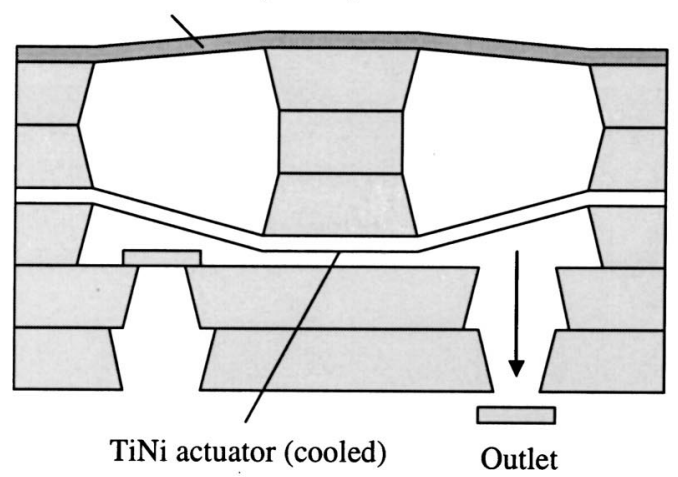

(b)

Fig. 20 Shape memory alloy micropump [78]: a) Suction mode and $b$ ) Pumping mode

rectification consist of sealing flaps (valve lids) attached to anchors by tethers (arms). The working principle of the check valves was similar to those described in [31]. The pump was fabricated using silicon micromachining techniques, with the TiNi films being sputter-deposited. Both the actuators were $8.4 \mathrm{~mm}$ square.

A TiNi/silicon bimorph was used for actuating a vibrating diaphragm micropump in $\mathrm{Xu}$ et al [79]. At room temperature, when TiNi is in the martensite phase and is very ductile, the bimorph is flat. However, as the bimorph is heated, TiNi becomes very stiff as it transforms to the austenite phase. Due to the difference in the thermal expansion coefficients of TiNi and the silicon substrate, the bimorph is under thermal stress and hence deforms (inwards or outwards, depending on the structure of the bimorph and the relative thermal expansion coefficients of the SMA and substrate). When the bimorph is cooled, it becomes flat again. The pump uses cantilever-type passive check valves for flow rectification. A meander-shaped TiNi film is sputter-deposited on top of the silicon substrate. The pump is fabricated using silicon micromachining techniques, has a diaphragm size of $3 \times 3 \mathrm{~mm}$, and operates with a square wave current of amplitude 120 $\mathrm{mA}$. The pump has higher flow rate, high frequency of operation, better reliability, smaller size, and simpler structure as compared to other SMA micropumps.

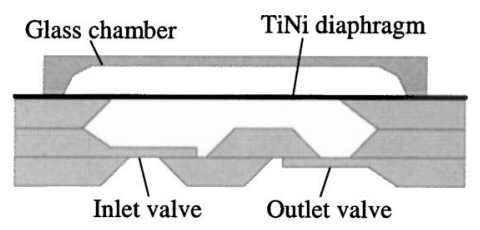

(a)

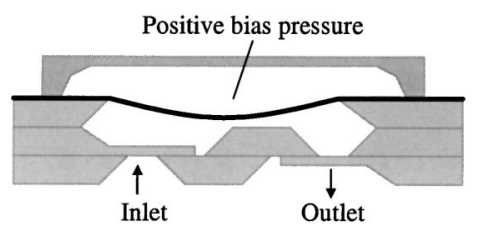

(b)

Fig. 21 Shape memory alloy micropump with $a$ ) no bias pressure and $b$ ) positive bias pressure [80]

For applications in microanalysis and microdosing systems, Makino et al [80] presented a shape memory alloy actuated micropump as shown in Fig. 21. The actuation mechanism of this micropump consists of a TiNi diaphragm, which has memorized a flat shape in the austenite phase (at high temperature). The diaphragm is connected to a glass chamber where the bias pressure can be controlled. If the chamber is pressurized, ie, the bias pressure is positive, then at room temperature the diaphragm is deformed (Figure 21a). When the diaphragm is heated, it recovers its initial flat shape. As the heating is turned off and the diaphragm is cooled, it moves back to the deformed state. This reciprocating motion of the diaphragm, along with cantilever-type passive check valves for flow rectification, causes the pumping action. The diaphragm is resistively heated and air-cooled. The pump was fabricated using standard silicon micromachining techniques, with the TiNi film deposited using flash evaporation. The micropump was $10 \times 20 \times 1.4 \mathrm{~mm}$ in size, and the TiNi diaphragm was $5 \mathrm{~mm}$ square. The frequency of the diaphragm was $0.2 \mathrm{~Hz}$. The average power input was $0.4 \mathrm{~W}$ while the peak power input was $20 \mathrm{~W}$.

Various aspects of TiNi thin films, such as, thermomechanical properties, dynamic response, and fabrication issues have been analyzed and reported in [81-84].

Photothermopneumatic actuation. Mizoguchi et al [85] described a light-driven peristaltic micropump. The micropump consists of a channel whose bottom surface is lined with pre-deflected membranes and the top surface is covered with a glass plate. Independent chambers (microcells) are formed on the other side of the pre-deflected membranes. One such chamber is shown in Fig. 22. These chambers contain the working fluid (Freon 113) and a piece of a light absorber material (carbon wool). An optical fiber connecting the chamber to a laser source guides light to the chamber. Carbon wool absorbs light efficiently and converts it to heat. This causes Freon 113 to vaporize (boiling point $47.6^{\circ} \mathrm{C}$ ), which leads to a pressure rise in the chamber, and causes the membrane to deflect. Peristaltic motion of an array of five such chambers causes the pumping action. Pre-deflected 


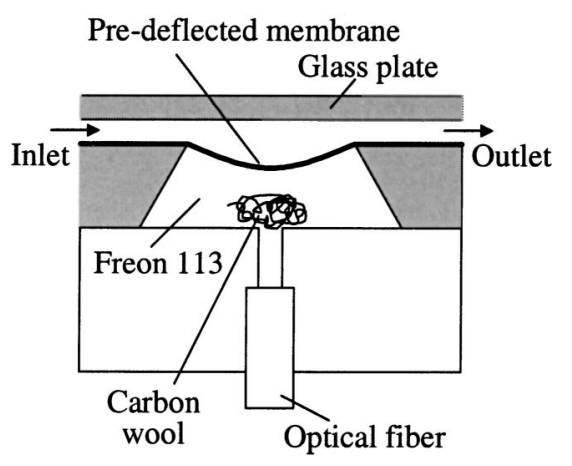

Fig. 22 One chamber in the light driven micropump of Mizoguchi et al [85]

membranes are used because they are able to achieve large displacements with relatively small forces. The pump was fabricated using standard silicon micromachining techniques, with each membrane being $800 \times 800 \mu \mathrm{m}$ in size with a channel height of $18 \mu \mathrm{m}$. The pump was tested with pneumatic actuation and a maximum flow rate of around $40 \mathrm{nl} / \mathrm{s}$ was observed. With laser light, the pump was projected to achieve a flow rate of around $90 \mathrm{nl} / \mathrm{s}$ for water with a power input of approximately $55 \mathrm{~mW}$.

A few other novel actuation mechanisms for vibrating diaphragm micropumps have also been reported in literature. These include magnetostrictive actuation [86-88], which is based on the change in shape of some materials, such as $\mathrm{SmFe}$ and $\mathrm{TbDyFe}$, under the influence of an external magnetic field. Quandt and Lutwig [88] reported a maximum flow rate of $290 \mu \mathrm{l} / \mathrm{min}$ and maximum pressure head of 490 $\mathrm{Pa}$ for a magnetostrictive nozzle-diffuser pump using a composite $\mathrm{TbFe} / \mathrm{Si} / \mathrm{SmFe}$ membrane.

Valveless Micropumps. Nozzle-diffuser elements have been successfully used for flow rectification instead of check valves in vibrating diaphragm micropumps (for example, Stemme and Stemme [89]). The rectification properties of these devices stem from the fact that a nozzle-diffuser element (with small angles) has higher flow rate in the diffuser direction than in the nozzle direction for equal pressure drops. The operating principle of such a micropump is shown in Fig. 23. As the volume of the pumping chamber increases and the pressure decreases, more fluid enters the pumping chamber from the element on the right which acts like a diffuser than the element on the left which acts like a nozzle. On the other hand, as the pressure in the pumping chamber decreases, more fluid flows out of the element on the left which now acts as a diffuser, while the element on the right acts as a nozzle. Thus net fluid transport is achieved in the pumping chamber from right to left. Using a simple analysis, Stemme and Stemme derived an expression for the efficiency of the pump and showed that pumping action exists as long as the pressure-loss coefficient in the nozzle direction is larger than that in the diffuser direction. The structure of the pump is shown in the Fig. 24. The pump was fabricated from brass. A piezoelectric disc attached to a thin brass membrane was used for actuation. The pumping chamber was $19 \mathrm{~mm}$ in

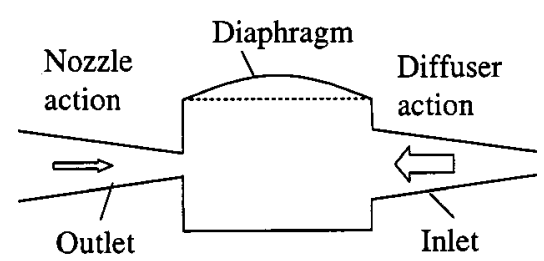

(a)

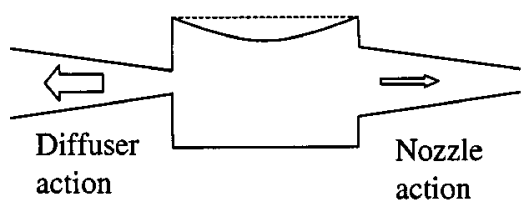

(b)

Fig. 23 Flow rectification in a valveless micropump: $a$ ) Expansion mode, and $b$ ) Contraction mode. The thicker arrows imply higher volume flow rates.

diameter. The pump was tested with two different sizes of conical nozzle-diffuser elements with cone half angles of $2.65 \mathrm{deg}$ and $5.35 \mathrm{deg}$. The pump was able to achieve higher pumping rates (Tables 1-3) than pumps with passive check valves of similar dimensions, in spite of its poor flow rectification properties. This is primarily because it was able to operate at much higher frequencies, close to the resonant frequency of the system, which in general, is an order of magnitude higher than the operating frequencies of pumps with passive check valves. Further, passive check valves have a much larger respont time. Therefore, at driving frequencies higher than the first resonance frequency of the valves, there is a phase shift between the valve motion and the pressure difference driving the fluid which leads pumping in the reverse direction [36].

Olsson et al [90] designed and fabricated a nozzlediffuser pump with two pumping chambers in parallel. Each pump had two vibrating diaphragms acting opposite to each other, as shown in Fig. 25. All the diaphragms were actuated piezoelectrically. Planar (rectangular) nozzle-diffuser elements were used, where two walls were flat and the other two were converging/diverging. The diaphragms of the two pumping chambers were actuated with opposite phases. The overall flow rate and pressure drop for this mode of operation was reported to be much higher than their in-phase op-

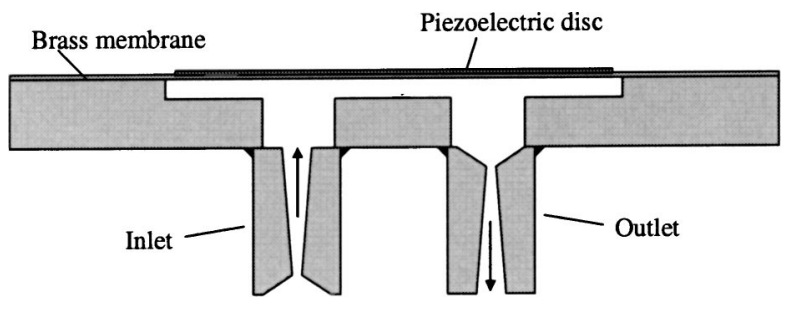

Fig. 24 Nozzle-diffuser micropump [89] 


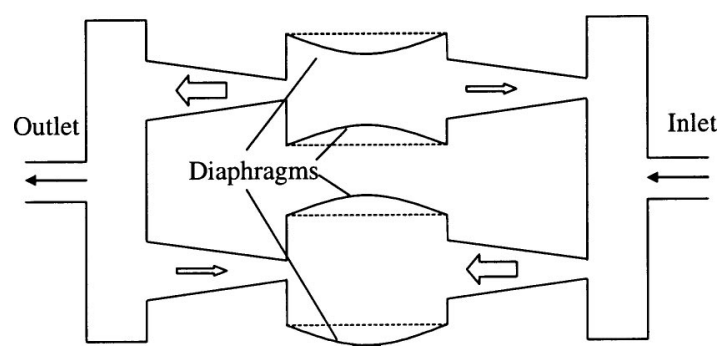

Fig. 25 Structure and operation of the nozzle-diffuser pump presented in [90]

eration. The pump was fabricated in brass as in [89]. The diameter of the pumping chamber was $13 \mathrm{~mm}$ and the thickness of the pump was $1 \mathrm{~mm}$.

A miniaturized version of the pump discussed in [90] was also fabricated in silicon [91]. Three different lengths for the nozzle-diffuser elements with the same inlet cross section and diffuser half-angle ( $2 \mathrm{deg})$ were considered. The volume flow rate was found to increase with increasing length. This is because the outlet velocity and hence the exit losses decrease as the diffuser length increases. Therefore, the use of longer diffusers ensures that the pressure differential is used to mostly overcome the pipe losses, thus resulting in greater flow rates. The diameter of the pumping chamber was $6 \mathrm{~mm}$ and the size of the chip containing the pump was 15 $\times 18 \mathrm{~mm}$. The pump thickness was $1.4 \mathrm{~mm}$. Because they were isotropically etched, the nozzle-diffuser elements had half-oval cross sections. In [92], Olsson et al described the fabrication of a similar micropump using deep reactive ion etching (DRIE), which led to the cross section of the nozzlediffuser elements being rectangular instead of half-oval shaped [91]. The half-angles of the nozzle-diffuser elements were varied from 3.5 to $6.5 \mathrm{deg}$. The capabilities of both kinds of pumps are summarized in Tables 1-3. Cheaper fabrication of a similar micropump using thermoplastic replication was also reported [93], as was the use of a single chamber pump for fluids containing particles or living tissues [94].

Piezoelectric actuation was used in a nozzle-diffuser micropump by Gerlach et al [95]. The nozzle-diffuser elements were truncated pyramids in shape. Their half-angle was $35.26 \mathrm{deg}$ as compared to much smaller values of 2 to $6 \mathrm{deg}$ in earlier work [89-91]. At these large angles, flow separation occurs in the diffuser, which leads to higher pressure loss coefficients in the diffuser direction than in the nozzle direction. Hence, a net pumping action is observed in the nozzle direction (from left to right in Fig. 23), which is opposite to the pumping direction for the nozzle-diffuser elements with smaller angles. The pump was fabricated using silicon micromachining techniques. The base of the pumping chamber was $10 \times 10 \mathrm{~mm}$ in size.

Forster et al [96] analyzed and fabricated vibrating diaphragm micropumps using nozzle-diffuser elements and valvular conduits (Fig. 26). Valvular conduits also utilize different pressure drop characteristics for flow in opposite directions to cause flow rectification. All the pumps were piezoelectrically actuated. The pumps were fabricated using

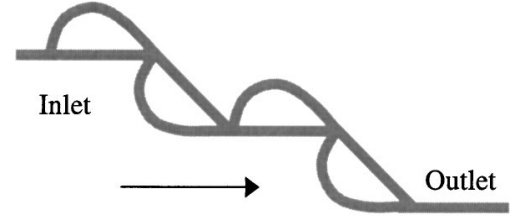

Fig. 26 Structure of a valvular conduit described in [96] and resultant fluid flow direction

silicon micromachining techniques. The diameter of the pumping chamber was $10 \mathrm{~mm}$ and the membrane was 150 $\mu \mathrm{m}$ thick for all pumps.

A linear-frequency-domain model of a valveless micropump was developed by Bardell et al [97] for predicting the frequency response of the diaphragm and fluid mass system. The parameter values used in the model, such as the membrane stiffness and resonant frequency, and pump chamber fluid capacitance and inertance, were calculated numerically and verified against experiments. The model was used to design a stiffer micropump, which had a smaller pumping chamber diameter $(6 \mathrm{~mm})$ and larger diaphragm thickness $(500 \mu \mathrm{m})$ as compared to the pump in [96]. Jang et al $[98,99]$ used the micropump design described in [97] to transport particle-laden fluids. For flow rectification, valvular conduits [96] were employed. The pump, fabricated using silicon micromachining techniques, was able to transport fluids with particle sizes of up to $20.3 \mu \mathrm{m}$ without any change in the viscous properties of the fluid. For smaller particles of size $3.1 \mu \mathrm{m}$, more than 90,000 particles/s were transported through the pump. They also found that charged particles had better pumping performance than uncharged particles. The smallest cross section of the valves was $117 \times 114 \mu \mathrm{m}$.

A nozzle-diffuser micropump with a screen-printed PZT layer as the actuator on a $100 \mu \mathrm{m}$ thick silicon membrane was investigated by Koch et al [100]. The base of the membrane was $8 \times 4 \mathrm{~mm}$ and the PZT layer was $7 \times 3 \mathrm{~mm}$. At a half-angle for the pyramidal nozzle-diffuser elements of 35.3 deg, the pump achieved a maximum flow rate of $155 \mu \mathrm{l} / \mathrm{min}$ and maximum back pressure of $1000 \mathrm{~Pa}$ at $600 \mathrm{~V}_{\mathrm{pp}}$ and 2 $\mathrm{kHz}$. For an identical pump design, a surface mounted actuator of size $6.25 \times 3.25 \mathrm{~mm}$ achieved a maximum flow rate of $114 \mu \mathrm{l} / \mathrm{min}$ and maximum pressure of $1 \mathrm{kPa}$ at $240 \mathrm{~V}_{\mathrm{pp}}$ and $2.2 \mathrm{kHz}$. Schabmueller et al [101] presented an optimized design of this pump with a much smaller dead volume, which was tolerant to gas bubbles and was able to pump both liquids and gases. The valve unit was designed so that it would fit into the membrane unit, which allowed selfaligning of the pump. The base size of the diaphragm was $7 \times 7 \mathrm{~mm}$. A $6 \times 6 \mathrm{~mm}$ piezoelectric strip of thickness 250 $\mu \mathrm{m}$ was used for actuation. Pyramidal nozzle-diffuser elements of half-angle $35.3 \mathrm{deg}$ were used as in [100].

Electromagnetic actuation for a micropump with nozzlediffuser elements was explored by Jiang et al [102]. A plastic rubber membrane of size $3 \times 3 \mathrm{~mm}$ was used. The nozzlediffuser elements composed of several uniform channels 


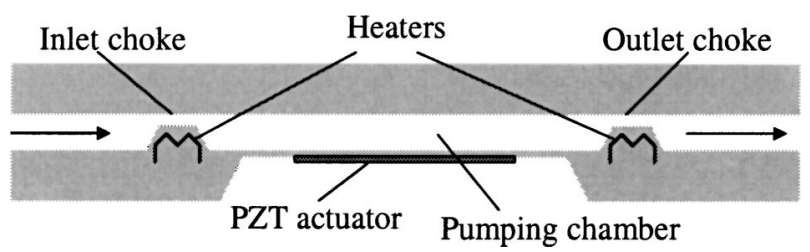

Fig. 27 Structure of the valveless micropump presented in [115]. The flow direction can be reversed by changing the actuation sequence of the heaters relative to that of the PZT actuator.

with sudden expansions/contractions with varying depth of etch. The half-angle of the nozzle-diffuser elements was 2.5 deg.

A thermopneumatically actuated micropump using nozzle-diffuser elements for flow rectification was discussed by Jeong and Yang $[103,104]$. The pump uses a corrugated $\mathrm{p}+$ diaphragm (corrugated diaphragm, doped with boron), which is more flexible and facilitates larger-amplitude deflections than a flat diaphragm. The actuation principle of the micropump is similar to that described in [75], except that there are no channels connecting the air-filled cavity to the outside. This enables the pump to work at higher frequencies because the thermal response time is shorter than that for the pneumatic case. The air in the cavity is heated resistively and naturally cooled. The pump was fabricated using standard silicon micromachining techniques. A square diaphragm of size $4 \mathrm{~mm} \times 4 \mathrm{~mm} \times 2 \mu \mathrm{m}$ was used. The actuator air cavity was $5 \mu \mathrm{m}$ deep. The nozzle-diffuser elements were pyramidal in shape and were $100 \times 100 \mu \mathrm{m}$ at the neck and 560 $\times 560 \mu \mathrm{m}$ at the wide end.

Since the performance of nozzle-diffuser micropumps depends on the flow rectification ability of the nozzle-diffuser elements, many numerical, analytical, and experimental studies have been directed at better understanding the fluid dynamic behavior and flow rectification properties of nozzlediffuser elements [105-110]. Other analytical and numerical studies on nozzle-diffuser micropumps are available in [111$114]$.

In a variation from micropumps with nozzle-diffuser elements, Matsumoto et al [115] investigated a piezoelectrically actuated bidirectional valveless micropump. The rectification principle of the pump is based on the temperature dependence of liquid viscosity, which causes a variation in the flow resistance. The structure of the micropump, fabricated by silicon micromachining, is shown in Fig. 27. The pumping chamber with a piezoelectrically actuated diaphragm is attached to the inlet and outlet through small cross section chokes. Boron-doped silicon heaters are used to locally heat the inlet and outlet chokes. When the diaphragm is actuated, the volume of the pumping chamber decreases and the pressure increases. The outlet choke is heated simultaneously, so that the local viscosity of the liquid at the outlet decreases and hence more liquid goes out of the outlet than through the inlet, and vice versa. The PZT used for actuation was 5 $\times 5 \mathrm{~mm}$ and the height of the choke was $5 \mu \mathrm{m}$.

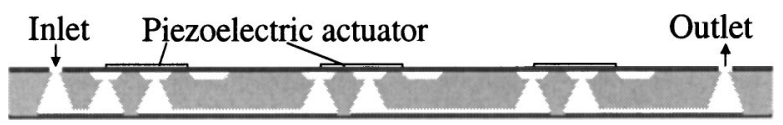

Fig. 28 Peristaltic micropump [10]. The flow direction can be reversed by changing the actuation sequence of the diaphragms.

\subsubsection{Peristaltic pumps}

Among the first micropump designs proposed was a peristaltic micropump with piezoelectric actuation [10], designed for insulin delivery applications. The pump had three pumping chambers and followed the simple pumping sequence described in Section 2.1.3 (Fig. 3). The structure of this pump is shown in Fig. 28. The pump was fabricated using silicon micromachining techniques.

A thermopneumatically actuated planar peristaltic micropump was investigated by Grosjean and Tai [116]. The pump uses a soft flexible composite silicon/parylene membrane, which is capable of large deflections, for achieving high flow rates, and a precision-machined acrylic pumping chamber for its good sealing properties. The actuation mechanism consists of island resistive heaters suspended in a cavity filled with a working fluid enclosed on one side by the membrane and on the other by a glass backplate as shown in Fig. 29. The pump uses island heaters for faster thermal response times. When a particular heater is turned on, pressure is generated in the cavity due to heating of the working fluid, which pushes the membrane outwards, closes the pumping chamber, and pushes fluid out of the chamber. The peristaltic actuation sequence of the three chambers causes the pumping action. The composite membrane and the island heaters were fabricated using silicon micromachining while the pumping chamber was machined on a CNC milling machine. Each membrane was $2 \times 2.8 \mathrm{~mm}$ in size. The working fluids (fluids in the cavity) studied were 3M PF5080 and air. The pressure generated in the cavity by the heating was in the range of $27.5-34.5 \mathrm{kPa}(4-5 \mathrm{psi})$. For pumping water, a maximum flow rate of $4.2 \mu \mathrm{l} / \mathrm{min}$ at $1 \mathrm{~Hz}$ was achieved with PF5080 as the working fluid. The corresponding power input was $400 \mathrm{~mW}$. Data for air as the working fluid are provided in Tables 1-3. The pump was also tested with pneumatic actuation, which yielded a maximum flow rate of $120 \mu \mathrm{l} / \mathrm{min}$ at $16 \mathrm{~Hz}$ for an actuation pressure of $55.16 \mathrm{kPa}(8 \mathrm{psi})$. Under pneumatic operation, the pump was able to pump both water and air. Both the pumps were self-priming in nature.

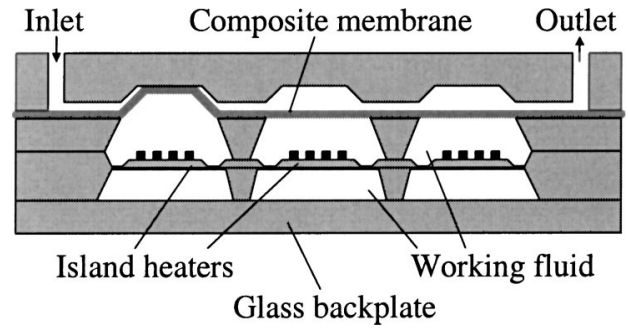

Fig. 29 Thermopneumatically actuated micropump [116]. The flow direction can be reversed by changing the actuation sequence of the membranes. 
Table 1. Quantitative comparison of different micropumps in the literature

\begin{tabular}{|c|c|c|c|c|c|c|c|c|c|}
\hline \multirow[b]{2}{*}{$\begin{array}{l}\text { Micropumping } \\
\text { Technique }\end{array}$} & \multirow[b]{2}{*}{$\begin{array}{l}\text { Actuation } \\
\text { Method }\end{array}$} & \multirow[b]{2}{*}{$\begin{array}{c}Q_{\max }(\mu \mathrm{l} / \mathrm{min}), \\
Q_{\max } / A \\
\left(\mu \mathrm{l} / \mathrm{min}_{.} \mathbf{m m}^{2}\right)\end{array}$} & \multirow[b]{2}{*}{$\begin{array}{l}p_{\text {back,max }} \\
(\mathbf{k P a})\end{array}$} & \multirow[b]{2}{*}{$\begin{array}{l}V(\mathrm{~V}), V / Q \\
(\mathrm{~V} \cdot \mathrm{min} / \mathrm{ml})\end{array}$} & \multirow[b]{2}{*}{$\begin{array}{l}P(\mathrm{~W}), P / Q \\
(\mathrm{~W} . \mathrm{min} / \mathrm{ml})\end{array}$} & \multicolumn{2}{|l|}{ Size } & \multirow[b]{2}{*}{$\nu$} & \multirow[b]{2}{*}{ Reference } \\
\hline & & & & & & $\begin{array}{l}\text { In-plane } \\
(\mathbf{m m} \times \mathbf{m m})\end{array}$ & $\begin{array}{l}\text { Out of } \\
\text { plane } \\
(\mathrm{mm})\end{array}$ & & \\
\hline Rotary & Magnetic & $\begin{array}{l}24 \text { (insulin in } \\
\text { saline buffer), } \\
112.23\end{array}$ & 10 & 3,125 & $0.5,20.83$ & $2 \times 2$ & 0.16 & $\begin{array}{l}5000 \\
\mathrm{rpm}\end{array}$ & $\begin{array}{l}\text { Ahn and } \\
\text { Allen (1995) } \\
{[8]}\end{array}$ \\
\hline Rotary & $\begin{array}{l}\text { Magnetic } \\
\text { micromotor }\end{array}$ & $\begin{array}{l}350 \text { (water), } \\
115.32\end{array}$ & 14 & - & - & $\begin{array}{l}3.17 \times 3.17 \\
\text { (without } \\
\text { motor) }\end{array}$ & 0.6 & $\begin{array}{l}5000 \\
\mathrm{rpm}\end{array}$ & Dewa et al (1997) [24] \\
\hline $\begin{array}{l}\text { Vibrating } \\
\text { Diaphragm }\end{array}$ & Piezoelectric & $\begin{array}{l}20 \text { (DI water), } \\
2.5\end{array}$ & 7.8 & 90,4500 & - & $8 \times 10$ & 10 & $\begin{array}{l}20 \\
\mathrm{~Hz}\end{array}$ & $\begin{array}{l}\text { Esashi et al } \\
(1989) \text { [31] }\end{array}$ \\
\hline $\begin{array}{l}\text { Vibrating } \\
\text { Diaphragm }\end{array}$ & Piezoelectric & $\begin{array}{l}1500 \text { (water), } \\
53.4\end{array}$ & 17 & $\begin{array}{l}200 \\
133.33\end{array}$ & - & $5.3 \times 5.3$ & 1.5 & $\begin{array}{l}190 \\
\mathrm{~Hz}\end{array}$ & $\begin{array}{l}\text { Stehr et al } \\
\text { (1996) [35] }\end{array}$ \\
\hline $\begin{array}{l}\text { Vibrating } \\
\text { Diaphragm }\end{array}$ & Piezoelectric & $\begin{array}{l}120 \text { (ethanol), } \\
3.75\end{array}$ & 2 & $\begin{array}{l}600(\mathrm{pp}) \\
5000\end{array}$ & - & $8 \times 4$ & & $\begin{array}{l}200 \\
\mathrm{~Hz}\end{array}$ & $\begin{array}{l}\text { Koch et al } \\
\text { (1998) [42] }\end{array}$ \\
\hline $\begin{array}{l}\text { Vibrating } \\
\text { Diaphragm }\end{array}$ & Piezoelectric & $\begin{array}{l}450 \text { (water), } \\
5.73 \\
3500 \text { (air), } \\
44.56\end{array}$ & $\begin{array}{l}210 \\
50\end{array}$ & - & - & $12 \times 12$ & 3.5 & $\begin{array}{l}60 \\
\mathrm{~Hz}\end{array}$ & $\begin{array}{l}\text { Kaemper et al } \\
\text { (1998) [44] }\end{array}$ \\
\hline $\begin{array}{l}\text { Vibrating } \\
\text { Diaphragm }\end{array}$ & Piezoelectric & $\begin{array}{l}3000 \text { (silicone } \\
\text { oil), } 294.73\end{array}$ & 300 & $1200(\mathrm{pp})$ & & $8.6 \times 7.7$ & & $\begin{array}{l}4.5 \\
\mathrm{kHz}\end{array}$ & $\begin{array}{l}\text { Li et al } \\
(2000)[48]\end{array}$ \\
\hline $\begin{array}{l}\text { Vibrating } \\
\text { Diaphragm }\end{array}$ & Electrostatic & $850,17.35$ & 31 & $\begin{array}{l}200, \\
235.29\end{array}$ & $\begin{array}{l}0.005 \\
5.88 \times 10^{-3}\end{array}$ & $7 \times 7$ & 2 & $\begin{array}{l}800 \\
\mathrm{~Hz}\end{array}$ & $\begin{array}{l}\text { Zengerle et al } \\
\text { (1995) [36] }\end{array}$ \\
\hline $\begin{array}{l}\text { Vibrating } \\
\text { Diaphragm }\end{array}$ & Electrostatic & $\begin{array}{l}30,000 \text { (air), } \\
133.33\end{array}$ & 2 & $200,6.67$ & $\begin{array}{l}0.008, \\
2.67 \times 10^{-4}\end{array}$ & $15 \times 15$ & 1 & $\begin{array}{l}95 \\
\mathrm{~Hz}\end{array}$ & $\begin{array}{l}\text { Cabuz et al } \\
(2001)[66]\end{array}$ \\
\hline $\begin{array}{l}\text { Vibrating } \\
\text { Diaphragm }\end{array}$ & $\begin{array}{l}\text { Electro- } \\
\text { magnetic }\end{array}$ & $\begin{array}{l}2100 \text { (water), } \\
26.74 \\
40,000 \text { (air), } \\
509.3\end{array}$ & $\begin{array}{l}10 \\
12.5\end{array}$ & $5^{\dagger}, 2.38$ & $0.5^{\dagger}, 0.24$ & $10 \times 10$ & 8 & $\begin{array}{l}50 \\
\mathrm{~Hz}\end{array}$ & $\begin{array}{l}\text { Böhm et al } \\
\text { (1999) [71] }\end{array}$ \\
\hline $\begin{array}{l}\text { Vibrating } \\
\text { Diaphragm }\end{array}$ & $\begin{array}{l}\text { Thermo- } \\
\text { pneumatic }\end{array}$ & $\begin{array}{l}660 \text { (water), } \\
8.4\end{array}$ & 10 & & $1.8,2.73$ & $14 \times 17.5$ & 3.2 & $\begin{array}{l}1.8 \\
\mathrm{~Hz}\end{array}$ & $\begin{array}{l}\text { Wego and } \\
\text { Pagel }(2001) \\
{[76]}\end{array}$ \\
\hline $\begin{array}{l}\text { Vibrating } \\
\text { Diaphragm } \\
\text { Vibrating } \\
\text { Diaphragm }\end{array}$ & $\begin{array}{l}\text { Shape } \\
\text { Memory Alloy } \\
\text { Piezoelectric }\end{array}$ & $\begin{array}{l}340 \text { (DI water), } \\
37.78 \\
3500 \\
\text { (methanol), } \\
61.89 \\
2300 \text { (water), } \\
40.67\end{array}$ & 58.84 & $\begin{array}{l}200^{\dagger} \\
86.96 \\
\text { (water) }\end{array}$ & - & $15 \times 17$ & $1.4^{\dagger}$ & $\begin{array}{l}50-60 \\
\mathrm{~Hz} \\
3-4 \\
\mathrm{kHz}\end{array}$ & $\begin{array}{l}\text { Xu et al } \\
(2001) \text { [79] } \\
\text { Olsson et al } \\
\text { (1997) [92] }\end{array}$ \\
\hline $\begin{array}{l}\text { Vibrating } \\
\text { Diaphragm }\end{array}$ & Piezoelectric & $\begin{array}{l}750 \text { (DI water), } \\
26.52\end{array}$ & 46.58 & 290 & - & dia 6 & & $\begin{array}{l}100 \\
\mathrm{kHz}\end{array}$ & $\begin{array}{l}\text { Bardell et al } \\
\text { (1997) [97] }\end{array}$ \\
\hline $\begin{array}{l}\text { Vibrating } \\
\text { Diaphragm }\end{array}$ & Piezoelectric & $\begin{array}{l}1500 \text { (ethanol), } \\
30.61 \\
1000 \text { (air), } \\
20.41\end{array}$ & $\begin{array}{l}1 \mathrm{kPa} \\
\text { (ethanol) }\end{array}$ & $190(\mathrm{pp})$ & - & $12 \times 12$ & 0.85 & $\begin{array}{l}2.4-2.5 \\
\mathrm{kHz}\end{array}$ & $\begin{array}{l}\text { Schabmueller } \\
\text { et al }(2000) \\
{[101]}\end{array}$ \\
\hline Peristaltic & $\begin{array}{l}\text { Thermo- } \\
\text { pneumatic }\end{array}$ & $\begin{array}{l}6.3 \text { (water), } \\
0.375\end{array}$ & $\begin{array}{l}3.45 \\
(2 \mathrm{~Hz})\end{array}$ & - & $\begin{array}{l}0.291 \\
46.19\end{array}$ & $10 \times 3$ & & $4 \mathrm{~Hz}$ & $\begin{array}{l}\text { Grosjean and } \\
\text { Tai }(1999) \\
{[116]}\end{array}$ \\
\hline EHD & Injection-type & $\begin{array}{l}14,000 \\
\text { (ethanol), } \\
1555.56\end{array}$ & 2.48 & $\begin{array}{l}800, \\
57.14\end{array}$ & - & $3 \times 3$ & $0.76^{\dagger}$ & $\mathrm{DC}$ & $\begin{array}{l}\text { Richter et al } \\
\text { (1991) [119] }\end{array}$ \\
\hline EHD & Induction-type & $\begin{array}{l}0.286^{\dagger} \text { (water), } \\
31.77\end{array}$ & & $\begin{array}{l}50 \\
175000\end{array}$ & - & $0.12 \times 0.075$ & & $\begin{array}{l}538 \\
\mathrm{kHz}\end{array}$ & $\begin{array}{l}\text { Fuhr et al } \\
\text { (1992) [124] }\end{array}$ \\
\hline EHD & Polarization & $(\mathrm{R}-134 \mathrm{a})$ & 0.25 & 150 & & 0.07 & & DC & $\begin{array}{l}\text { Darabi et al } \\
(2001) \text { [13] }\end{array}$ \\
\hline Electroosmotic & & $\begin{array}{l}800 \text { (DI water), } \\
10.19\end{array}$ & 202.65 & $\begin{array}{l}1000 \\
1250\end{array}$ & & dia 10 & 15 & $\mathrm{DC}$ & $\begin{array}{l}\text { Zeng et al } \\
(2002) \text { [129] }\end{array}$ \\
\hline Electroosmotic & & $\begin{array}{l}15 \text { (DI water), } \\
438.6\end{array}$ & 151.99 & $\begin{array}{l}3000 \\
1200000\end{array}$ & $0.021,1.4$ & $\begin{array}{l}38 \times \\
\left(0.9 \times 10^{-4}\right)\end{array}$ & 1 & DC & $\begin{array}{l}\text { Chen et al } \\
(2000) \text { [131] }\end{array}$ \\
\hline MHD & & $\begin{array}{l}18.3(1 \mathrm{M} \\
\mathrm{NaCl}), 60.2\end{array}$ & & 6.6 & $\begin{array}{l}8.92 \\
487.43\end{array}$ & $\begin{array}{l}0.8 \times 0.38 \\
\text { (without } \\
\text { electro- } \\
\text { magnet) }\end{array}$ & & $\begin{array}{l}1 \\
\mathrm{kHz}\end{array}$ & $\begin{array}{l}\text { Lemoff and } \\
\text { Lee }(2000) \\
{[140]}\end{array}$ \\
\hline Bubble & & $\begin{array}{l}4.5 \text { (water), } \\
5.73\end{array}$ & 0.38 & 20 & $0.5,111.11$ & $4 \times 1^{\dagger}$ & & $\begin{array}{l}400 \\
\mathrm{~Hz}\end{array}$ & $\begin{array}{l}\text { Tsai and Lin } \\
(2002) \text { [153] }\end{array}$ \\
\hline Bubble & & $\begin{array}{l}150 \text { (salt } \\
\text { water), } 74.6\end{array}$ & 0.31 & 46 & & dia 1.6 & $3^{\dagger}$ & $\begin{array}{l}50 \\
\mathrm{kHz}\end{array}$ & $\begin{array}{l}\text { Geng et al } \\
\text { (2001) [152] }\end{array}$ \\
\hline $\begin{array}{l}\text { Flexural Plate } \\
\text { Waves }\end{array}$ & Piezoelectric & $\begin{array}{l}1.6 \\
\text { (Fluorinert), } \\
333.33\end{array}$ & & $5-10$ & & $0.3 \times 0.016$ & 0.5 & $\begin{array}{l}2-5 \\
\mathrm{MHz}\end{array}$ & $\begin{array}{l}\text { Black and } \\
\text { White (1999) } \\
{[160]}\end{array}$ \\
\hline $\begin{array}{l}\text { Vibrating } \\
\text { Diaphragm }\end{array}$ & Electrowetting & $\begin{array}{l}63(0.15 \mathrm{M} \\
\left.\mathrm{Na}_{2} \mathrm{SO}_{4}\right), 1.26\end{array}$ & $\begin{array}{l}0.6 \\
(10 \\
\mathrm{Hz})\end{array}$ & $2.3(\mathrm{pp})$ & $\begin{array}{l}3.0 \times 10^{-7} \\
4.76 \times 10^{-6}\end{array}$ & $25 \times 20^{\dagger}$ & & $\begin{array}{l}15 \\
\mathrm{~Hz}\end{array}$ & $\begin{array}{l}\text { Yun et al } \\
(2001)[20]\end{array}$ \\
\hline
\end{tabular}

\footnotetext{
${ }^{\dagger}$ Inferred from paper
} 


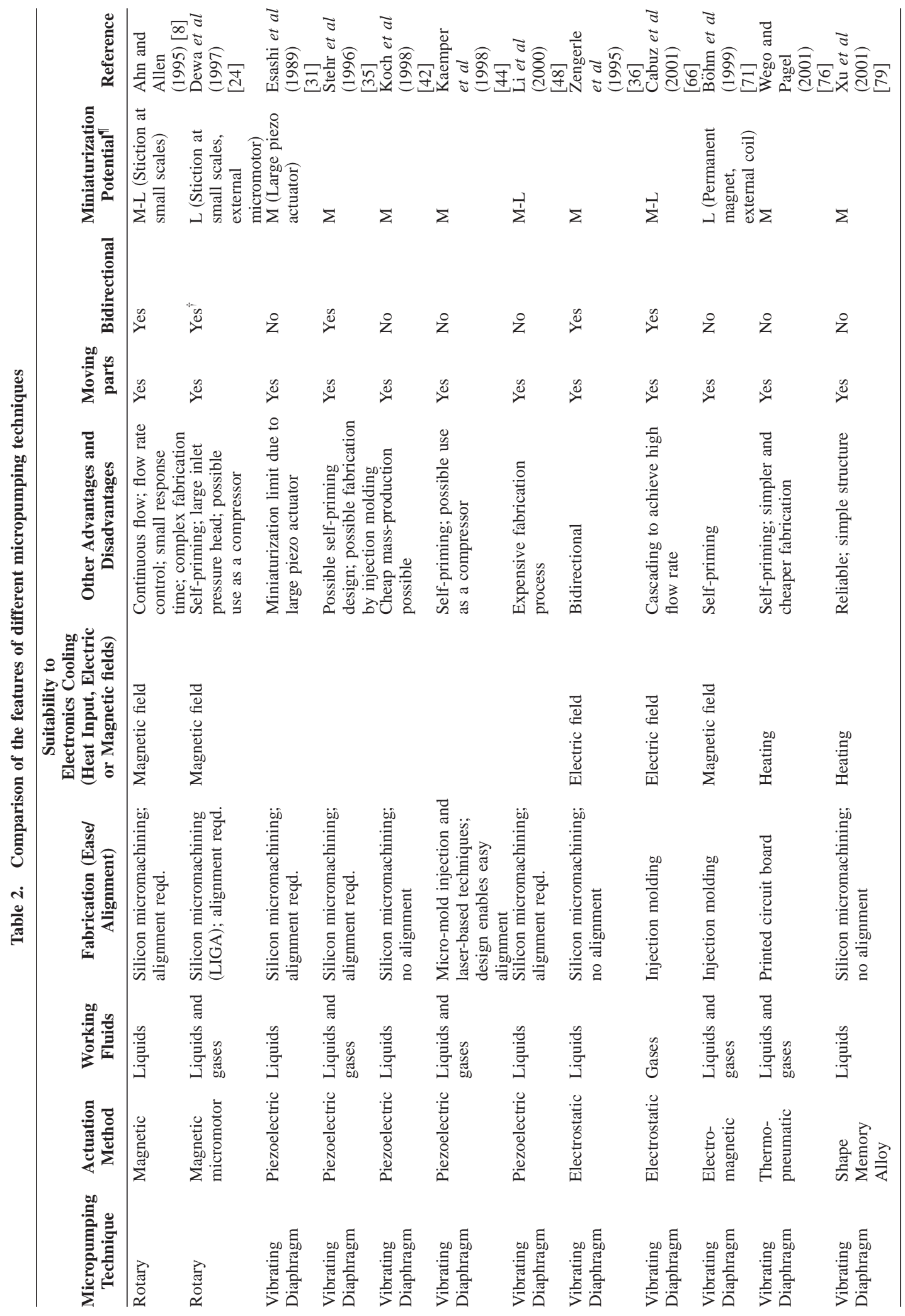




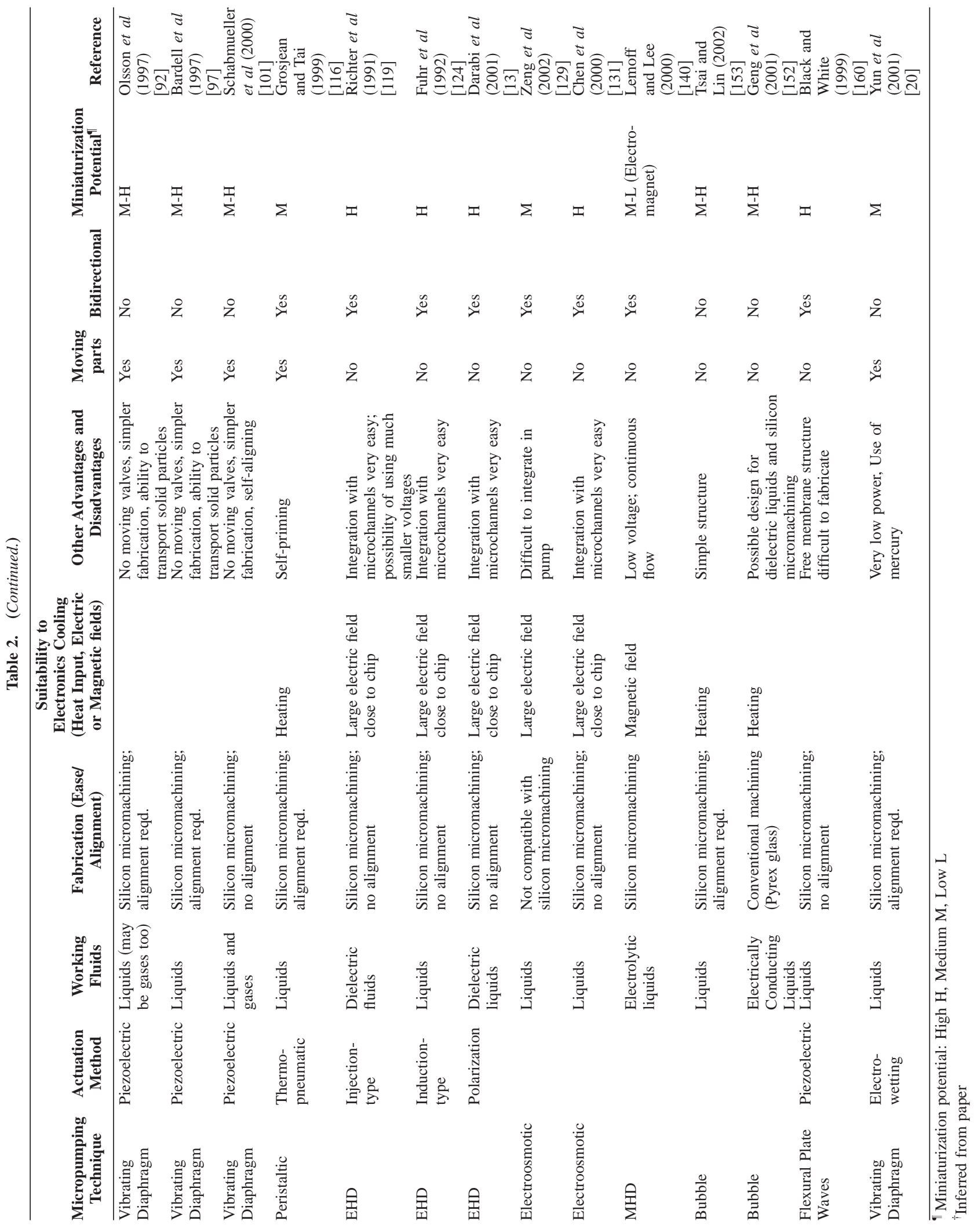


Table 3. Quantitative data for other micropumps

\begin{tabular}{|c|c|c|c|c|}
\hline $\begin{array}{l}\text { Micropumping } \\
\text { Technique }\end{array}$ & $\begin{array}{l}\text { Actuation } \\
\text { Method }\end{array}$ & $Q$ & $p_{\text {back,max }}$ & Reference \\
\hline Rotary & - & $\begin{array}{l}200 \mathrm{ml} / \mathrm{min} \text { along with a pressure head of } 1 \mathrm{MPa} \text { at } \\
4000 \mathrm{rpm} \text { for pump with outer diameter of } 10 \mathrm{~mm} \text { and } \\
8 \mathrm{ml} / \mathrm{min} \text { for pump with outer diameter of } 2.5 \mathrm{~mm}\end{array}$ & $\begin{array}{l}\text { 5 MPa for larger pump and } \\
1.5 \mathrm{MPa} \text { for smaller pump }\end{array}$ & $\begin{array}{l}\text { Weisener et al } \\
(1996) \\
{[22]}\end{array}$ \\
\hline Rotary & Ferrofluidic & $\begin{array}{l}47.8 \mu \mathrm{l} / \mathrm{min} \text { with a motor speed of } 8 \mathrm{rpm} \text { for an input } \\
\text { power of } 11.6 \mathrm{~mW} \text { and } 22.5 \mu \mathrm{l} / \mathrm{min} \text { at } 4 \mathrm{rpm}\end{array}$ & $\begin{array}{l}1.37 \mathrm{kPa} \text { at } 8 \mathrm{rpm} \text { and } 1.18 \\
\mathrm{kPa} \text { at } 4 \mathrm{rpm}\end{array}$ & $\begin{array}{l}\text { Hatch et al } \\
\text { (2001) [25] }\end{array}$ \\
\hline $\begin{array}{l}\text { Vibrating } \\
\text { Diaphragm }\end{array}$ & Piezoelectric & $\begin{array}{l}8 \mu \mathrm{l} / \mathrm{min} \text { at } 100 \mathrm{~V} \text { and } 1 \mathrm{~Hz} \text { for the two-valve pump and } \\
0.6 \mu \mathrm{l} / \mathrm{min} \text { at } 125 \mathrm{~V} \text { and } 0.1 \mathrm{~Hz} \text { for the three-valve } \\
\text { pump }\end{array}$ & & $\begin{array}{l}\text { van Lintel et al } \\
\text { (1988) } \\
{[26]}\end{array}$ \\
\hline $\begin{array}{l}\text { Vibrating } \\
\text { Diaphragm }\end{array}$ & Piezoelectric & $\begin{array}{l}40 \mu \mathrm{l} / \mathrm{min} \text { at } 100 \mathrm{~V} \text { and } 45 \mathrm{~Hz} \text { with water for the dual } \\
\text { pump and } 30 \mu \mathrm{l} / \mathrm{min} \text { at } 85 \mathrm{~Hz} \text { for the buffer pump }\end{array}$ & $\begin{array}{l}15.69 \mathrm{kPa} \text { at } 100 \mathrm{~V} \text { and } 30 \\
\mathrm{~Hz} \text { for the buffer pump }\end{array}$ & $\begin{array}{l}\text { Shoji et al } \\
\text { (1990) [32] }\end{array}$ \\
\hline $\begin{array}{l}\text { Vibrating } \\
\text { Diaphragm }\end{array}$ & Piezoelectric & $45 \mu \mathrm{l} / \mathrm{s}$ at an actuation voltage of $300 \mathrm{~V}$ at $70 \mathrm{~Hz}$ & $24.5 \mathrm{kPa}$ & $\begin{array}{l}\text { Carrozza et al } \\
(1995) \\
{[34]}\end{array}$ \\
\hline $\begin{array}{l}\text { Vibrating } \\
\text { Diaphragm }\end{array}$ & Piezoelectric & $\begin{array}{l}\text { Maximum ejection velocity of } 9.7 \mathrm{~m} / \mathrm{s} \text { with } 90 \mathrm{~V} \text { and } \\
2500 \mathrm{~Hz}\end{array}$ & & $\begin{array}{l}\text { Ederer et al } \\
\text { (1997) [38] }\end{array}$ \\
\hline $\begin{array}{l}\text { Vibrating } \\
\text { Diaphragm }\end{array}$ & Piezoelectric & $\begin{array}{l}\sim 100 \mathrm{~mm}^{3} / \mathrm{s} \text { at driving frequency of } 850 \mathrm{~Hz} \text { using tap } \\
\text { water }\end{array}$ & $250 \mathrm{kPa}$ & $\begin{array}{l}\text { Park et al } \\
\text { (1997) [39] }\end{array}$ \\
\hline $\begin{array}{l}\text { Vibrating } \\
\text { Diaphragm }\end{array}$ & Piezoelectric & $\sim 110 \mathrm{~mm}^{3} / \mathrm{s}$ at frequency of approximately $2200 \mathrm{~Hz}$ & $320 \mathrm{kPa}$ & $\begin{array}{l}\text { Park et al } \\
(1999)[40]\end{array}$ \\
\hline $\begin{array}{l}\text { Vibrating } \\
\text { Diaphragm }\end{array}$ & Piezoelectric & $120 \mu \mathrm{l} / \mathrm{min}$ & $5.5 \mathrm{kPa}$ & $\begin{array}{l}\text { Cunneen et al } \\
(1998) \\
{[43]}\end{array}$ \\
\hline $\begin{array}{l}\text { Vibrating } \\
\text { Diaphragm }\end{array}$ & Piezoelectric & $\begin{array}{l}1.4 \mathrm{ml} / \mathrm{min} \text { for water at } 220 \mathrm{~Hz} \text { and } 3 \mathrm{ml} / \mathrm{min} \text { for gases } \\
\text { at } 1000 \mathrm{~Hz} \text { with a rectangular } 120 \mathrm{~V} /-40 \mathrm{~V} \text { signal }\end{array}$ & $100 \mathrm{kPa}$ for water & $\begin{array}{l}\text { Linnemann } \\
\text { et al }(1998) \\
{[45]}\end{array}$ \\
\hline $\begin{array}{l}\text { Vibrating } \\
\text { Diaphragm }\end{array}$ & Piezoelectric & $\begin{array}{l}250 \mu \mathrm{l} / \mathrm{hr} \text { at a frequency of } 2 \mathrm{~Hz} \text { with power } \\
\text { consumption of } 0.73 \mathrm{~mJ} / \mu \mathrm{l}\end{array}$ & & $\begin{array}{l}\text { Maillefer et al } \\
\text { (1999) } \\
{[46]}\end{array}$ \\
\hline $\begin{array}{l}\text { Vibrating } \\
\text { Diaphragm }\end{array}$ & Electrostatic & $70 \mu \mathrm{l} / \mathrm{min}$ with $170 \mathrm{~V}$ and $25 \mathrm{~Hz}$ & $2.5 \mathrm{kPa}$ & $\begin{array}{l}\text { Zengerle et al } \\
\text { (1992) [9] }\end{array}$ \\
\hline $\begin{array}{l}\text { Vibrating } \\
\text { Diaphragm }\end{array}$ & $\begin{array}{l}\text { Thermo- } \\
\text { pneumatic }\end{array}$ & $\begin{array}{l}34 \mu \mathrm{l} / \mathrm{min} \text { with } 6 \mathrm{~V} \text { and square wave frequency of } \\
0.5 \mathrm{~Hz}\end{array}$ & $5 \mathrm{kPa}$ & $\begin{array}{l}\text { van de Pol et al } \\
(1990) \\
{[75]}\end{array}$ \\
\hline Vibrating & Shape & $50 \mu \mathrm{l} / \mathrm{min}$ for complementary actuator pump and 6 & $519 \mathrm{~Pa}$ for complementary & Benard et al \\
\hline Diaphragm & Memory Alloy & $\mu \mathrm{l} / \mathrm{min}$ for polyimide pump at frequency of $0.85 \mathrm{~Hz}$ & actuator pump & (1998) $[78]$ \\
\hline Vibrating & Shape & $4.8 \mu \mathrm{l} / \mathrm{min}$ with a bias pressure of $100 \mathrm{kPa}$ in the glass & Estimated to be several & Makino et al \\
\hline Diaphragm & Memory Alloy & chamber & hundred $\mathrm{kPa}$ & $(2001)[80]$ \\
\hline $\begin{array}{l}\text { Vibrating } \\
\text { Diaphragm }\end{array}$ & Piezoelectric & $\begin{array}{l}16 \mathrm{ml} / \mathrm{min} \text { with water for the pump with half-angle of } \\
5.35^{\circ} \text { at } 350 \mathrm{~V} \text { and } 310 \mathrm{~Hz} \text { and } 4.3 \mathrm{ml} / \mathrm{min} \text { with water } \\
\text { at } 110 \mathrm{~Hz} \text { for the pump with half-angle of } 2.65^{\circ} .35 \\
\mathrm{ml} / \mathrm{min} \text { with air at } 20 \mathrm{~V} \text { and } 6 \mathrm{kHz}\end{array}$ & $\begin{array}{l}\left.7.85 \mathrm{kPa} \text { (half-angle } 5.35^{\circ}\right) \\
19.61 \mathrm{kPa} \text { (half-angle } \\
2.65^{\circ} \text { ) and } 2.45 \mathrm{kPa} \text { (air) }\end{array}$ & $\begin{array}{l}\text { Stemme and } \\
\text { Stemme } \\
(1993)[89]\end{array}$ \\
\hline $\begin{array}{l}\text { Vibrating } \\
\text { Diaphragm }\end{array}$ & Piezoelectric & $\begin{array}{l}16 \mathrm{ml} / \mathrm{min} \text { at } 130 \mathrm{~V} \text { and } 560 \mathrm{~Hz} \text { for out-of-phase } \\
\text { operation }\end{array}$ & $16.67 \mathrm{kPa}$ & $\begin{array}{l}\text { Olsson et al } \\
(1995)[90]\end{array}$ \\
\hline $\begin{array}{l}\text { Vibrating } \\
\text { Diaphragm }\end{array}$ & Piezoelectric & $\begin{array}{l}230 \mu \mathrm{l} / \mathrm{min} \text { with } 120 \mathrm{~V}_{\mathrm{pp}} \text { square wave voltage at the } \\
\text { resonance frequency of } 1318 \mathrm{~Hz} \text { with methanol }\end{array}$ & $16.67 \mathrm{kPa}$ & $\begin{array}{l}\text { Olsson et al } \\
\text { (1996) [91] }\end{array}$ \\
\hline $\begin{array}{l}\text { Vibrating } \\
\text { Diaphragm }\end{array}$ & Piezoelectric & $\begin{array}{l}260 \mu \mathrm{l} / \mathrm{min} \text { for frequencies between } 100 \mathrm{~Hz} \text { and } 1 \mathrm{kHz} \\
\text { and } 480 \mu \mathrm{l} / \mathrm{min} \text { at } 8 \mathrm{kHz} \text { (close to resonance } \\
\text { frequency) }\end{array}$ & & $\begin{array}{l}\text { Gerlach et al } \\
\text { (1995) [95] }\end{array}$ \\
\hline $\begin{array}{l}\text { Vibrating } \\
\text { Diaphragm }\end{array}$ & Piezoelectric & $\begin{array}{l}38 \mu \mathrm{l} / \mathrm{min} \text { with water for square wave excitation } \\
\text { frequency of } 114 \mathrm{~Hz}\end{array}$ & & $\begin{array}{l}\text { Forster et al } \\
\text { (1995) [96] }\end{array}$ \\
\hline $\begin{array}{l}\text { Vibrating } \\
\text { Diaphragm }\end{array}$ & Piezoelectric & $155 \mu \mathrm{l} / \mathrm{min}$ at $600 \mathrm{~V}_{\mathrm{pp}}$ and $2 \mathrm{kHz}$ & $1 \mathrm{kPa}$ & $\begin{array}{l}\text { Koch et al } \\
(1998)[100]\end{array}$ \\
\hline $\begin{array}{l}\text { Vibrating } \\
\text { Diaphragm }\end{array}$ & Electromagnetic & $28 \mu \mathrm{l} / \mathrm{min}$ at $500 \mathrm{~Hz}$ and power input of $50 \mathrm{~mW}$ & $1 \mathrm{kPa}$ & $\begin{array}{l}\text { Jiang et al } \\
(1998)[102]\end{array}$ \\
\hline Vibrating & Thermo- & $14 \mu \mathrm{l} / \mathrm{min}$ at $4 \mathrm{~Hz}$ for the corrugated diaphragm and & & Jeong and \\
\hline Diaphragm & pneumatic & $\begin{array}{l}4.3 \mu \mathrm{l} / \mathrm{min} \text { at } 3 \mathrm{~Hz} \text { for the flat diaphragm with a square } \\
\text { wave input of } 8 \mathrm{~V} \text { and duty ratio of } 40 \%\end{array}$ & & $\begin{array}{l}\text { Yang }(2000) \\
{[104]}\end{array}$ \\
\hline $\begin{array}{l}\text { Vibrating } \\
\text { Diaphragm }\end{array}$ & Piezoelectric & $5.5 \mu \mathrm{l} / \mathrm{min}$ with $60 \mathrm{~V}$ and $50 \mathrm{~Hz}$ & & $\begin{array}{l}\text { Matsumoto } \\
\text { et al }(1999) \\
{[115]}\end{array}$ \\
\hline $\begin{array}{l}\text { Vibrating } \\
\text { Diaphragm }\end{array}$ & Piezoelectric & $\begin{array}{l}3 \mathrm{ml} / \mathrm{min} \text { with } 175-200 \mathrm{~V} \text { square and frequency of } \\
50-75 \mathrm{~Hz}\end{array}$ & $3.73 \mathrm{kPa}$ & $\begin{array}{l}\text { Nguyen and } \\
\text { Huang }\end{array}$ \\
\hline Peristaltic & & $\begin{array}{l}3 \mathrm{ml} / \mathrm{min} \text { with } 175-200 \mathrm{~V} \text { square and frequency of } \\
50-75 \mathrm{~Hz}\end{array}$ & $7.06 \mathrm{kPa}$ & $(2001)[117]$ \\
\hline Peristaltic & Piezoelectric & $\begin{array}{l}100 \mu \mathrm{l} / \mathrm{min} \text { with an actuation voltage of } 80 /-20 \mathrm{~V} \text { and } \\
15 \mathrm{~Hz} \text { for water }\end{array}$ & $5.88 \mathrm{kPa}$ & $\begin{array}{l}\text { Smits }(1990) \\
{[10]}\end{array}$ \\
\hline EHD & Injection-type & $2 \mathrm{nl} / \mathrm{s}$ for ethanol at a voltage of $100 \mathrm{~V}$ & & $\begin{array}{l}\text { Furuya et al } \\
\text { (1996) [120] }\end{array}$ \\
\hline EHD & Injection-type & $\begin{array}{l}\text { Projected to be } 2.5 \mathrm{ml} / \mathrm{min} \text { for } 1 \mathrm{~cm} \text { long microchannel } \\
\text { of cross-section } 100 \mu \mathrm{m} \times 100 \mu \mathrm{m}\end{array}$ & $287 \mathrm{~Pa}$ with $120 \mathrm{~V}$ & $\begin{array}{l}\text { Wong et al } \\
\text { (1996) }[121]\end{array}$ \\
\hline EHD & Injection-type & $\begin{array}{l}60 \mu \mathrm{l} / \mathrm{min} \text { for ethanol with } 120 \mathrm{~V} \text { DC for channel depth } \\
\text { of } 200 \mu \mathrm{m} \text { and } 20 \mu \mathrm{l} / \mathrm{min} \text { for the channel depth of } \\
100 \mu \mathrm{m}\end{array}$ & $\begin{array}{l}100 \mathrm{~Pa} \text { and } 250 \mathrm{~Pa} \text { for } \\
\text { channel depths of } 200 \mu \mathrm{m} \\
\text { and } 100 \mu \mathrm{m}\end{array}$ & $\begin{array}{l}\text { Ahn and Kim } \\
(1998)[122]\end{array}$ \\
\hline
\end{tabular}


Table 3. (Continued.)

\begin{tabular}{|c|c|c|c|c|}
\hline $\begin{array}{l}\text { Micropumping } \\
\text { Technique }\end{array}$ & $\begin{array}{l}\text { Actuation } \\
\text { Method }\end{array}$ & $Q$ & $p_{\text {back,max }}$ & Reference \\
\hline Electroosmotic & & $\begin{array}{l}3.6 \mu \mathrm{l} / \mathrm{min} \text { at } 2 \mathrm{kV} \text { with deionized water and } 17 \mu \mathrm{l} / \mathrm{min} \\
\text { at } 10 \mathrm{kV}\end{array}$ & $\begin{array}{l}2.38 \mathrm{MPa} \text { at } 2 \mathrm{kV} \text { and } 3.63 \\
\mathrm{MPa} \text { at } 10 \mathrm{kV}\end{array}$ & $\begin{array}{l}\text { Zeng et al } \\
(2001)[127]\end{array}$ \\
\hline Electroosmotic & & $\begin{array}{l}1 \mathrm{ml} / \mathrm{min} \text { for water at } 200 \mathrm{~V} \text { and } 7 \mathrm{ml} / \mathrm{min} \text { for } 1 \mathrm{mM} \\
\text { borate buffer solution }\end{array}$ & $\begin{array}{l}25.33 \mathrm{kPa} \text { for water and } \\
253.3 \mathrm{kPa} \text { for } 1 \mathrm{mM} \text { borate } \\
\text { buffer solution }\end{array}$ & $\begin{array}{l}\text { Yao et al } \\
(2001)[130]\end{array}$ \\
\hline MHD & & $20 \mu \mathrm{l} / \mathrm{s}$ at $14 \mathrm{~V}$ with $2 \% \mathrm{NaOH}$ solution & & $\begin{array}{l}\text { Heng et al } \\
(2000)[142]\end{array}$ \\
\hline MHD & & $\begin{array}{l}63 \mu \mathrm{l} / \mathrm{min} \text { with sea water with a magnetic field density } \\
\text { of } 0.44 \mathrm{~T} \text { and current level of } 1.8 \mathrm{~mA}\end{array}$ & $\begin{array}{l}176 \mathrm{~Pa} \text { with current level of } \\
38 \mathrm{~mA}\end{array}$ & $\begin{array}{l}\text { Jang and } \\
\text { Lee }(2000) \\
{[143]}\end{array}$ \\
\hline Bubble & & $\begin{array}{l}0.5 \mathrm{nl} / \mathrm{min} \text { with multiple-bubble operation for } \\
\text { isopropanol }\end{array}$ & $800 \mathrm{~Pa}$ & $\begin{array}{l}\text { Jun and Kim } \\
(1996)[16]\end{array}$ \\
\hline Bubble & & $\begin{array}{l}300 \mu \mathrm{l} / \mathrm{min} \text { with input power in the range of } 8-12 \mathrm{~W} \\
\text { with deionized water }\end{array}$ & $588 \mathrm{~Pa}$ & $\begin{array}{l}\text { Song and } \\
\text { Zhao }(2001) \\
{[154]}\end{array}$ \\
\hline $\begin{array}{l}\text { Flexural Plate } \\
\text { Waves }\end{array}$ & Piezoelectric & $\begin{array}{l}\text { Maximum flow velocity of } 130 \mu \mathrm{m} / \mathrm{s} \text { at an actuation } \\
\text { voltage of } 7.1 \mathrm{~V} \text { and frequency of } 3.5 \mathrm{MHz}\end{array}$ & & $\begin{array}{l}\text { Moroney et al } \\
(1990) \\
{[18]}\end{array}$ \\
\hline $\begin{array}{l}\text { Flexural Plate } \\
\text { Waves }\end{array}$ & Piezoelectric & $\begin{array}{l}\text { Maximum flow velocity of } 120 \mu \mathrm{m} / \mathrm{s} \text { near the focus for } \\
\text { water at } 4 \mathrm{~V} \text { and } 6 \mathrm{MHz}\end{array}$ & & $\begin{array}{l}\text { Moroney et al } \\
(1991) \\
{[157]}\end{array}$ \\
\hline
\end{tabular}

Nguyen and Huang [117] presented a piezoelectrically actuated nozzle-diffuser and a peristaltic micropump fabricated using PCB technology. Both the nozzle-diffuser pump and the peristaltic pump had nonplanar designs and used circular brass membranes of diameter $15 \mathrm{~mm}$ glued to piezo discs of $12 \mathrm{~mm}$ diameter for actuation. By testing pumps with different spacings between the two nozzle-diffuser elements, it was found that the smaller spacing leads to a better pump performance. The peristaltic pump generated a higher water flow rate $(1.5 \mathrm{ml} / \mathrm{min}$ compared to $220 \mu \mathrm{l} / \mathrm{min})$ and a higher back pressure (7.06 $\mathrm{kPa}$ compared to $3.73 \mathrm{kPa}$ ) than the nozzle-diffuser pump with the same excitation signal, a 100 V square wave at $50 \mathrm{~Hz}$.

Cao et al [118] presented a design for a normally-closed piezoelectrically actuated peristaltic micropump for microdosing applications. The inlet and the outlet ports of the pump were closed, with valve-closers attached to the membranes of the first and last pumping chamber, respectively, when these membranes are not actuated. However, when one of these membranes is actuated, it deflects and hence the valve-closer moves away and opens the corresponding port. Analytical and FEM studies were performed for optimizing the performance of this micropump.

The peristaltic mechanism was also used for the photothermopneumatically actuated micropump described earlier [85].

\subsection{Electrokinetic and magnetokinetic micropumps}

\subsubsection{Electrohydrodynamic pumps}

Injection type. An injection-type EHD pump for pumping polar fluids was proposed by Richter et al $[12,119]$. The pump consisted of two grids each measuring $3 \times 3 \mathrm{~mm}$. The separation between the two grids was $350 \mu \mathrm{m}$. Both grids have square holes of either 70 or $140 \mu \mathrm{m}$. The structure of the pump is shown in Fig. 30. The pump was fabricated using silicon micromachining techniques. The pump was tested with organic liquids such as ethanol, propanol, metha- nol, and acetone (Tables 1-3). Deionized water was also tested, but was found to electrolyze at high voltages, which led to the formation of gases and a degradation of the pump performance.

An ion drag pump was fabricated by Furuya et al [120] as an application of magnetically controlled RIE of fluorinated polyimide. Grids of poles of diameter $15 \mu \mathrm{m}$ and height 100 $\mu \mathrm{m}$ were used as the electrodes. The $400 \mu \mathrm{m}$ wide cross section of the pumping channel contained grids of 18 such poles. Pairs of such grids formed counter electrodes and were placed through the length of the channel. The micropump achieved a flow rate of $2 \mathrm{nl} / \mathrm{s}$ for ethanol at a voltage of 100 $\mathrm{V}$. The low flow rates indicate that the electrodes probably do not inject ions into the pumping fluid. Instead, the pumping action appears to be caused merely due to the ionic impurities in ethanol.

An injection-type EHD pump designed for electronic cooling applications was proposed by Wong et al [121]. The structure and working principle of the pump were similar to the pump described in [119]. The pump was fabricated by laser micromachining using a Nd:YAG laser. The pump con-

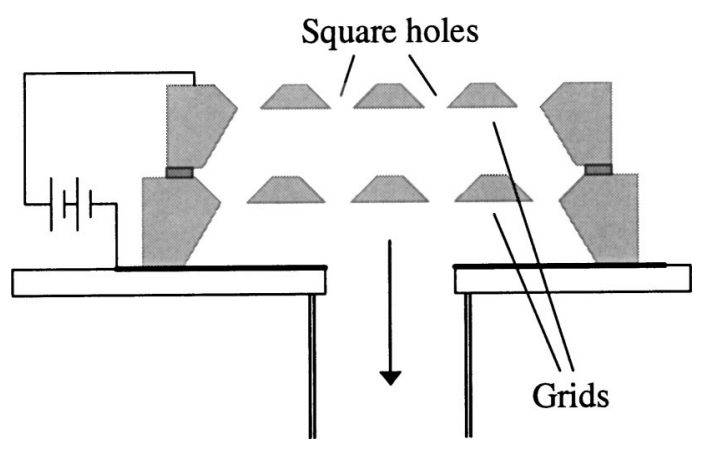

Fig. 30 Structure of the injection-type EHD pump [12,119]. The flow direction can be reversed by changing the polarity of the electrodes. 
sisted of two silicon grids with gold electrodes deposited on one side. The grids had circular holes of diameter ranging from 76 to $102 \mu \mathrm{m}$ and were spaced 102 to $254 \mu \mathrm{m}$ apart. The size of the two grids was $4.57 \times 3.81 \mu \mathrm{m}$ and that of the silicon structures containing the grids was $7.87 \times 8.64 \mathrm{~mm}$. The spacing between the gold electrodes varied from 50 to $330 \mu \mathrm{m}$. The power input to the pump was in the range of a few watts.

Ahn and Kim [122] presented a planar injection-type EHD micropump. The design and actuation principle of the pump was similar to [120], in that there were pairs of equally spaced electrodes through the length of the channel. However, the electrodes were deposited on the surface of the pumping chamber and spanned the width of the channel. The pumping action was from the positive to the negative electrodes because the positive ions are less mobile than the negative ions. Each electrode was $100 \mu \mathrm{m}$ wide and the spacing between the counter electrodes was also $100 \mu \mathrm{m}$. Thirty electrode pairs were used along the length of the channel, with a spacing between each electrode pair of $200 \mu \mathrm{m}$. The channel was $3 \mathrm{~mm}$ wide and $30 \mathrm{~mm}$ long. Pumps with two different channel depths of $100 \mu \mathrm{m}$ and $200 \mu \mathrm{m}$ were fabricated by silicon micromachining. The pump was bidirectional with similar performance in both directions, and the switching time ranged from a few seconds to 1 to 2 minutes for different fluids.

Induction type. A microfabricated induction-type EHD pump for fluids with low thermal conductivities was discussed in Bart et al [11]. The pump consisted of $10 \mu \mathrm{m}$ wide, $1.75 \mu \mathrm{m}$ thick, and approximately $250 \mu \mathrm{m}$ long silicon electrodes which were electrically isolated from the substrate. These electrodes were spaced $10 \mu \mathrm{m}$ apart. The structure of the pump was similar to that shown in Fig. $4 a$. Every third electrode was connected to one phase. These three phases were connected to a three-phase square wave. Low viscosity semi-insulating silicone oil was the working fluid. The authors observed pumping action for frequencies ranging from $1 \mathrm{~Hz}$ to $2 \mathrm{kHz}$ and reported that lower frequencies led to better pumping performance. However, no quantitative data were provided. The source of charge induction was not mentioned.

An induction-type EHD pump which was also able to pump fluids with high thermal conductivities was proposed by Fuhr et al $[123,124]$. The structure of the pump was very similar to the one described in [11]; however, it used much higher driving frequencies and electrodes of smaller width and spacing. Temperature gradients caused by anisotropic heating by the traveling waves generate the electrical conductivity and permittivity gradients required for charge induction. The pump consisted of $30 \mu \mathrm{m}$ wide electrodes spaced $30 \mu \mathrm{m}$ apart in a 50 to $500 \mu \mathrm{m}$ deep, 70 to $700 \mu \mathrm{m}$ wide, and $4 \mathrm{~mm}$ long closed pumping channel. A maximum flow rate of $5 \mu \mathrm{l} / \mathrm{min}$ was reported in this study (additional data in Tables 1-3). The switching time for reversing the flow direction was a few seconds. In further work, Fuhr et al
[125] described induction-type EHD pumps with electrode widths of less than $1 \mu \mathrm{m}$ which were able to pump water with an excitation voltage of 1 to $3 \mathrm{~V}$.

Moesner and Higuchi [126] discussed induction-type EHD devices for transporting particles in the diameter range of 5 to $400 \mu \mathrm{m}$.

Polarization type. A polarization-type EHD micropump which was used to pump liquids in the vertical direction was reported by Darabi et al [13]. The pump was part of an integrated cooling system, which also had a thin film evaporative cooling system and temperature sensors. The pump consisted of 10 or $20 \mu \mathrm{m}$ wide electrodes deposited on a polished quartz wafer at a spacing of 50 and $100 \mu \mathrm{m}$, respectively. One free end of the electrodes was dipped into the fluid chamber containing R-134a. The nonhomogeneous electric field acting at the free end of the electrodes force the dipoles to move up between the electrodes (to the regions of higher electric field density), which leads to the pumping action. No flow rate measurements were reported.

\subsubsection{Electroosmotic pumps}

An electroosmotic micropump fabricated in a packed capillary was investigated by Zeng et al $[127,128]$. The pumping channel of the micropump consisted of a 500 to $700 \mu \mathrm{m}$ diameter fused-silica capillary densely packed with $3.5 \mu \mathrm{m}$ diameter nonporous silica particles. The particles were held in the capillary by using porous silicon frits on either end of the capillary. The electric field was generated by electrodes outside the capillary. The diameter and the length of the pump were $530 \mu \mathrm{m}$ and $5.4 \mathrm{~cm}$, respectively. A variation of this pump design for achieving higher flow rates (Tables 1-3) was reported in [129]. The pumping channel fabricated in acrylic was approximately $1 \mathrm{~cm}$ in diameter and 2 to 4 $\mathrm{mm}$ in length. It was surrounded on either side by $5 \mathrm{~mm}$ thick frits, resulting in a total channel length of $15 \mathrm{~mm}$. The larger pumping cross-sectional area and smaller length of the pumping channel were considered responsible for achieving the higher flow rate than in [127]. Even larger flow rates were achieved in this manner in [130]. In this design, a sintered glass frit of thickness 1.5 to $3 \mathrm{~mm}$ was used as the pumping channel. It was surrounded on either side by an inlet and an outlet fixture which contained the electrodes and the inlet and outlet ports.

Chen et al [131] described a planar electroosmotic micropump fabricated on a glass substrate using silicon micromachining techniques. The closed pumping channel was $1 \mathrm{~mm}$ long, $0.9 \mu \mathrm{m}$ deep, and $38 \mathrm{~mm}$ wide. A maximum flow rate of $2.5 \mu \mathrm{l} / \mathrm{min}$ and maximum pressure of $152 \mathrm{kPa}(1.5 \mathrm{~atm})$ were reported for deionized water with a power supply of 3 $\mathrm{kV}$ and $7 \mu \mathrm{A}$. The flow rate of the pump decreased more than 100-fold over a period of eight weeks, although the pressure head remained fairly constant.

Other experimental and theoretical investigations on electroosmotic pumping in microchannels are reported in $[14,132-139]$.

\subsubsection{Magnetohydrodynamic pumps}

The MHD pump illustrated in Fig. 31 was discussed in Lemoff et al [15] and Lemoff and Lee [140]. The pump uses the 


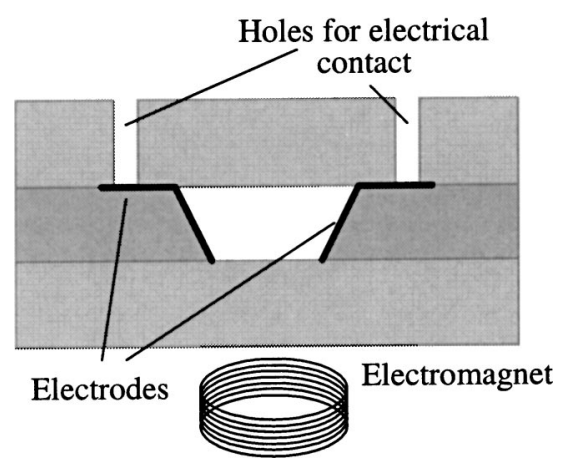

Fig. 31 Cross-section of the MHD pump presented by Lemoff and Lee [140]. The pumping direction is perpendicular to the plane of the paper.

Lorentz force generated when an electric field through the working fluid interacts with a perpendicular magnetic field. The electric field is generated by application of an AC voltage between electrodes deposited on sidewalls of a V-groove microchannel. The magnetic field is generated by applying a synchronous $\mathrm{AC}$ voltage to an electromagnet placed directly beneath the microchannel. The microchannel depth and top width were 380 and $800 \mu \mathrm{m}$, respectively. The total length of the channel was $20 \mathrm{~mm}$. The pump was tested in a closed loop, so as to avoid any additional pressure head from connecting tubes or channels. The electromagnet core measured $6.35 \mathrm{~mm}$ in diameter and height. The voltage and current amplitudes for the electromagnet were $25 \mathrm{~V}$ and $320 \mathrm{~mA}$, respectively, and for the electrodes were $6.6 \mathrm{~V}$ and $140 \mathrm{~mA}$, respectively. The frequency of both voltages was $1 \mathrm{kHz}$. An AC instead of a DC electric field was used because the DC electric field electrolyses the aqueous solution. Bubbles formed from the electrolysis would hamper the performance of the electrodes. However, a high frequency AC electric field reverses the chemical reactions sufficiently rapidly so that bubbles do not have a chance to form.

Heng et al [141,142] described DC and AC versions of an MHD micropump. The electric field in the DC pump was generated by applying a direct voltage to the nickel electrodes deposited on the sidewalls of a microchannel. A pair of permanent magnets was used for the magnetic field. This pump achieved a maximum flow rate (Tables $1-3$ ) with a voltage of $14 \mathrm{~V}$. At higher voltages, bubble generation hindered the pump performance. In the AC pump, an alternating, instead of a direct, voltage was used to generate the electric field. However, such a system will not lead to a pumping action because the direction of the Lorentz force will also alternate with the voltage. Therefore, nozzlediffuser elements were used to achieve flow rectification. Flow characteristics of the AC pump were not reported.

Permanent magnets were employed to generate the magnetic field in a DC MHD pump by Jang and Lee [143]. The aluminum electrodes for generating the constant electric field were deposited on the top and the bottom of a closed silicon microchannel of height $0.4 \mathrm{~mm}$, width $1 \mathrm{~mm}$, and length 40

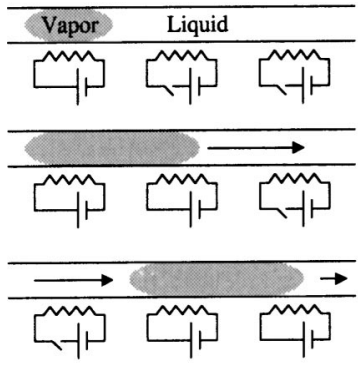

(a)

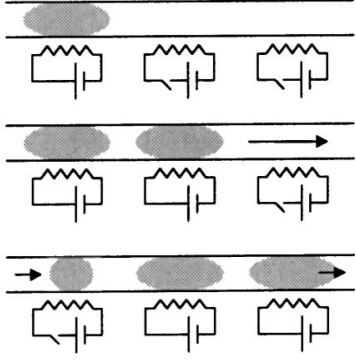

(b)
Fig. 32 Operation of the bubble pump of Jun and Kim [16,144] under $a$ ) single-bubble mechanism and $b$ ) multiple-bubble mechanism. The flow direction can be reversed by changing the actuation sequence of the heaters.

$\mathrm{mm}$. Electrolysis of seawater and subsequent bubble formation were found to lead to higher than expected flow rates and pressure heads.

\subsection{Phase change micropumps}

\subsubsection{Bubble pumps}

Two actuation mechanisms for bubble pumps were discussed by Jun and Kim $[16,144]$. In the first mechanism, called the single-bubble mechanism, asymmetric heating of a vapor bubble spanning the cross section of a closed microchannel causes a gradient in vapor pressure and surface tension along the length of the bubble, in turn creating a pressure gradient which leads to the pumping action. In the second mechanism, the multiple-bubble mechanism, multiple bubbles, each spanning the cross section of the microchannel, are generated in sequence from one end of the microchannel to the other. The existing bubbles act as anchors or check valves during the formation of new bubbles. Hence the fluid displaced due to the formation of new bubbles moves in one direction. The operation of pump under both mechanisms is shown in Fig. 32. The pump was fabricated using silicon micromachining techniques and consisted of a closed microchannel $2 \mu \mathrm{m}$ high, $30 \mu \mathrm{m}$ wide, and $726 \mu \mathrm{m}$ long. Three polysilicon heaters of thickness $0.7 \mu \mathrm{m}$ were deposited on the top surface of the microchannel. During the operation of the pump, these heaters were actuated using individual phases of a 3-phase square wave power supply of amplitudes ranging from $18-26 \mathrm{~V}$, pulse width ranging from $0.25-1 \mathrm{~s}$, and pulse overlap ranging from $50-90 \%$. For large voltage amplitudes and large pulse widths, the pump operated in a single-bubble mode, while for low voltages and short pulses, operation in a multiple-bubble mode was observed. A pump employing the single-bubble actuation mechanism was also presented by Ozaki [145]. Theoretical models for single- and multiple-bubble pumps have been reported in [146-148].

A variation of the single-bubble micropump has been used for the pumping of discrete liquid droplets in microchannels. The mechanism, known as a thermocapillary pump, involves heating one end of a droplet, which causes a difference in surface tension and hence a pressure drop between the two 


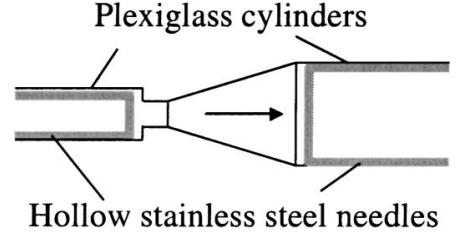

Fig. 33 Structure of the bubble micropump presented by Geng et al $[152]$

ends of the droplet. Sammarco and Burns [149] presented a thermocapillary pump using this principle for chemical analysis systems and reported a maximum droplet velocity of $20 \mathrm{~mm} / \mathrm{min}$ for toluene. Models for thermocapillary pumping are available in $[150,151]$.

The asymmetry in surface tension forces experienced by a growing and collapsing bubble in a nonuniform cross section microchannel carrying electrically conducting liquid was exploited in a bubble micropump by Geng et al [152]. The structure of this micropump is shown in Fig. 33. The pump consists of two plexiglass cylinders of inner diameters 0.8 $\mathrm{mm}$ and $1.6 \mathrm{~mm}$. A short narrow channel of diameter 500 $\mu \mathrm{m}$ is connected to the smaller cylinder. This channel is connected to the larger cylinder through a gradually expanding connector of an approximately conical shape. Hollow stainless steel needles with outer diameter slightly smaller than the inner diameter of the plexiglass cylinders are connected to two salt water reservoirs. When an electric voltage is applied between the two needles, the higher current density in the small channel leads to localized heating and formation of a vapor bubble. If the voltage is maintained, the bubble grows and fills the conical portion and a part of the larger cylinder. A difference in curvature of the bubble causes a difference in the surface tension forces, which creates a pressure difference in the channel. Hence, when the voltage is removed, the bubble does not collapse at the point where it originated, but some distance down the conical

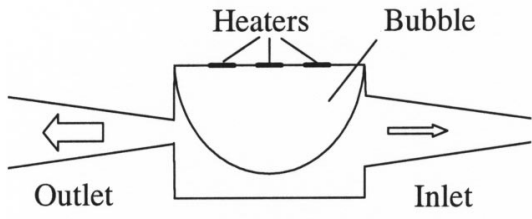

(a)

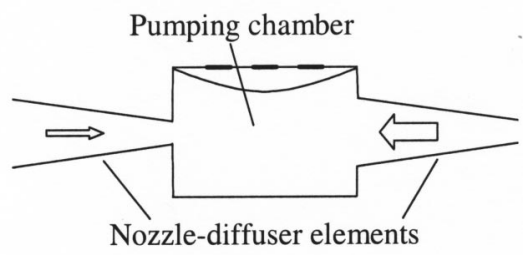

(b)

Fig. 34 Operation of the bubble pump presented by Tsai and Lin [153] when $a$ ) heaters are on (bubble expanding) and $b$ ) heaters are off (bubble collapsing)

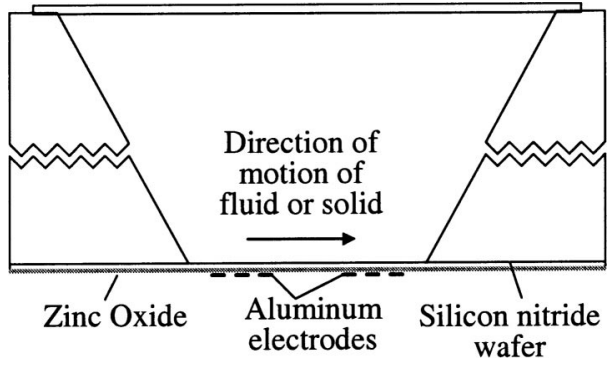

Fig. 35 Flexural plate wave device $[18,156]$. The flow direction can be reversed by changing the polarity of the electrodes.

channel, which causes a net movement of the fluid, and hence a pumping action. At maximum flow rate, the frequency of bubble formation was approximately $10 \mathrm{~Hz}$. The pump can also be made to work with dielectric liquids by using resistive heaters deposited in the conical section.

Another concept for a bubble micropump as illustrated in Fig. 34 was proposed by Tsai and Lin [153]. The pump consists of a circular pumping chamber of diameter $1 \mathrm{~mm}$ and depth $50 \mu \mathrm{m}$ connected to a pair of planar nozzle-diffuser elements of width $30 \mu \mathrm{m}$ at the neck and $274 \mu \mathrm{m}$ at the wide end (half-angle $7 \mathrm{deg}$ ). The pump is covered with a Pyrex glass wafer with meander-shaped aluminum heaters deposited above the pumping chamber. When the heaters are turned on, an expanding bubble pushes fluid out of the pumping chamber and when they are turned off, pressure drop due to the shrinking bubble causes fluid to enter the pumping chamber. The nozzle-diffuser elements cause flow rectification, which leads to a pumping action in the diffuser direction. The pump was actuated using two different modes based on the heater pattern used: single-bubble or dualbubble. A maximum flow rate of $5 \mu \mathrm{l} / \mathrm{min}$ was achieved in the single-bubble mode with a power consumption of $1 \mathrm{~W}$ and frequency of $250 \mathrm{~Hz}$. The corresponding quantities in the dual-bubble mode are presented in Tables 1-3.

Song and Zhao [154] presented a bubble micropump with structure and working principle similar to the single-bubble pump in [144]. The micropump consisted of 12 Pyrex glass tubes connected in series, each of inner diameter $1.0 \mathrm{~mm}$ and length $31.0 \mathrm{~mm}$. Twelve equally spaced constantan wire solenoid heaters of inner diameter $0.6 \mathrm{~mm}$, outer diameter 1.0 $\mathrm{mm}$, and length $30.0 \mathrm{~mm}$ were inserted into the tubes.

\subsubsection{Electrochemical pumps}

An electrochemical micropump which implements the pumping mechanism described in section 2.3.2 was investigated by Bohm et al [17]. The pump consisted of a meandershaped channel and a connected reservoir etched in a silicon wafer, with a Pyrex glass sheet with platinum electrodes as a cover. The pump, designed for microdialysis applications, had a very accurately controlled flow rate with a linear relationship between the volume pumped and the current applied. A flow rate of more than $3 \mu \mathrm{l} / \mathrm{min}$ was reported at a current of approximately $300 \mu \mathrm{A}$. 


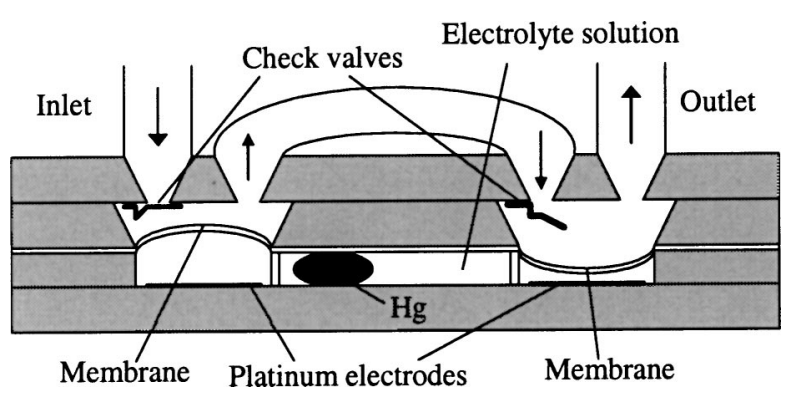

Fig. 36 Electrowetting micropump [20]

\subsection{Other/novel micropumps}

\subsubsection{Flexural plate wave devices}

The structure of a flexural plate wave device $[18,155,156]$ is shown in Fig. 35. It consists of a $2 \mu \mathrm{m}$ thick membrane of low-stress silicon nitride formed on a $250 \mu \mathrm{m}$ thick silicon wafer. A $1 \mu \mathrm{m}$ piezoelectric zinc oxide layer is sputtered below it and $0.4 \mu \mathrm{m}$ thick aluminum interdigital electrodes are formed below that. The typical size of the membrane is $8 \times 3 \mathrm{~mm}$ and the period of the interdigital electrodes, ie, the spacing between the adjacent electrodes of the same polarity, is $100 \mu \mathrm{m}$. Actuation of the piezoelectric layer causes formation of flexural plate waves with velocities of several hundred $\mathrm{m} / \mathrm{s}$. In the devices investigated, these waves led to the motion of deionized water (Tables 1-3). They were also used for transporting solid particles. For instance, silicon flakes of cross section $100 \times 250 \mu \mathrm{m}$ and $250 \times 500 \mu \mathrm{m}$ with a thickness of $2 \mu \mathrm{m}$ were transported in an ambient of air at $2 \mathrm{~cm} / \mathrm{s}$ at a $10 \mathrm{~V}$ actuation voltage. Moroney et al [157] used circular, instead of flat, interdigital electrodes to concentrate acoustic energy, which led to larger amplitude waves and, hence, larger streaming velocities. The inner and outer radii of the electrodes were 2 and $4 \mathrm{~mm}$, respectively, and the aperture angle was $40 \mathrm{deg}$.

A flexural plate wave device fabricated by silicon micromachining techniques was investigated by Luginbuhl et al $[158,159]$. The device, essentially a composite membrane, consisted of a $1 \mu \mathrm{m}$ silicon nitride layer followed by a Ta/Pt $(10 \mathrm{~nm} / 150 \mathrm{~nm})$ ground plane, a $750 \mathrm{~nm}$ layer of sol-gel derived PZT, and Ta/Pt $(10 \mathrm{~nm} / 150 \mathrm{~nm})$ interdigital electrodes. Membranes with two different sizes, $8 \times 2 \mathrm{~mm}$ and $8 \times 1 \mathrm{~mm}$, were fabricated. The period of the interdigital electrodes was $100 \mu \mathrm{m}$. Motion of glass microspheres (50$250 \mu \mathrm{m}$ ) with a maximum velocity of $20 \mathrm{~cm} / \mathrm{s}$ was observed. A micropump with inlet and outlet apertures perpendicular to the membrane was fabricated and pumping of water with a flow rate of $0.25 \mu \mathrm{l} / \mathrm{min}$ was reported.

A micropump using flexural waves for actuation was proposed by Black and White [160]. The pump consisted of a closed microchannel, $300 \mu \mathrm{m}$ wide and $16 \mu \mathrm{m}$ deep. The bottom surface of the channel consisted of a composite membrane of silicon nitride, zinc oxide, and interdigital electrodes, similar to the one presented in [155] (Fig. 35). Holes in the glass lid used as the channel ceiling were used as inlet and outlet ports.

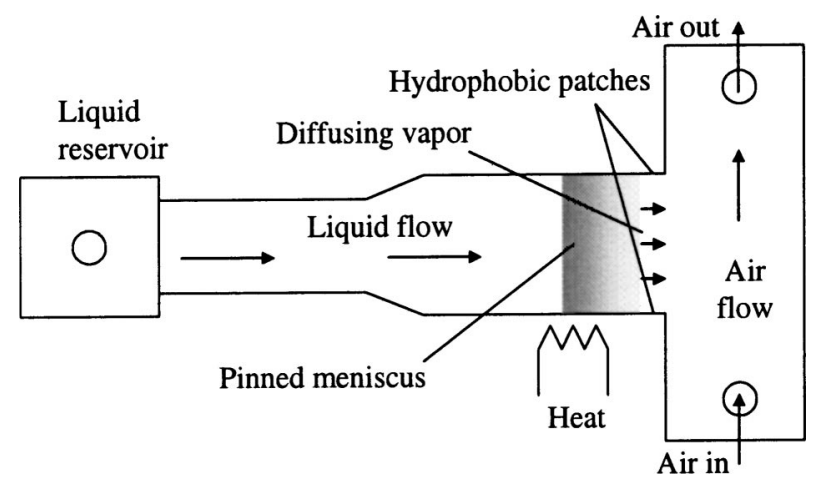

Fig. 37 Structure of the micropump presented by Namasivayam et al [169]

Investigations on flexural plate wave devices have also been reported in $[134,161-163]$.

\subsubsection{Electrowetting micropumps}

Yun et al [20] presented a micropump using actuation by continuous electrowetting. The structure of the micropump fabricated using silicon micromachining techniques is shown in Fig. 36. The actuation unit consists of a mercury drop in an electrolyte-filled microchannel with platinum electrodes on either end. When a voltage is applied across the electrodes, the mercury droplet moves along the channel, pushing along the electrolyte solution. This creates a pressure gradient which deflects the membranes. A voltage gradient in the opposite direction causes the mercury droplet to move back, causing a reverse pressure gradient and resultant deflection of membranes. Passive check valves are used for flow rectification. Three different kinds of membranes, silicon rubber, Parylene $\mathrm{C}$, and composite silicon rubber/ Parylene $\mathrm{C}$, were used. Each membrane was $5 \times 5 \mathrm{~mm}$ in size.

An investigation of electrowetting as an actuation mechanism for micropumps has also been reported by Matsumoto and Colgate [164]. Other studies that have considered electrowetting as an actuation mechanism are described in [165168].

Namasivayam et al [169] presented a micropump based on liquid motion to compensate for diffusion from a pinned meniscus. The structure of the micropump is shown in Fig. 37. Hydrophobic patches are formed at the end of the microchannel by selective hydrophobic patterning. Liquid from the reservoir enters the microchannel by capillary action till it reaches the hydrophobic patch. The liquid meniscus at the hydrophobic end is heated. This causes evaporation of the liquid from the meniscus. The resulting vapor is exhausted by an air stream in the perpendicular channel. Because the meniscus is pinned, more liquid enters the channel to maintain the steady state and results in a pumping action. The flow rate in the channel can be controlled by the evaporation rate. This in turn can be further controlled by the amount of heat supplied or the velocity of the air stream. The pump provides continuous non-pulsatile flow. A maximum velocity of approximately $550 \mu \mathrm{m} / \mathrm{s}$ was reported for water. 


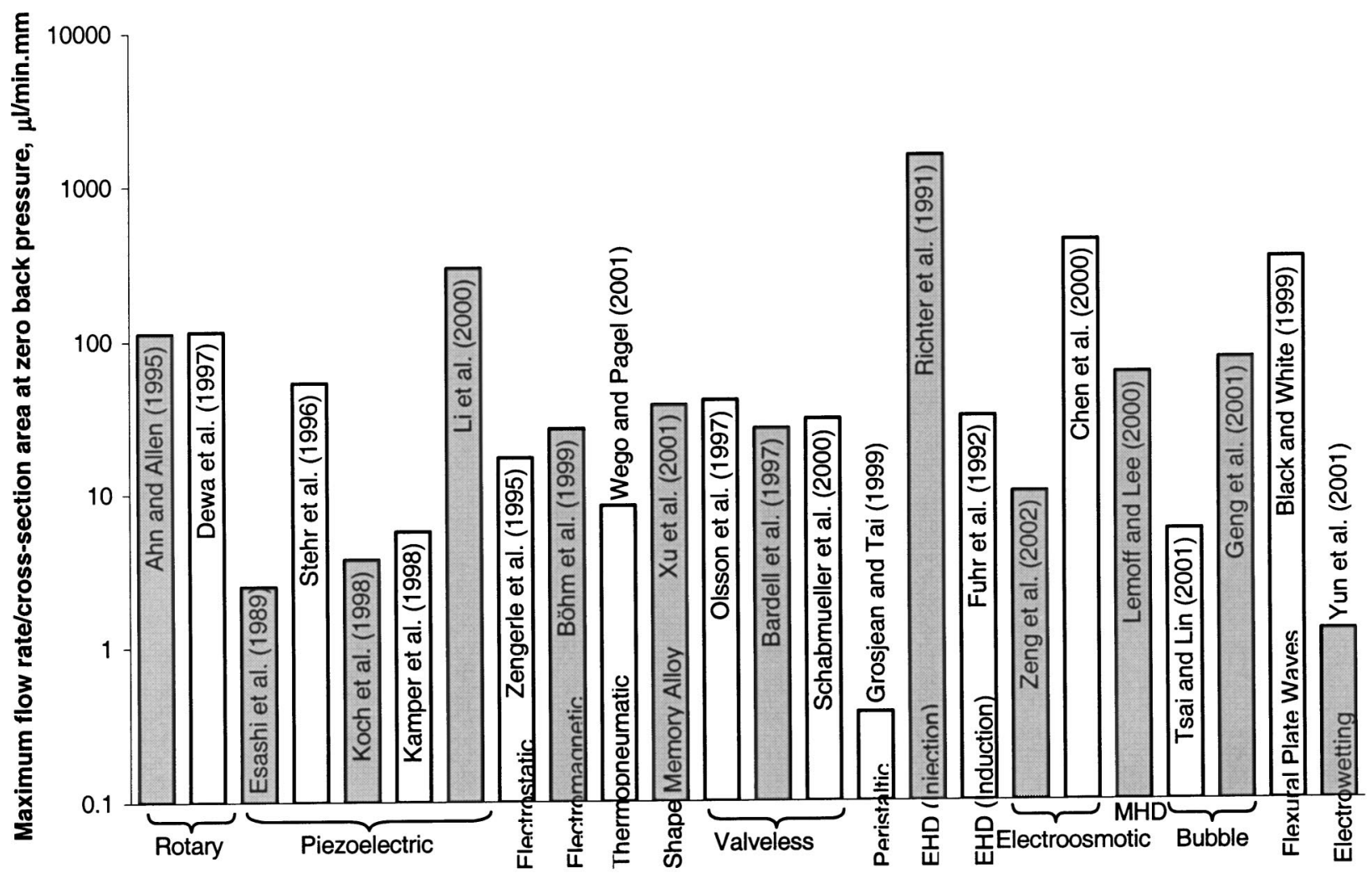

(a)

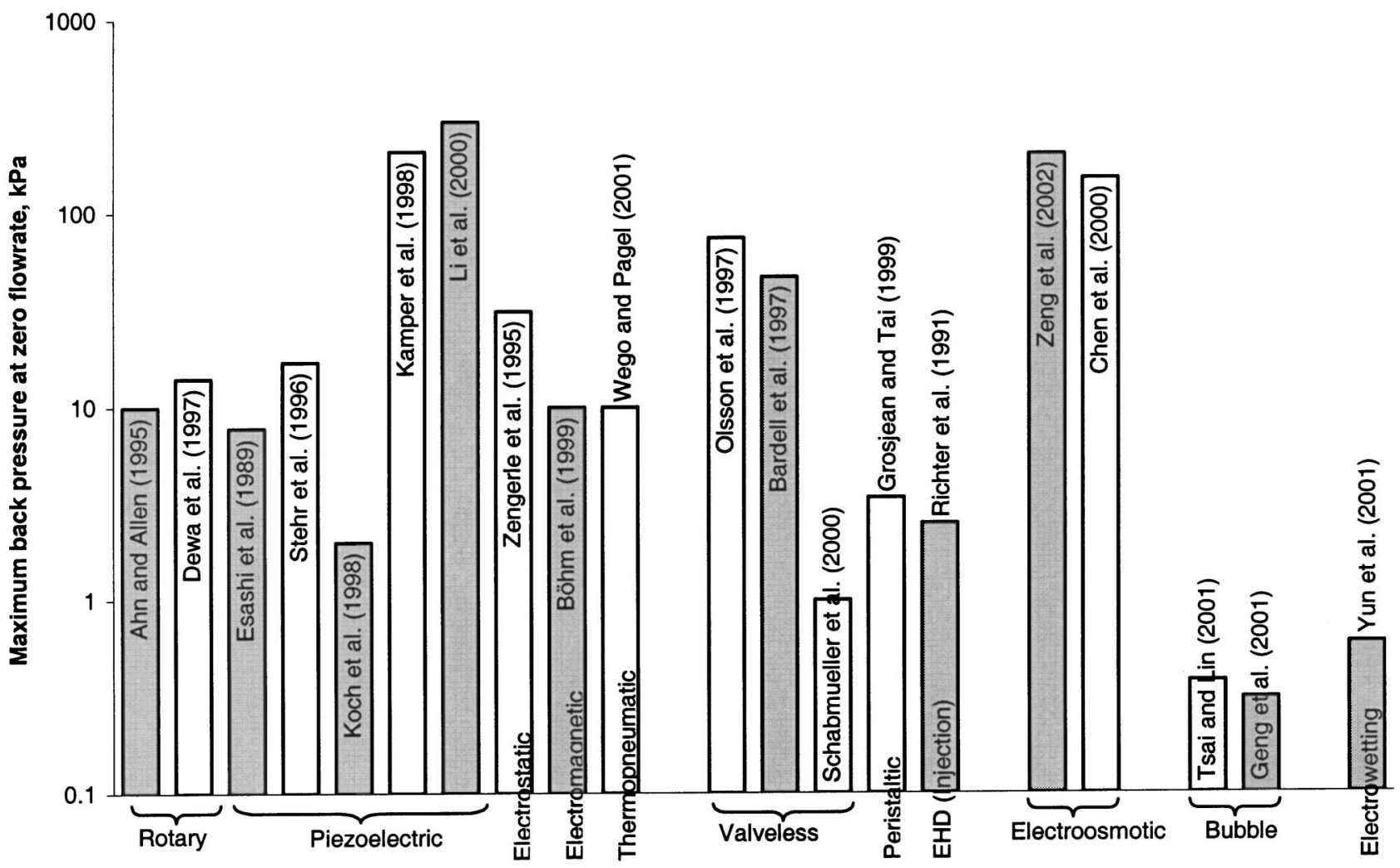

(b)

Fig. 38 a) Maximum flow rate per unit cross-sectional area at zero back pressure and $b$ ) maximum back pressure at zero flow rate of various micropumps presented in literature. The maximum back pressure was not reported for the Shape Memory Alloy pump [79], Induction-type EHD pump [123,124], MHD pump [140] and Flexural Plate Wave pump [160]. 


\section{EVALUATION AND COMPARISON OF MICROPUMPING TECHNIQUES}

The large variety of micropumping techniques presented in Section 2 and the specific micropump designs covered in Section 3 are compared in this section with respect to their suitability in integrated microchannel cooling systems.

A quantitative comparison of various micropumps (for which fairly complete quantitative descriptions were available) is presented in Table 1. The pumps are compared based on their maximum reported flow rate per unit area, maximum achievable back pressure, voltage, power input, and frequency of operation for peak performance. The use of flow rate per unit area scales out the direct effect of pump size on flow rate. One of the critical parameters for a pump in a cooling system is the surface area of the pump. Hence for vibrating diaphragm micropumps, the cross-sectional area of the pumping chamber is used for determining flow rate per unit area. The area covered by the valves and that devoted to the electrical and fluidic connections are not included as they could potentially be minimized in an integrated system. Moreover, some parts of a pump, such as the nozzle-diffuser elements, can be considered as parts of the microchannel cooling system itself. For this reason, only the crosssectional area of the electrodes or that of the channel under the electric/magnetic field has been used for EHD, MHD, and electroosmotic pumps. However, the cross-sectional sizes of the pumps reported in the table include the sizes of all the fluidic and electrical connections.

These pumps are also compared in Table 2 based on more qualitative features, such as the ability to pump different liquids, type and ease of the fabrication method used, and other advantages and disadvantages of these pumps which render them suitable or unsuitable for certain applications. In addition, the presence of moving parts is noted, as is the ability of the pump to pump fluids bi-directionally. The miniaturization potential of different pumps has been estimated. In addition, their suitability to electronics cooling with respect to their use of heat, or electric or magnetic fields, as part of the actuation mechanism, is reported. The presence of a magnetic or electric field may interfere with the proper functioning of electronic devices, while heating of the working or driving fluid can defeat the purpose of the pump in such applications. However, it is possible to insulate electronics from the imposed magnetic/electric fields in a relatively straightforward manner, and designs can be envisioned for various bubble pumps and thermopneumatically actuated pumps where the heat from the chips is used for actuation. This could reduce the power requirement and provide indirect cooling as well.

In cases of micropump designs for which less complete quantitative information was provided in the original references, Table 3 summarizes such data.

To illustrate the potential of different pumps graphically, the maximum flow rate per unit area as well as the maximum back pressure are plotted in Fig. $38 a$ and $38 b$, respectively, for all the pumps presented in Tables 1 and 2. It can be observed that, in general, the pumping techniques using surface effects such as electroosmosis and flexural plate waves perform better in terms of flow rate per unit area. However, as can be noted from Table 1, these pumps use very shallow channels to maximize surface forces. On the other hand, in a microchannel cooling system, channel depths would be much larger and surface effects less dominant.

Some comparative remarks about the suitability of various micropumping techniques available in the literature under specific constraints are in order. The pumps with the highest flow rate per unit area presented in the literature are the nozzle-diffuser micropumps with piezoelectric actuation, injection-type EHD pumps, electroosmotic micropumps, and flexural plate wave pumps. However, most pump designs have not been rigorously optimized, and with design improvements, rotary pumps and other actuation schemes such as shape memory alloys also have the potential to achieve high flow rates. In particular, the optimal microchannel widths for integrated electronics cooling applications are known to be in the range of 50 to $100 \mu \mathrm{m}$, with channel aspect ratios of 4 to $6[170,171]$. Nozzle-diffuser and EHD micropumps are therefore best suited for this application because they have good miniaturization potential and use body forces instead of surface effects for actuation. Electroosmotic micropumps can be attractive as external pumps (not integrated into the microchannel heat sink) because of the high back pressures achievable as well as their simple structure and lack of moving parts. At present, therefore, for the suggested dimensions of microchannels, micropumps relying on body forces rather than surface forces are best suited for heat sink applications. However, if technological advances make it possible to use smaller wall thicknesses in the heat sinks, the optimal microchannel dimensions for integrated electronics cooling may decrease to around 5-10 $\mu \mathrm{m}$. At such small dimensions, the surface forces may start to dominate volume forces, and surface forces-based pumping mechanisms such as electroosmotic, flexural plate waves, and electrowetting pumping may become more suitable.

Among the micropumps presented in the literature, vibrating diaphragm micropumps with check valves, electroosmotic pumps, and valveless micropumps using nozzlediffuser elements achieve the highest pressure heads, in that order. If the power input to the micropump is a constraint, electrowetting micropumps are ideal because they have minimal power requirement per unit flow rate. Vibrating diaphragm micropumps using electrostatic actuation also have low power requirements. Moreover, vibrating diaphragm pumps operating specifically at the resonant frequency of the system have the potential to achieve very high flow rates per unit power input.

\section{CLOSURE}

A detailed description of the available techniques and concepts for micropumping is provided, complete with illustrative diagrams. A comprehensive review of the state of the art with respect to particular micropump designs discussed in the literature is also presented. The applicability of various micropumping techniques for electronics cooling has been studied both qualitatively and quantitatively in terms of flow rate per unit cross-sectional area of the pump, maximum 
pressure head achievable, and power required per unit flow rate. Recommendations are formulated for different kinds of cooling systems and different micropumping needs.

\section{REFERENCES}

[1] Thermal management technology roadmap of the National Electronics Manufacturing Initiative (NEMI), 2002.

[2] Garimella SV and Sobhan CB (2003), Transport in microchannels: A critical review, Аппи. Rev. Heat Transfer 15, 1-50.

[3] Gravesen P, Branebjerg J, and Jensen OS (1993), Microfluidics: A review, J. Micromech. Microeng. 3, 168-182.

[4] Shoji S and Esashi M (1994), Microflow devices and systems, $J$. Micromech. Microeng. 4, 157-171.

[5] Elwenspoek M, Lammerink TSJ, Miyake R, and Fluitman JHJ (1994), Towards integrated microliquid handling systems, J. Micromech. Microeng. 4, 227-245.

[6] Ho C-M and Tai Y-C (1998), Micro-Electro-Mechanical-Systems (MEMS) and fluid flows, Annu. Rev. Fluid Mech. 30, 579-612.

[7] Gad-el-Hak M (1999), The fluid mechanics of microdevices: The Freeman Scholar Lecture, ASME J. Fluids Eng. 121, 5-33.

[8] Ahn CH and Allen MG (1995), Fluid micropumps based on rotary magnetic actuators, Proc of IEEE Micro Electro Mechanical Systems (MEMS), Amsterdam, Netherlands, 408-412.

[9] Zengerle R, Richter A, and Sandmaier H (1992), A micro membrane pump with electrostatic actuation, Proc of IEEE Micro Electro Mechanical Systems Workshop, 19-24.

[10] Smits JG (1990), Piezoelectric micropump with three valves working peristaltically, Sens. Actuators, A 21, 203-206.

[11] Bart SF, Tavrow LS, Mehregany M, and Lang JH (1990), Microfabricated electrohydrodynamic pumps, Sens. Actuators, A 21-23, 193 197

[12] Richter A and Sandmaier H (1990), An electrohydrodynamic micropump, Proc of IEEE Micro Electro Mechanical Systems (MEMS), 99-104.

[13] Darabi J, Ohadi MM, and DeVoe D (2001), An electrohydrodynamic polarization micropump for electronic cooling, J. Microelectromech Syst. 10, $98-106$

[14] Manz A, Effenhauser CS, Burggraf N, Harrison DJ, Seiler K, and Fluri K (1994), Electroosmotic pumping and electrophoretic separations for miniaturized chemical analysis systems, J. Micromech. Microeng. 4, 257-265.

[15] Lemoff AV, Lee AP, Miles RR, and McConaghy CF (1999), An AC magnetohydrodynamic micropump: Towards a true integrated microfluidic system, Transducers' 99, Sendai, Japan, 1126-1129.

[16] Jun TK and Kim C-J (1996), Microscale pumping using traversing vapor bubbles in microchannels, 1996 Solid-State Sensor and Actuator Workshop, Hilton Head, South Carolina, 144-147.

[17] Bohm S, Olthuis W, and Bergveld P (1999), An electrochemically actuated micropump for use in a "push-pull" microdialysis based in-vivo monitoring system, Transducers' 99, Sendai, Japan, 880-881.

[18] Moroney RM, White RM, and Howe RT (1990), Fluid motion produced by ultrasonic lamb waves, IEEE Ultrasonics Symp, 355-358.

[19] Bockeris JOM and Reddy AKN (1970), Modern Electrochemistry, Plenum, New York.

[20] Yun K-S, Cho I-J, Bu J-U, Kim G-H, Jeon Y-S, Kim C-J, and Yoon E (2001), A micropump driven by continuous electrowetting actuation for low voltage and low power operations, Proc of IEEE Micro Electro Mechanical Systems (MEMS), 487-490.

[21] Weisener T, Voegele G, Widmann M, Bark C, Schraft RD, Bertholds A, and Braunschweiler A (1996), Micropump/fluidic micromotor, Proc of Actuator 96: 5th Int Conf on New Actuators, H Borgmann (ed), 104-107.

[22] Weisener T, Bark C, Schraft RD, Voegele G, Widmann M, Bertholds A, and Braunschweiler A (1996), Development and fabrication of a rotary micropump and its industrial and medical applications, Proc. of SPIE, 2882, 218-225.

[23] Sen M, Wajerski D, and Gad-el-Hak M (1996), A novel pump for MEMS applications, ASME J. Fluids Eng. 118, 624-627.

[24] Dewa AS, Deng K, Ritter DC, Bonham C, Guckel H, and MassoodAnsari S (1997), Development of LIGA-fabricated, self-priming, inline gear pumps, Transducers' 97, Chicago, 757-760.

[25] Hatch A, Kamholz AE, Holman G, Yager P, and Bohringer KF (2001), A ferrofluidic magnetic micropump, J. Microelectromech. Syst. 10, 215-221.

[26] van Lintel HTG, van De Pol FCM, and Bouwstra S (1988), A piezoelectric micropump based on micromachining of silicon, Sens. Actuators $\mathbf{1 5}, 153-167$.
[27] van der Schoot BH, Jeanneret S, van den Berg A, and de Rooij NF (1993), A modular miniaturized chemical analysis system, Sens. Actuators $B$ 13, 333-335.

[28] van der Schoot BH, Jeanneret S, van den Berg A, and de Rooij NF (1993), Modular setup for a miniaturized chemical analysis system, Sens. Actuators B 15, 211-213.

[29] Gass V, van der Schoot BH, Jeanneret S, and de Rooij NF (1993), Micro liquid handling using a flow-regulated silicon micropump, $J$ Micromech. Microeng. 3, 214-215.

[30] Gass V, van der Schoot BH, Jeanneret S, and de Rooij NF (1994), Integrated flow-regulated silicon micropump, Sens. Actuators, A $\mathbf{4 3}$, $335-338$.

[31] Esashi M, Shoji S, and Nakano A (1989), Normally closed microvalve and micropump fabricated on a silicon wafer, Sens. Actuators 20, 163-169.

[32] Shoji S, Nakagawa S, and Esashi M (1990), Micropump and sampleinjector for integrated chemical analyzing systems, Sens. Actuators, A 21, 189-192.

[33] Shoji S, Esashi M, van der Schoot B, and de Rooij N (1992), A study of a high-pressure micropump for integrated chemical analysing systems, Sens. Actuators, A 32, 335-339.

[34] Carrozza MC, Croce N, Magnani B, and Dario P (1995), A piezoelectric-driven stereolithography-fabricated micropump, J. Micromech. Microeng. 5, 177-179.

[35] Stehr M, Messner S, Sandmaier H, and Zengerle R (1996), The VAMP-A new device for handling liquids or gases, Sens. Actuators, A 57, 153-157.

[36] Zengerle R, Ulrich J, Kluge S, Richter M, and Richter A (1995), A bidirectional silicon micropump, Sens. Actuators, A 50, 81-86.

[37] Nguyen NT, Schubert S, Richter S, and Dötzel W (1998), Hybridassembled micro dosing system using silicon-based micropump/valve and mass flow sensor, Sens. Actuators, A 69, 85-91.

[38] Ederer I, Raetsch P, Schullerus W, Tille C, and Zech U (1997), Piezoelectrically driven micropump for on-demand fuel-drop generation in an automobile heater with continuously adjustable power output, Sens. Actuators, A 62, 752-755.

[39] Park JH, Yoshida K, and Yokota S (1997), A piezoelectric micropump using resonance drive; proposal of resonance drive and basic experiments on pump characteristics, Fluid Power Systems and Technology, ASME FPST 4/DSC 63, 77-82.

[40] Park JH, Yoshida K, and Yokota S (1999), Resonantly driven piezoelectric micropump; fabrication of a micropump having high power density, Mechatronics 9, 687-702.

[41] Koch M, Harris N, Maas R, Evans AGR, White NM, and Brunnschweiler A (1997), A novel micropump design with thick-film piezoelectric actuation, Meas. Sci. Technol. 70, 49-57.

[42] Koch M, Harris N, Evans AGR, White NM, and Brunnschweiler A (1998), A novel micromachined pump based on thick-film piezoelectric actuation, Sens. Actuators, A 70, 98-103.

[43] Cunneen J, Lin YC, Caraffini S, Boyd JG, Hesketh PJ, Lunte SM, and Wilson GS (1998), A positive displacement micropump for microdialysis, Mechatronics 8, 561-583.

[44] Kaemper K-P, Doepper J, Ehrfeld W, and Oberbeck S (1998), A selffilling low-cost membrane micropump, Proc of IEEE Micro Electro Mechanical Systems (MEMS), 432-437.

[45] Linnemann R, Woias P, Senfft C-D, and Ditterich JA (1998), Selfpriming and bubble-tolerant piezoelectric silicon micropump for liquids and gases, Proc of IEEE Micro Electro Mechanical Systems (MEMS), 532-537.

[46] Maillefer D, van Lintel H, Ray-Mermet G, and Hirschi R (1999), A high-performance silicon micropump for an implantable drug delivery system, Proc of 12th IEEE Conf on Micro Electro Mechanical Systems, Orlando FL, 541-546.

[47] Maillefer D, Gamper S, Frehner B, Balmer P, van Lintel H, and Renaud P (2001), A high-performance silicon micropump for disposable drug delivery systems, Proc of IEEE Micro Electro Mechanical Systems (MEMS), 413-417.

[48] Li HQ, Roberts DC, Steyn JL, Turner KT, Carretero JA, Yaglioglu O, Su YH, Saggere L, Haggod NW, Spearing SM, Schmidt MA, Mlcak $\mathrm{R}$, and Breuer KS (2000), A high frequency high flow rate piezoelectrically driven MEMS micropump, 2000 Solid-State Sensor and Actuator Workshop, Hilton Head SC, 69-72.

[49] King TG, Preston ME, Murphy BJM, and Cannell DS (1990), Piezoelectric ceramic actuators: A review of machinery applications, Precis. Eng. 12, 131-136.

[50] Brei DE and Blechschmidt J (1992), Design and static modeling of a semiconductor polymeric piezoelectric microactuator, J. Microelectromech. Syst. 1, 106-115.

[51] Low TS and Guo W (1995), Modeling of a three-layer piezoelectric 
bimorph beam with hysteresis, J. Microelectromech. Syst. 4, 230237.

[52] DeVoe DL and Pisano AP (1997), Modeling and optimal design of piezoelectric cantilever microactuators, J. Microelectromech. Syst. 6, 266-270.

[53] Weinberg MS (1999), Working equations for piezoelectric actuators and sensors, J. Microelectromech. Syst. 8, 529-533.

[54] Debeda H, Freyhold Tv, Mohr J, Wallrabe U, and Wengelink J (1999), Development of miniaturized piezoelectric actuators for optical applications realized using LIGA technology, J. Microelectromech. Syst. $258-263$.

[55] Accoto D, Carrozza MC, and Dario P (2000), Modelling of micropumps using unimorph piezoelectric actuator and ball valves, $J$. Micromech. Microeng. 10, 277-281.

[56] Morris CJ and Forster FK (2000), Optimization of a circular piezoelectric bimorph for a micropump driver, J. Micromech. Microeng. 10, 459-465.

[57] Ilzhofer A, Ritter B, and Tsakmakis Ch (1995), Development of passive microvalves by the finite element method, J. Micromech. Microeng. 5, 226-230.

[58] Ulrich J and Zengerle R (1996), Static and dynamic flow simulation of a KOH-etched microvalve using the finite-element method, Sens. Actuators, A 53, 379-385.

[59] Zhang Y and Wise KD (1994), Performance of non-planar silicon diaphragms under large deflections, J. Microelectromech. Syst. 3, 5968.

[60] Zengerle R and Richter M (1994), Simulation of microfluid systems, J. Micromech. Microeng. 4, 192-204.

[61] Bourouina T and Grandchamp J-P (1996), Modeling micropumps with electrical equivalent networks, J. Micromech. Microeng. 6, 398 404.

[62] Carmona M, Marco S, Samitier J, and Morante JR (1996), Dynamic simulations of micropumps, J. Micromech. Microeng. 6, 128-130.

[63] Voigt P, Schrag G, and Wachutka G (1998), Electrofluidic full-system modelling of a flap valve micropump based on Kirchhoffian network theory, Sens. Actuators, A 66, 9-14

[64] Richter M, Linnemann R, and Woias P (1998), Robust design of gas and liquid micropumps, Sens. Actuators, A 68, 480-486.

[65] Voigt P, Schrag G, and Wachutka G (1998), Microfluidic system modeling using VHDL-AMS and circuit simulation, Microelectron. J. 29, 791-797.

[66] Cabuz C, Herb WR, Cabuz EI, and Lu SL (2001), The dual diaphragm pump, Proc of IEEE Micro Electro Mechanical Systems (MEMS), 519-522.

[67] Bourouina T, Bossebuf A, and Grandchamp J-P (1997), Design and simulation of an electrostatic micropump for drug-delivery applications, J. Micromech. Microeng. 10, 186-188.

[68] Français O, Dufour I, and Sarraute E (1997), Analytical static modelling and optimization of electrostatic micropumps, J. Micromech. Microeng. 7, 183-185.

[69] Français O and Dufour I (1998), Dynamic simulation of an electrostatic micropump with pull-in and hysteresis phenomena, Sens. Actuators, A 70, 56-60.

[70] Français O and Dufour I (2000), Enhancement of elementary displaced volume with electrostatically actuated diaphragms: Application to electrostatic micropumps, J. Micromech. Microeng. 10, 282286.

[71] Böhm S, Olthuis W, and Bergveld P (1999), A plastic micropump constructed with conventional techniques and materials, Sens. Actuators, A 77, 223-228.

[72] Gong Q, Zhou Z, Yang Y, and Wang X (2000), Design, optimization and simulation on microelectromagnetic pump, Sens. Actuators, A 83, 200-207.

[73] Khoo M and Liu C (2001), Micro magnetic silicone elastomer membrane actuator, Sens. Actuators, A 89, 259-266.

[74] Kallenbach E, Kube H, Zöppig V, Feindt K, Hermann R, and Beyer F (1999), New polarized electromagnetic actuators as integrated mechatronic components-design and application, Mechatronics 9, 769784.

[75] van de Pol FCM, van Lintel HTG, Elwenspoek M, and Fluitman JHJ (1990), A thermopneumatic micropump based on micro-engineering techniques, Sens. Actuators, A 21, 198-202.

[76] Wego A and Pagel L (2001), A self-filling micropump based on PCB technology, Sens. Actuators, A 88, 220-226.

[77] Wego A, Glock HW, Pagel L, and Richter S (2001), Investigations on thermo-pneumatic volume actuators based on PCB technology, Sens. Actuators, A 93, 95-102.

[78] Benard WL, Kahn H, Heuer AH, and Huff MA (1998), Thin-film shape-memory alloy actuated micropumps, J. Microelectromech. Syst. 7, 245-251.

[79] Xu D, Wang L, Ding G, Zhou Y, Yu A, and Cai B (2001), Characteristics and fabrication of NiTi/Si diaphragm micropump, Sens. Actuators, A 93, 87-92.

[80] Makino E, Mitsuya T, and Shibata T (2001), Fabrication of TiNi shape memory micropump, Sens. Actuators, A 88, 256-262.

[81] Makino E, Shibata T, and Kato K (1999), Dynamic thermomechanical properties of evaporated TiNi shape memory thin film, Sens. Actuators, A 78, 163-167.

[82] Makino E, Mitsuya T, and Shibata T (2000), Dynamic actuation properties of TiNi shape memory diaphragm, Sens. Actuators, A 79, $128-$ 135.

[83] Makino E, Mitsuya T, and Shibata T (2000), Micromachining of TiNi shape memory thin film for fabrication of micropump, Sens. Actuators, A 79, 251-259.

[84] Krulevitch P, Lee AP, Ramsey PB, Trevino JC, Hamilton J, and Northrup MA (1996), Thin film shape memory alloy microactuators, J. Microelectromech. Syst. 5, 270-282.

[85] Mizoguchi H, Ando M, Mizuno T, Takagi T, and Nakajima N (1992), Design and fabrication of light driven micropump, Proc of IEEE Micro Electro Mechanical Systems Workshop, 31-36.

[86] Quandt E and Seemann K (1995), Fabrication and simulation of magnetostrictive thin-film actuators, Sens. Actuators, A 50, 105-109.

[87] Body C, Reyne G, Meunier G, Quandt E, and Seemann K (1997), Application of magnetostrictive thin films for Microdevices, IEEE Trans. Magn. 33, 2163-2166.

[88] Quandt E and Ludwig A (2000), Magnetostrictive actuation in microsystems, Sens. Actuators, A 81, 275-280.

[89] Stemme E and Stemme G (1993), A valveless diffuser/nozzle-based fluid pump, Sens. Actuators, A 39, 159-167.

[90] Olsson A, Stemme G, and Stemme E (1995), A valve-less planar fluid pump with two pump chambers, Sens. Actuators, A 47, 549-556.

[91] Olsson A, Enoksson P, Stemme G, and Stemme E (1996), A valveless planar pump isotropically etched in silicon, J. Micromech. Microeng. 6, 87-91.

[92] Olsson A, Enoksson P, Stemme G, and Stemme E (1997), Micromachined flat-walled valveless diffuser pumps, J. Microelectromech. Syst. 6, 161-166.

[93] Olsson A, Stemme G, Larsson O, Holm J, Lundbladh L, and Öhman O (1998), Valve-less diffuser micropumps fabricated using thermoplastic replication, Sens. Actuators, A 64, 63-68.

[94] Andersson H, van der Wijngaart W, Nilsson P, Enoksson P, and Stemme G (2001), A valve-less diffuser micropump for microfluidic analytical systems, Sens. Actuators B 72, 259-265.

[95] Gerlach T, Schuenemann M, and Wurmus H (1995), A new micropump principle of the reciprocating type using pyramidic micro flowchannels as passive valves, J. Micromech. Microeng. 5, 199-201.

[96] Forster FK, Bardell RL, Afromowitz MA, Sharma NR, and Blanchard A (1995), Design, fabrication and testing of fixed-valve micro-pumps, Proc of ASME Fluids Engineering Division, FED 234, 39-44.

[97] Bardell RL, Sharma NR, Forster FK, Afromowitz MA, and Penney RJ (1997), Designing high-performance micro-pumps based on nomoving-parts valves, ASME Microelectromechanical Systems, DSC 62/HTD 354, 47-53.

[98] Jang LS, Morris CJ, Sharma NR, Bardell RL, and Forster FK (1999), Transport of particle-laden fluids through fixed-valve micropumps, Microelectromechanical Systems, ASME MEMS 1, 503-509.

[99] Jang LS, Sharma NR, and Forster FK (2000), The effect of particles on performance of fixed-valve micropumps, Proc of 4th Int Symp on Micro Total Analysis Systems ( $\mu$ TAS), Enschede, Netherlands, 283286.

[100] Koch M, Evans AGR, and Brunnschweiler A (1998), The dynamic micropump driven with a screen printed PZT actuator, J. Micromech. Microeng. 8, 119-122.

[101] Schabmueller CGJ, Koch M, Evans AGR, Brunnschweiler A, and Kraft M (2000), Design and fabrication of a self-aligning gas/liquid micropump, Proc of SPIE, 4177, 282-290.

[102] Jiang XN, Zhou ZY, Huang XY, Li Y, Yang Y, and Liu CY (1998), Micronozzle/diffuser flow and its application in micro valveless pumps, Sens. Actuators, A 70, 81-87.

[103] Jeong OC and Yang SS (2000), Fabrication of a thermopneumatic micropump with a corrugated $\mathrm{p}+$ diaphragm, Transducers' 99 , Sendai, Japan, 1780-1783.

[104] Jeong OC and Yang SS (2000), Fabrication and test of a thermopneumatic micropump with a corrugated $\mathrm{p}+$ diaphragm, Sens. Actuators, A 83, 249-255.

[105] Gerlach T and Wurmus H (1995), Working principle and performance of the dynamic micropump, Sens. Actuators, A 50, 135-140. 
[106] Olsson A, Stemme G, and Stemme E (1996), Diffuser-element design investigation for valve-less pumps, Sens. Actuators, A 57, 137-143.

[107] Heschel M, Mullenborn M, and Bouwstra S (1997), Fabrication and characterization of truly 3-D diffuser/nozzle microstructures in silicon, J. Microelectromech. Syst. 6, 41-47.

[108] Gerlach T (1998), Mirodiffusers as dynamic passive valves for micropump applications, Sens. Actuators, A 69, 181-191.

[109] Olsson A, Stemme G, and Stemme E (2000), Numerical and experimental studies of flat-walled diffuser elements for valve-less micropumps, Sens. Actuators, A 84, 165-175.

[110] Singhal V, Garimella SV, and Murthy J (2003), Numerical characterization of low Reynolds number flow through the nozzle-diffuser element in a valveless micropump, Proc of 6th ASME/JSME Thermal Engineering Joint Conf, Kohala Coast HI, TED-AJ03, 1-9.

[111] Ullmann A (1998), The piezoelectric valve-less pump-performance enhancement analysis, Sens. Actuators, A 69, 97-105.

[112] Olsson A, Stemme G, and Stemme E (1999), A numerical design study of the valveless diffuser pump using a lumped-mass model, $J$. Micromech. Microeng. 9, 34-44.

[113] Nguyen N-T and Huang X (2000), Numerical simulation of pulsewidth-modulated micropumps with diffuser/nozzle elements, Int Conf on Modeling and Simulation of Microsystems 636-639.

[114] Pan LS, Ng TY, Liu GR, Lam KY, and Jiang TY (2001), Analytical solutions for the dynamic analysis of a valveless micropump-A fluidmembrane coupling study, Sens. Actuators, A 93, 173-181.

[115] Matsumoto S, Klein A, and Maeda R (1999), Development of bidirectional valve-less micropump for liquid, Proc of 12th IEEE Conf on Micro Electro Mechanical Systems, Orlando FL, 141-146.

[116] Grosjean C and Tai Y-C (1999), A thermopneumatic peristaltic micropump, Transducers' 99, Sendai, Japan, 1776-1779.

[117] Nguyen N-T and Huang X (2001), Miniature valveless pumps based on printed circuit board technique, Sens. Actuators, A 88, 104-111.

[118] Cao L, Mantell S, and Polla D (2001), Design and simulation of an implantable medical drug delivery system using microelectromechanical systems technology, Sens. Actuators, A 94, 117-125.

[119] Richter A, Plettner A, Hofmann KA, and Sandmaier H (1991), A micromachined electrohydrodynamic (EHD) pump, Sens. Actuators, A 29, 159-168.

[120] Furuya A, Shimokawa F, Matsuura T, and Sawada R (1996), Fabrication of fluorinated polyimide microgrids using magnetically controlled reactive ion etching (MC-RIE) and their applications to an ion drag integrated micropump, J. Micromech. Microeng. 6, 310-319.

[121] Wong CC, Adkins DR, and Chu D (1996), Development of a micropump for microelectronic cooling, Microelectromechanical Systems (MEMS), DSC 59, 239-244

[122] Ahn S-H and Kim Y-K (1998), Fabrication and experiment of a planar micro ion drag pump, Sens. Actuators, A 70, 1-5.

[123] Fuhr G, Hagedorn R, Muller T, Benecke W, and Wagner B (1992), Pumping of water solutions in microfabricated electrohydrodynamic systems, Proc of IEEE Micro Electro Mechanical Systems Workshop, 25-30.

[124] Fuhr G, Hagedorn R, Muller T, Benecke W, and Wagner B (1992), Microfabricated electrohydrodynamic (EHD) pumps for liquids of higher conductivity, J. Microelectromech. Syst. 1, 141-146.

[125] Fuhr G, Schnelle T, and Wagner B (1994), Travelling wave-driven microfabricated electrohydrodynamic pumps for liquids, J. Micromech. Microeng. 4, 217-226.

[126] Moesner FM and Higuchi T (1995), Devices for particle handling by an AC electric field, Proc of IEEE Micro Electro Mechanical Systems, $66-71$.

[127] Zeng S, Chen CH, Mikkelsen Jr JC, and Santiago JC (2001), Fabrication and characterization of electroosmotic micropumps, , 79, 107114.

[128] Zeng S, Chen CH, Mikkelsen JC, and Santiago JG (2000), Fabrication and characterization of electrokinetic micro pumps, ITherm, Las Vegas NV 31-36.

[129] Zeng S, Chen CH, Santiago JG, Chen J-R, Zare RN, Tripp JA, Svec F, and Fréchet JMJ (2002), Electroosmotic flow pumps with polyme frits, Sens. Actuators B 82, 209-212.

[130] Yao S, Huber, D, Mikkelsen JC, and Santiago JC (2001), A large flowrate electroosmotic pump with micron pores, ASME IMECE, MEMS-23890, 1-7.

[131] Chen CH, Zeng S, Mikkelsen JC and Santiago JG (2000), Development of a planar electrokinetic micropump, Proc of ASME Int Mech Eng Congress and Exposition, Orlando FL, MEMS 1, 523-528.

[132] Paul PH, Arnold DW, and Rakestraw DJ (1998), Electrokinetic generation of high pressures using porous microstructures, Proc of $\mu-T A S$, Banff, Canada, 49-52.

[133] Deshpande M, Ghaddar C, Gilbert JR, John PMS, Woudenberg T,
Connell C, Molho J, Herr A, Mungal G, and Kenny T (1998), Numerical framework for the modeling of electrokinetic flows, Proc of SPIE, 3515, 217-227.

[134] Rife JC and Bell MI (1998), Acousto- and electroosmotic microfluidic controllers, Proc of SPIE, 3515, 125-135.

[135] Gan W-E, Yang L, He Y-Z, Zeng R-H, Cervera ML, and de la Guardia M (2000), Mechanism of porous core electroosmotic pump flow injection system and its application to determination of chromium (VI) in waste-water, Talanta 51, 667-675.

[136] Arulanandam S and Li D (2000), Liquid transport in rectangular microchannels by electroosmotic pumping, Colloids Surf., A 161, 89102.

[137] Moorthy J, Khoury C, Moore JS, and Beebe DJ (2001), Active control of electroosmotic flow in microchannels using light, Sens. Actuators B 75, 223-229.

[138] Morf WE, Guenat OT, and de Rooij NF (2001), Partial electroosmotic pumping in complex capillary systems - Part 1: Principles and general theoretical approach, Sens. Actuators B 72, 266-272.

[139] Guenat OT, Ghiglione D, Morf WE, and de Rooij NF (2001), Partial electroosmotic pumping in complex capillary systems - Part 2: Fabrication and application of a micro total analysis system (TAS) suited for continuous volumetric nanotitrations, Sens. Actuators B 72, 273282.

[140] Lemoff AV and Lee AP (2000), An AC magnetohydrodynamic micropump, Sens. Actuators B 63, 178-185.

[141] Heng K-H, Huang L, Wang W, and Murphy MC (1999), Development of a diffuser/nozzle type micropump based on magnetohydrodynamic (MHD) principle, Proc of SPIE, 3877, 66-73.

[142] Heng K-H, Wang W, Murphy MC, and Lian K (2000), UV-LIGA microfabrication and test of an AC-type micropump based on the magnetohydrodynamic (MHD) principle, Proc of SPIE, 4177, 174184.

[143] Jang J and Lee SS (2000), Theoretical and experimental study of MHD (magnetohydrodynamic) micropump, Sens. Actuators, A 80, 84-89.

[144] Jun TK and Kim C-J (1998), Valveless pumping using traversing vapor bubbles in microchannels, J. Appl. Phys. 83, 5658-5664.

[145] Ozaki K (1995), Pumping mechanism using periodic phase changes of a fluid, Proc of IEEE Micro Electro Mechanical Systems (MEMS), 31-36.

[146] Yuan H and Prosperetti A (1999), The pumping effect of growing and collapsing bubbles in a tube, J. Micromech. Microeng. 9, 402-413.

[147] Ory E, Yuan H, Prosperetti A, Popinet S, and Zaleski S (1999), Growth and collapse of a vapor bubble in a small tube, Phys. Fluids 12, 1268-1277.

[148] Yuan H, Oguz HN, and Prosperetti A (1999), Growth and collapse of a vapor bubble in a small tube, Int. J. Heat Mass Transfer 42, 36433657.

[149] Sammarco TS and Burns MA (1999), Thermocapillary pumping of discrete drops in microfabricated analysis devices, AIChE J. 45, 350366.

[150] Sammarco TS and Burns MA (2000), Heat-transfer analysis of microfabricated thermocapillary pumping and reaction devices, J. Micromech. Microeng. 10, 42-55.

[151] Gurrum SP, Murthy S, and Joshi YK (2002), Numerical simulation of thermocapillary pumping using level set method, 5th ISHMT/ASME Heat and Mass Transfer Conf, Kolkata, India, 1-6.

[152] Geng X, Yuan H, Oguz HN, and Prosperetti A (2001), Bubble-based micropump for electrically conducting liquids, J. Micromech. $\mathrm{Mi}$ croeng. 11, 270-276.

[153] Tsai J-H and Lin L (2002), A thermal-bubble-actuated micronozzlediffuser pump, J. Microelectromech. Syst. 11, 665-671.

[154] Song YJ and Zhao TS (2001), Modelling and test of a thermallydriven phase-change nonmechanical micropump, J. Micromech. Microeng. 11, 713-719.

[155] Moroney RM, White RM, and Howe RT (1991), Ultrasonically induced microtransport, IEEE MEMS, 277-282.

[156] Moroney RM, White RM, and Howe RT (1991), Microtransport induced by ultrasonic Lamb waves, Appl. Phys. Lett. 774-776.

[157] Moroney RM, White RM, and Howe RT (1991), Ultrasonically induced microtransport with cylindrical geometry, Micromechanical Sensors, Actuators, and Systems, ASME DSC 32, 181-190.

[158] Luginbuhl P, Collins SD, Racine G-A, Grétillat M-A, De Rooji NF, Brooks KG and Setter N (1998), Ultrasonic flexural Lamb-wave actuators based on PZT thin film, Sens. Actuators, A 57, 41-49.

[159] Luginbuhl P, Collins SD, Racine G-A, Grétillat M-A, De Rooji NF, Brooks KG and Setter N (1997), Microfabricated Lamb wave device based on PZT sol-gel thin film for mechanical transport of solid particles and liquids, J. Microelectromech. Syst. 6, 337-346. 
[160] Black JP and White RM (1999), Microfluidic applications of ultrasonic flexural plate waves, Transducers' 99, Sendai, Japan, 11341136.

[161] Nguyen NT and White RM (1999), Design and optimization of an ultrasonic flexural plate wave micropump using numerical simulation, Sens. Actuators, A 77, 229-236.

[162] Nguyen N-T, Meng AH, Black J, and White RM (2000), Integrated flow sensor for in situ measurement and control of acoustic streaming in flexural plate wave micropumps, Sens. Actuators, A 79, 115-121.

[163] Nguyen N-T and White RM (2000), Acoustic streaming in micromachined flexural plate wave devices: numerical simulation and experimental verification, IEEE Trans. Ultrason. Ferroelectr. Freq. Control 47, 1463-1471.

[164] Matsumoto H and Colgate JE (1990), Preliminary investigation of micropumping based on electrical control of interfacial tension, Proc of IEEE Micro Electro Mechanical Systems (MEMS), 105-110.

[165] Lee J and Kim C-J (1998), Microactuation by continuous electrowetting phenomenon and silicon deep RIE process, ASME MEMS (DSC), $66,475-480$.
[166] Pollack MG, Fair RB, and Shenderov AD (2000), Electrowettingbased actuation of liquid droplets for microfluidic applications, Appl. Phys. Lett. 77, 1725-1726.

[167] Lee J and Kim C-J (2000), Surface-tension-driven microactuation based on continuous electrowetting, J. Microelectromech. Syst. 9, $171-180$.

[168] Lee J, Moon H, Fowler J, Kim C-J, and Schoellhammer T (2001), Addressable micro liquid handling by electric control of surface tension, Proc of IEEE Micro Electro Mechanical Systems (MEMS), 499502.

[169] Namasivayam V, Kalyan H, Burke DT, Larson RG, and Burns MA (2000), Microfabricated valveless pump for delivering non-pulsatile flow, Proc of SPIE, 4177, 220-228.

[170] Tuckerman DB and Pease RFW (1981), High performance heat sinking for VLSI, IEEE Electron Device Letters, EDL-2, 126-129.

[171] Weisberg A, Bau HH, and Zemel JN (1992), Analysis of microchannels for integrated cooling, Int. J. Heat Mass Transfer 35, 24652474.

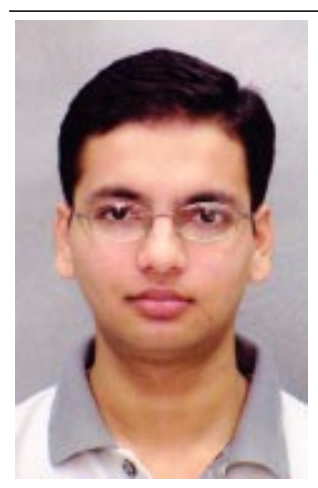

Vishal Singhal is a PhD student in the School of Mechanical Engineering at Purdue University. He received a Bachelor's degree in Energy Engineering from the Indian Institute of Technology, Kharagpur in 2000. He received a Master's degree in Mechanical Engineering from Purdue University in 2001 with a thesis which developed an analytical thermomechanical model for predicting the contact conductance at interfaces between metals, polymers, and ceramics. His doctoral research is focused on micropumping techniques for integrated microchannel cooling systems.

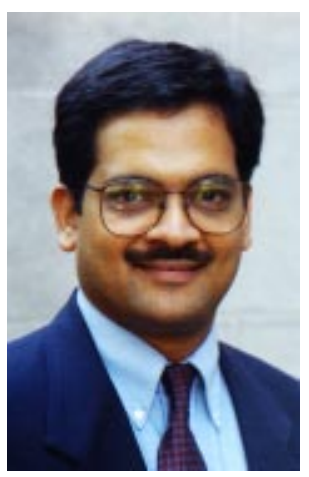

Suresh V Garimella received a PhD degree in Mechanical Engineering from the University of California at Berkeley in 1989 and an MS degree in Mechanical Engineering from Ohio State University. He is a Professor in the School of Mechanical Engineering at Purdue University, and the Director of the NSF Cooling Technologies Research Center (CTRC), an NSF Industry/University Cooperative Research Center. He also directs the Electronics Cooling Laboratory and the Solidification Heat Transfer Laboratory. His research interests include high-performance compact cooling technologies, electronics packaging and cooling, micro- and nano-scale thermal phenomena, and electronics packaging and composite materials processing. From 1990 to August 1999, Garimella held the Cray-Research Named Professorship at the University of Wisconsin-Milwaukee. He has published over 120 papers in archival journals and conference proceedings, and has also contributed to and edited several books. He has served as Editor of Heat Transfer-Recent Contents and is on the Editorial Board of Experimental Thermal and Fluid Science. He is a member of the K-16 (Heat Transfer in Electronic Equipment) Committee of the ASME Heat Transfer Division. His efforts in research and engineering education have been recognized with the Graduate School/UWM Foundation Research Award in recognition of Outstanding Research and Creative Activity, 1995; UWM Distinguished Teaching Award in recognition of Demonstrated Dedication to Excellence in Undergraduate Instruction, 1997; and the Society of Automotive Engineers' Ralph R Teetor Educational Award, 1992.

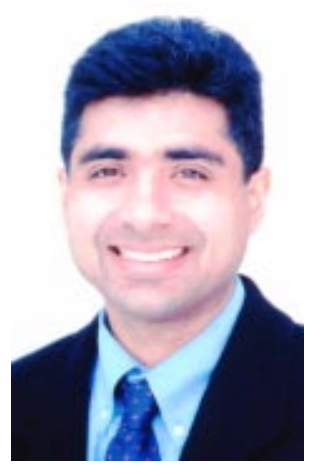

Arvind Raman is an Assistant Professor of Mechanical Engineering at Purdue University since 2000. He received a PhD degree in Mechanical Engineering in 1999 from the University of California, Berkeley, with a specialization in dynamics and mechanics. He is a recipent of the NSF CAREER award in 2002. His research interests span theoretical and experimental nonlinear dynamics with applications in fluid structure interactions, vibrations of rotating and translating flexible media, MEMS and scanning probe microscopy, and the vibrations of data storage systems. 